\title{
Design Optimisation for 3D printed SLM objects
}

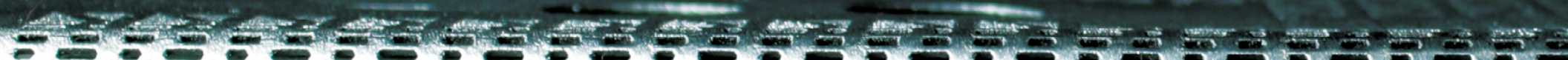

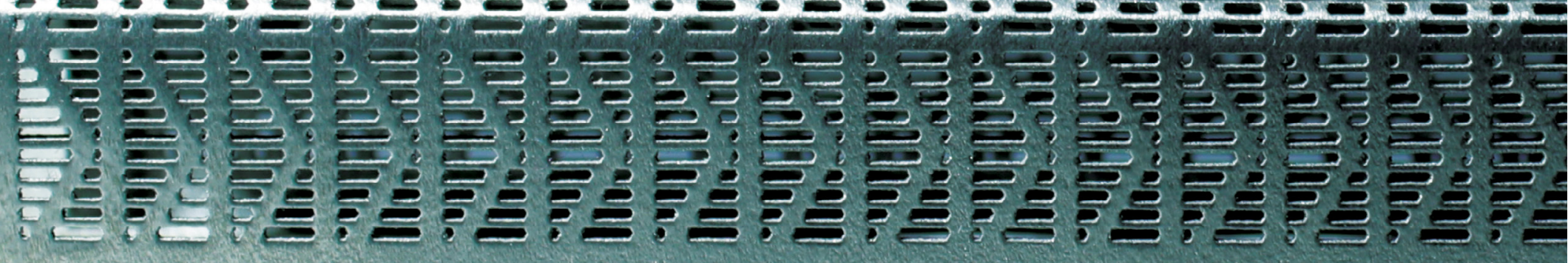




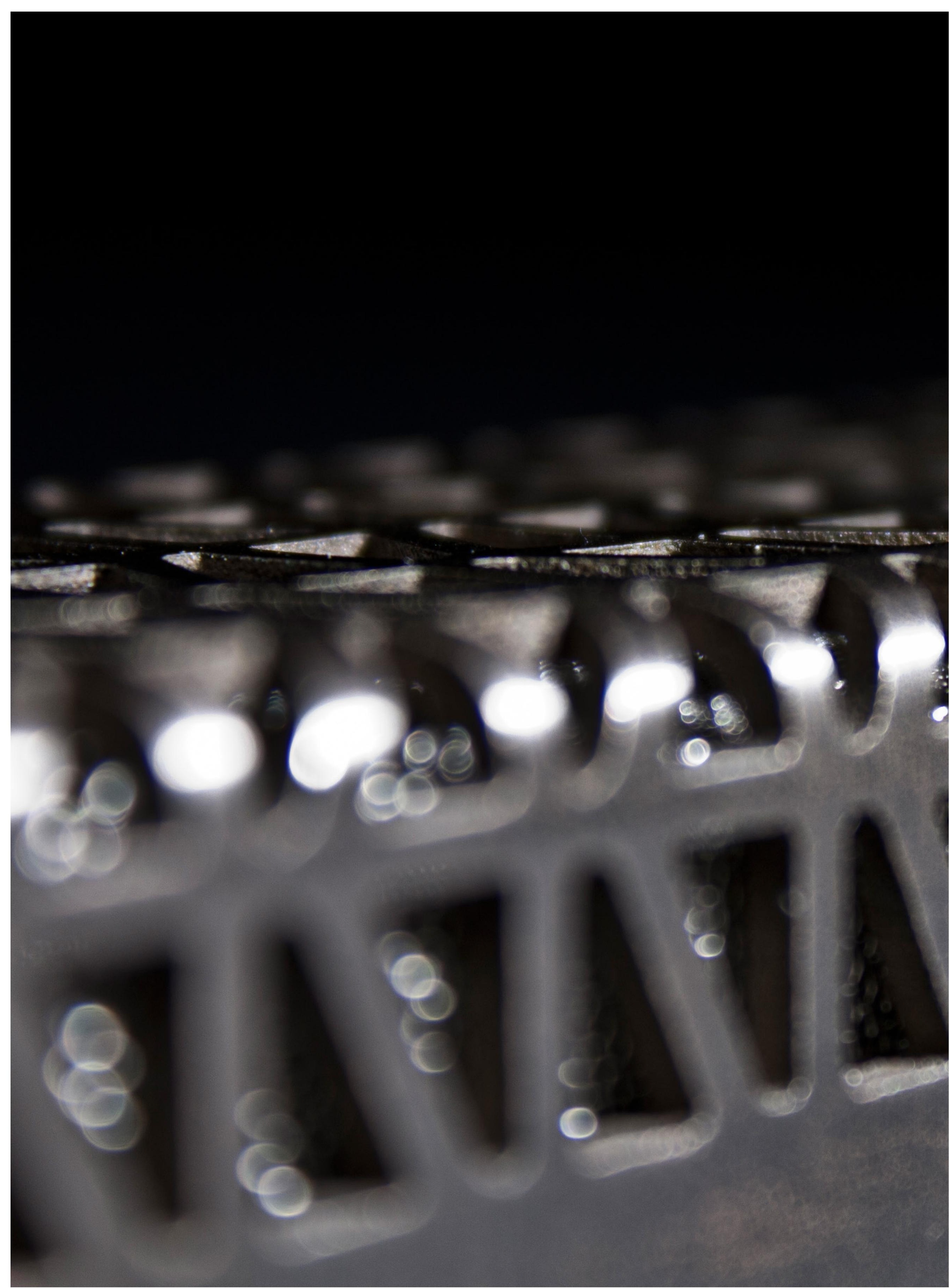





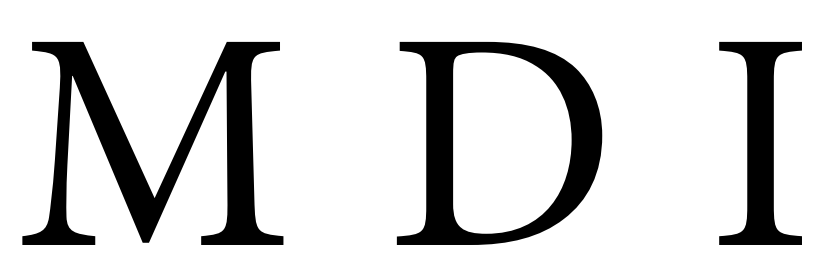

\title{
Design optimisation for 3D printed SLM objects
}

\author{
Stephen Tane Hill
}

A 90 point thesis submitted in fulfilment of the requirements for the Masters of Design Innovation

Victoria University of Wellington, School of Design

$-2016-$ 



\section{ACKNOWLEDGMENTS}

Firstly I would like to give thanks to my supervisor Ross Stevens who has put up with more than a supervisor should do and his insights into the murky realm of metal 3D printing.

I would also like to thank Simon Fraser for believing that this thesis had merit and providing enlightening critiques on the direction of this research.

I'd like to thank my fellow MDI students for their support and company through this experience.

And finally I would like to thank my friend, partner and wife Martina Hill, without your intelligence, support and calm guidance this experience would have been impossible to achieve. 
-viii- 
Design Optimization

$-i x-$ 
$-X-$ 


\section{TABLE OF CONTENTS}

Termonology

Xvii

Abstract

xix

Introduction

2

Case Study

6

Research Question // Aims

8

Literature Review

Methodology

3D Printing Process

Design Requirements

Preliminary Design

Experiments

Design Iterations

Developed Design

Conclusion

List of Figures 
How can Computer Aided Design be optimised for

Selective Laser Melting printing? 


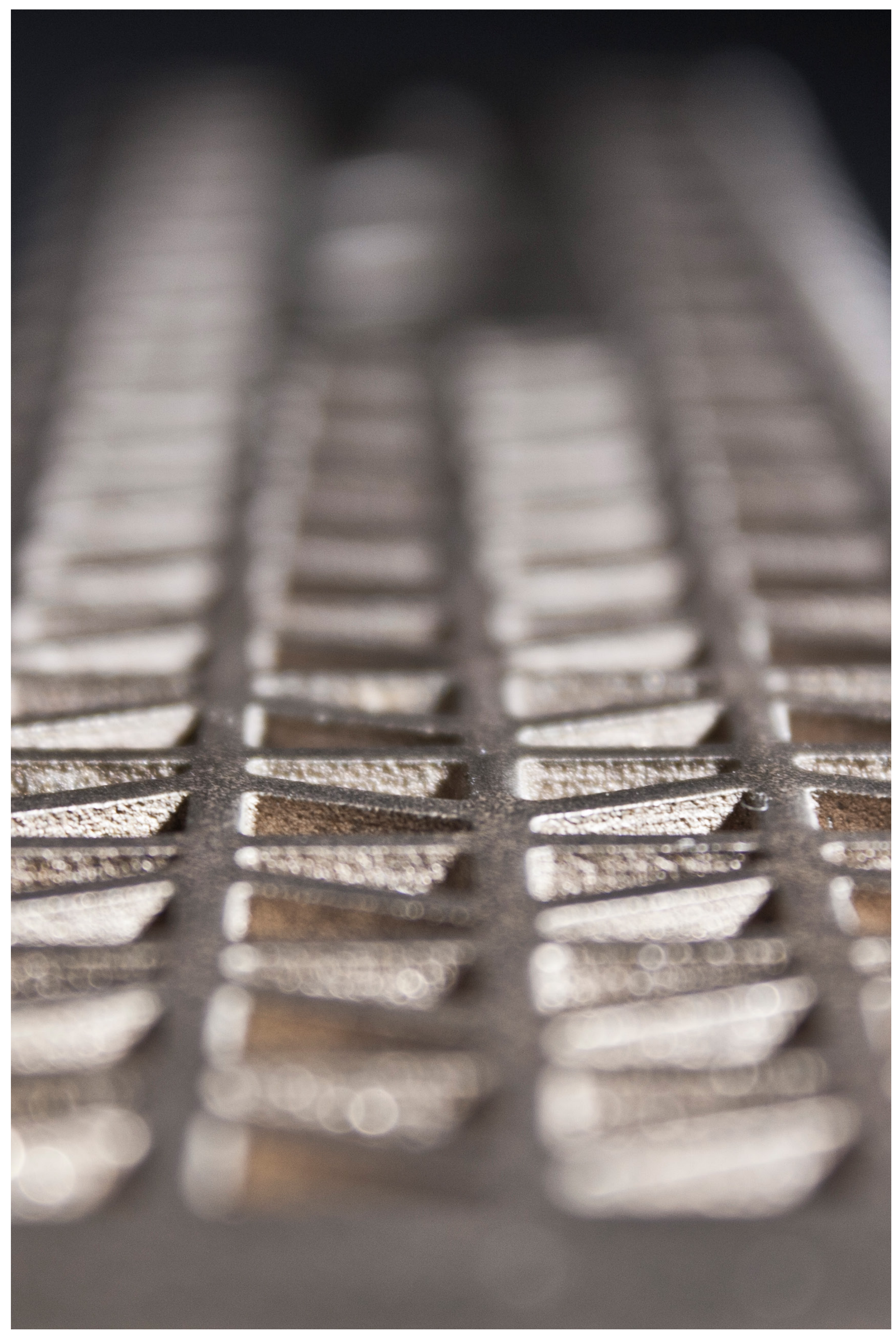

Figure 2: Model 1.3 Stainless Steel

-xiii- 
-xiv- 


$$
-X V-
$$


-XVi- 


\title{
TE R M IN O L O GY
}

\author{
( C A D )
}

Computer Aided Design is the use of computer systems to aid in the creation, modification, analysis, or optimisation of a design.

\section{( S L M )}

Selective Laser Melting is an additive manufacturing process that uses 3D CAD data as a digital information source and energy in the form of a high-power laser beam, to create threedimensional metal parts by fusing fine metal powders together.

\section{( E B M )}

Electron Beam Melting is a type of additive manufacturing or 3D printing, for metal parts. Metal powder or wire is welded together using an electron beam as the heat source.

\section{( F D M )}

Fused Deposition Modeling is an additive manufacturing technology commonly used for modelling, prototyping, and production applications. It is one of the techniques used for 3D printing. FDM works on an "additive" principle by laying down material in layers; a plastic filament or metal wire is unwound from a coil and supplies material to produce a part. 
"Design is what, for practical purposes, can be conveyed in words and by drawing: workmanship is what, for practical purposes, can not. In practice the designer hopes the workmanship will be good, but the workman decides whether it shall be good or not".

David Pye, The Nature and Art of Workmanship (1968) 


\section{A B S T R A C T}

\section{Design optimisation for 3D printed SLM objects}

A common misconception about additive manufacturing (3D printing) is that any shape can be made in any material at the press of a button. The reality is that each process and material requires distinct Computer Aided Design (CAD) files that need to be optimised to the physical limitations of the manufacturing process. This optimisation process can have significant effects on the designer's aesthetic intentions. Selective Laser Melting (SLM) is the new benchmark for functional 3D printed titanium designs where the optimisation process plays an important role in the outcome of the end product. The limitations imposed by the manufacturing process include build support material, heat transfer and post processing and designs are required to be optimised before the manufacturing process can commence. To date, case studies written on the SLM process have focused largely on engineering and functional applications in particular within the medical industry. However; this process has not been extensively studied from a visual and aesthetic industrial design perspective. This research will gather specific knowledge about the technical limitations involved in the Selective Laser Melting process and explore through a case study approach how a designer s intentions can be maintained or even enhanced when using this technology. With greater understanding of the SLM technology, the optimisation process may further provide positive outcomes to the designer by saving time, money and waste.

This case study is built on an existing product design file as a base model. Refinements to the model were made based on findings from existing design research as well as digital and physical models. The existing design research was focused on challenges designers encounter using 3D printing technologies including SLM as well as the optimisation process. Models and design iterations were developed using Nigel Cross's four step model of exploration, generation, evaluation and communication. By iteratively redesigning aspects of the model to conform to the SLM limitations, this study reviews opportunities for areas to reduce material without compromising the design intent. 
"3D printing in plastic is a cake walk compared to doing production in metal... With Direct Metal Laser Sintering, SLM and all its variants its much more difficult".

Joris Peels, Inside 3DP (2016) 


\section{N T R O D U C T I O N}

A common misconception about additive manufacturing (3D printing) is that any shape can be made in any material at the press of a button. The reality is that each process and material requires distinct Computer Aided Design (CAD) files that need to be optimised to the physical limitations of the printing process.

The amount of information that can be provided in a CAD file is an exponential amount more than what is given in a technical drawing. David Pye described in 'Design proposes. Workmanship disposes.' how once a designer relied on words, technical drawings and on the workman him/herself for the workmanship to be good (Pye, 1968). Jonathan Cagen and Craig Vogel also describe this as a perceptual gap between designers and engineers (Garner \& Evans, 2012). The 3D printing tools that have been developed today can capture much subtler and detailed understandings of what the object is supposed to be and bridge or even eliminate this gap. This is due to $3 \mathrm{D}$ printers having changed the way objects are designed, as a designer is not feeding the information to another human to produce the object, but to a machine that would not be able to interpret the design. The interpretation of the design requires it to be incorporated into the CAD file as part of the optimisation process before the object is $3 \mathrm{D}$ printed.

In the book Fabricated, Lipson and Kurman (2013) confirm this by explaining that "Computers play a critical role in the $3 \mathrm{D}$ printing process. Without instructions from a computer, a printer is paralyzed. A $3 \mathrm{D}$ printer comes to life when it is fed a well-designed electronic blueprint, or design file, that tells it where to place the raw material. In fact, a 3D printer without an attached computer and a good design file is as useless as an iPod without music" (p. 12).

With low cost FDM printing for example, the user is usually only a few meters from the machine and therefore able to watch the progress 
in real time. The convenience of stopping a print, tweaking a design file, then starting again is lost when designers have to design from a distance. This is becoming increasingly prevalent as metal printing machines come with a high price tag and purchasing them is a major investment and usually out of reach of individuals.

This is inherently true with the Selective Laser Melting (SLM) process. A small change in the geometry or aesthetic rigidity could cause a beautifully designed object in CAD to become an ongoing expensive nightmare to produce, with significant effects on the designer's aesthetic intentions. The limitations imposed by the SLM manufacturing process include build support material, heat transfer and post processing and require designs to be optimised before production. Today designers using the SLM process are required to increasingly focus their attention on the optimisation process, which plays an important role in the outcome of the final product (Wohlers Associates, 2014).

Thomas (2009) stated "SLM is not completely freeform as the inherent process difficulties can distort many part geometries, and designers often lack an understanding of these process issues and their effect on the final SLM product" (p. ii). The importance of understanding the printing and optimisation processes is also related to the number of design iterations. Because the cost of producing a part in titanium is much greater than polymers, the number of printed products must be kept to a minimum to avoid massive cost penalties. To a company, this may be included in $\mathrm{R} \& \mathrm{D}$ costs, but to private designers and students, this could become ruinous.

To date, case studies written on the SLM technology and associated optimisation processes have focused largely on engineering and functional medical applications. However, this process has not been extensively studied from a visual and aesthetic industrial design perspective and how designers can maintain their design intentions using 3D printing technology and its optimisation processes to achieve an optimal outcome.

The aim of this research is to gather specific knowledge about the technical limitations involved in the Selective Laser Melting process and explore how the designer's intentions can be maintained or even enhanced. This includes exploring opportunities for designers to improve CAD files for SLM printing to reduce support material, leading to reduced heat transfer through the model and post processing, allowing the design to be streamlined. With 
greater understanding of the SLM process, the optimisation process may further provide positive outcomes to the designer by saving time, money and waste.

The objective of the research is twofold. Firstly existing design research will be completed and analysed to translate into design principles and decisions. Secondly a case study will be prepared using an existing product design file as a base model. Various iterations of the base model will be developed applying the design principles from the design research, material reviews and evaluation results from previous digital and physical models. The iterations will be informed through the use of innovative geometry and techniques to provide insight of lasting design principles on the breadth of creating an object using SLM technology.

The existing design research is focused on the challenges designers encounter using 3D printing technologies as well as research on the optimisation and SLM processes using various primary and secondary sources. The design iterations and digital and physical models were developed using Nigel Cross's model of exploration, generation, evaluation and communication. The base model was initially produced in other materials as a comparison of the 3D printing capabilities of the SLM process. The core research was based on titanium 3D printed objects using Rapid Advanced Manufacturing machines in Tauranga and aspects of the model were iteratively redesigned to conform to the SLM limitations.

First the research paper will provide the reader with the design brief, research question and aims followed by the literature review. The paper will then provide the reader with methodologies used to address the research questions and aims followed by a more detailed overview of the $3 \mathrm{D}$ printing process. The research then outlines the detailed design requirements and criteria, which are later reflected in the design iterations, prints and evaluations. Lastly the paper will conclude with a summary of the final developed design and conclusion. 
"Good design is making something intelligible and memorable. Great design is making something memorable and meaningful"

Dieter Rams, Basic design 01 (2012) 


\section{A S E S T U D}

\section{Case Study and Design Brief}

This study has its pedigree in a product that is already on the market. Ross Steven's amplifiers, produced by his company Pure Audio has a defined aesthetic in both its design and construction. Using the company's designed cut-outs and surface finishes, an approach was decided on to produce an additively manufactured product from a subtractively manufactured design. The design brief given had a set of criteria that had to be achieved

- $\quad$ SLM production method using titanium

- $\quad$ Thin walled structure

- $\quad$ Reduction of material (waste)

- Connection to original design intent

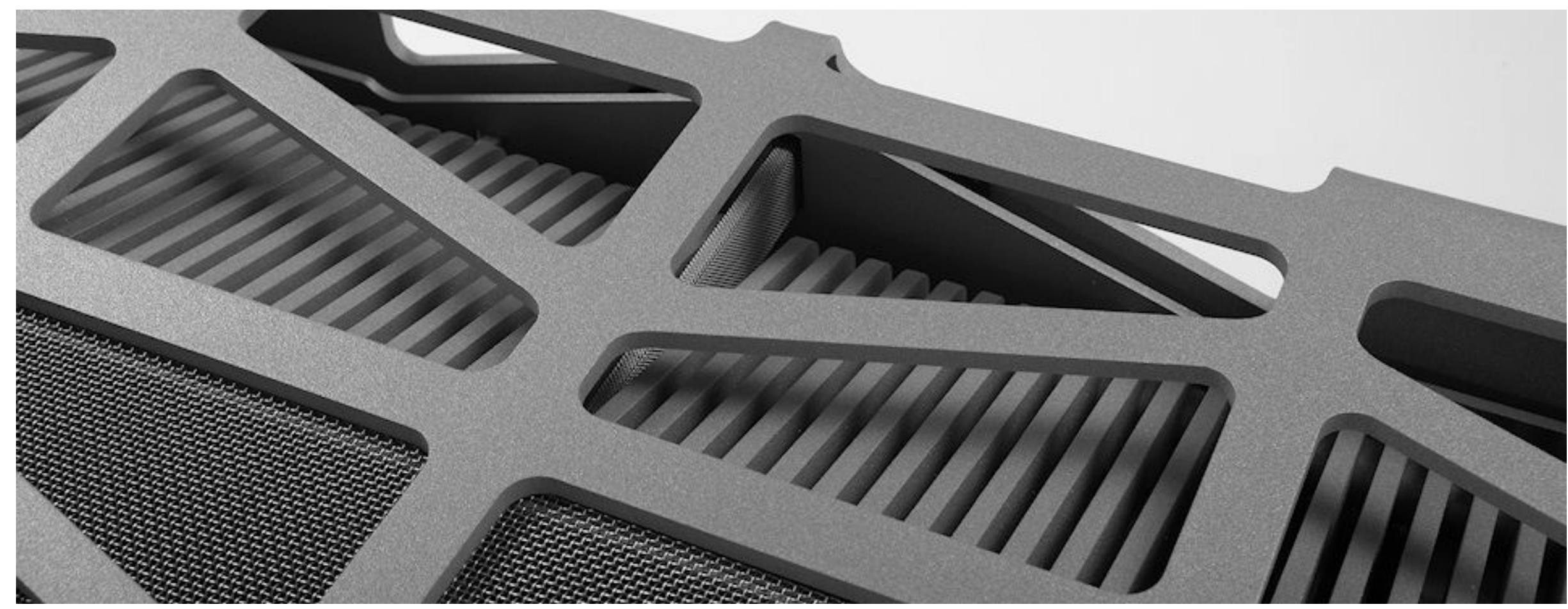

Figure 3: Reference Class A Monoblock «pureaudio. 
$-7-$ 


\section{QUESTION // AIMS}

\section{Research Questions}

$\mathrm{B}^{\mathrm{s}}$ ased on the problems outlined in the introduction and the design brief the following two research questions have been defined for this research:

1. What are the design limitations when producing an object using the selective laser melting process?

2. What is required in an optimisation process to maintain or enhance a design when producing an object using the selective laser melting process?

\section{Aims}

This research paper has two research themes, SLM process limitations and optimisation process. To answer the above research questions the following aims were developed:

\section{SLM Process limitations}

1.1 To understand the technical limitations involved in the Selective Laser Melting process.

\section{Optimisation Process}

2.1 To explore how the optimisation process can address the technical limitations of the SLM process.

2.2 To investigate how the designer's intentions can be maintained or even enhanced through the optimisation process.

2.3 To help understand if there are opportunities or design principles that can be applied for designers to streamline their designs in the future.

The challenges of this research are to understand the root design limitations of the SLM process, using the machines at Rapid Advanced Manufacturing (RAM) in Tauranga. This company is only one of three commercially available companies in the New Zealand and arguably one with the most experience in the industry. However, using this company at distance has thrown up a number of design challenges.

Knowledge gained by this research would help a range of people and professions including students, industrial designers, engineering and design professionals. This research will describe in detail the processes that have been used and the challenges that have been overcome by using CAD modelling, discussions with RAM and observation. 


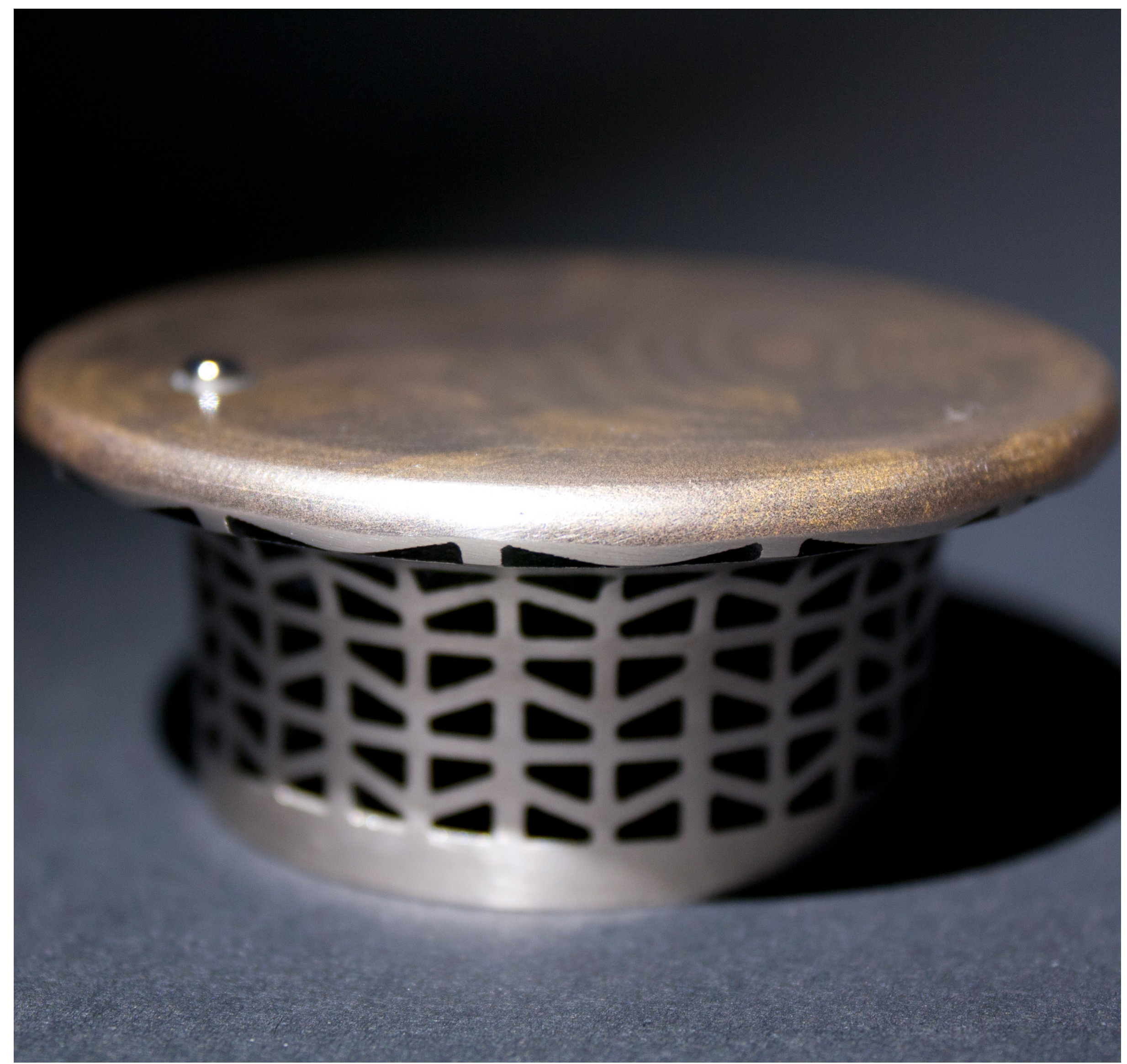

Figure 4: Stainless Steel volume control knob 


\section{LITERATURE REVIEW}

Lipson and Kurman (2013) describe that additive manufacturing offers designers' freedom in form and function. Although 3D printing is perceived to be a designers ultimate answer to producing anything - designers are challenged to achieve the outcome they want with current 3D printing technologies. The purpose of the literature review is to provide a wider overview of the $3 \mathrm{D}$ printing context with regard to the opportunities and challenges designers face when designing objects using $3 \mathrm{D}$ printing technologies and in particular SLM. Further the research is to gain knowledge on specific manufacturing constraints for SLM including pre- and post-processing and critically assess these for this research and to identify possible design principles and input into design decisions for this case study.

\section{Is $3 \mathrm{D}$ printing an opportunity for designers?}

In the book Fabricated (2013), Lipson and Kurman imagine a world where every conceivable item can be constructed using additive manufacturing, or also called 3D printing. From food replicators, that can regulate prescription drug intake, to luxury homes made by just one worker and a large building fabrication machine. The intention of the authors is to imagine the scope of what could be, as opposed to what is possible with current $3 \mathrm{D}$ printing technology.

While this imaginary world seems more like science fiction rather than science fact, rapid changes to manufacturing and design has seen an increase in $3 \mathrm{D}$ printed products that have only until recently been speculated on. A report by Price Waterhouse Cooper states "The technology for 3-D printing, also known as additive manufacturing, has existed in some form since the 1980s. However, the technology has not been capable enough or cost-effective for most end-product or high-volume commercial manufacturing. Expectations are running high that these shortcomings are about to change" (Earls \& Baya, 2015). This is reflected by the industry investing large amounts of capital into new 3D printing techniques. New Zealand has also seen significant growth and investment 
not only from industry, but also considerable government funding (Wohlers Associates, 2014).

Companies and private individuals provide today customised 3D printed footwear for athletes and the fashion conscious, 3D printed clothing and jewellery (Stewart, 2015), as well as entire buildings, interior and complex metal parts. The Zhuoda Group for example has 3D printed a house with six modules within ten days (Zhou, 2015). General Electric has been given US Federal approval to replace parts on their 777 jet engines with metal 3D printed parts (Radis, 2015). And in New Zealand, Air New Zealand has started working on 3D printed components for its Business Premier cabins. Their CEO Bruce Parton said that "it seems the possibilities are limited only by our imagination" (Air New Zealand, 2016).

Rocket Lab is another company investing in 3D printing technology. In an interview Rocket Lab's CEO Peter Beck explained that they chose to use $3 \mathrm{D}$ printing technologies because "it was really the only technology that showed promise to be able to produce components with the complexity, reliability, high performance, cost and in the time we need" (Sykes, 2015).

The advantages of 3D printing are manifold. It provides the ability to produce complex geometries in different materials that could otherwise not be manufactured (Neely, 2015). Further advantages are that the digital design can immediately be manufactured with minimal human interaction and allows the production of parts without the need of assembly resulting in time and cost savings. 3D printing allow designers to selectively place material only where it is needed '(Chow, 2011, p. 5) and supports waste reduction in comparison to traditional manufacturing. In particular metal $3 \mathrm{D}$ printed objects create less waste and almost all of the waste material can be re-used, which is more environmentally friendly in comparison to traditional metal production methods. On the other hand disadvantages include the physical limitations of 3D printers, for example limitation of the size an object can be printed in, materials and volumes (Lipson \& Kurman, 2013).

Based on the significant improvements in metalbased laser melting equipment, the market has globally seen an increase in sales, which has resulted in a backlog of orders with machine supplier not being able to meet demands (Wohlers, 2014). The improved SLM machines make them not only interesting for prototyping, but also manufacturing (Kruth, J.-P. et al, 2005). Companies like LayerWise (LayerWise, 2016) or Rapid Advanced Manufacturing (RAM, 2016) have recognised the capabilities of these machines. This is due to the advantages of SLM that can produce complex geometries and surface textures not only for prototyping but also production. The most often used material at RAM is currently titanium due to its strong properties and corrosion resistance. Based on the increase in demand and limited machines the delivery timeframes for 3D printed objects vary. At Rapid Advanced Manufacturing for example complex designs can be printed on SLM machines within a two-week period (RAM, 2016).

Campanelli et al (2010) explain how for SLM technology cellular complex structures can be printed in metal allowing for improved products, functionally and mechanically. Miguel Seabra et al confirm the advantages of SLM as an additive manufacturing process. They refer not only to the significant advantages in regard to the ability to create complex geometries, but also through using the topology optimisation, they were able to reduce the material volume 


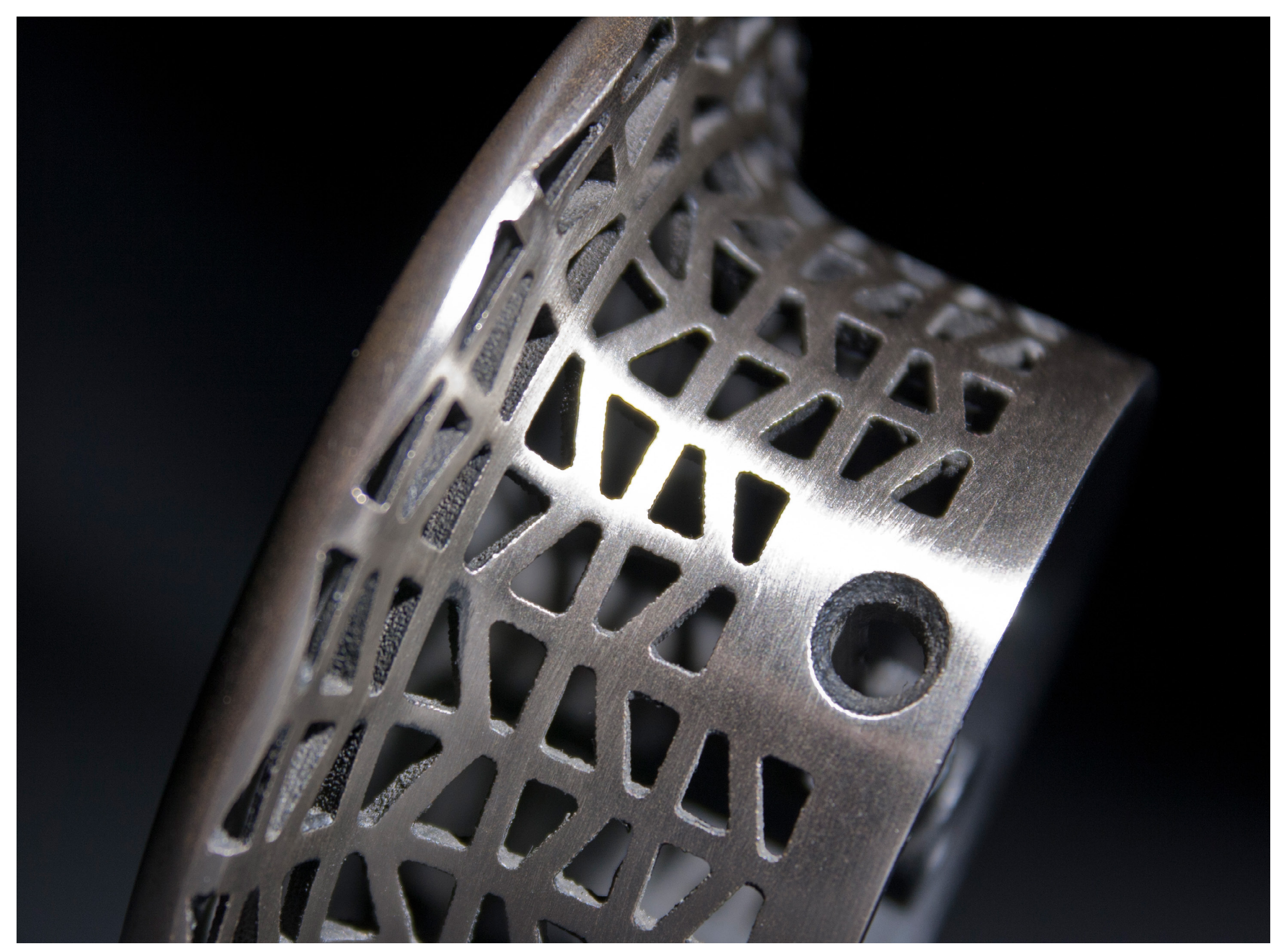

figure 5

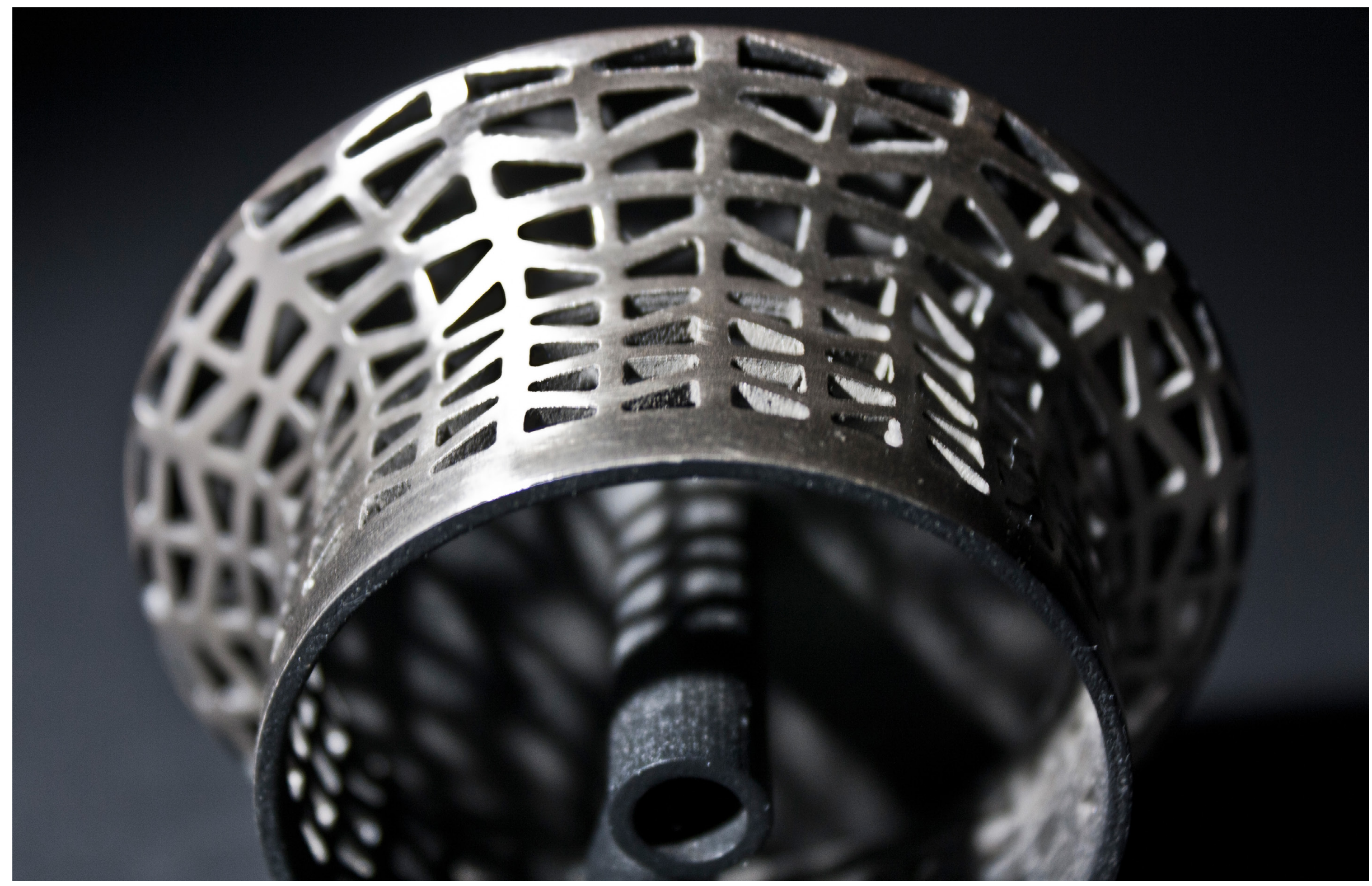

figure 6 


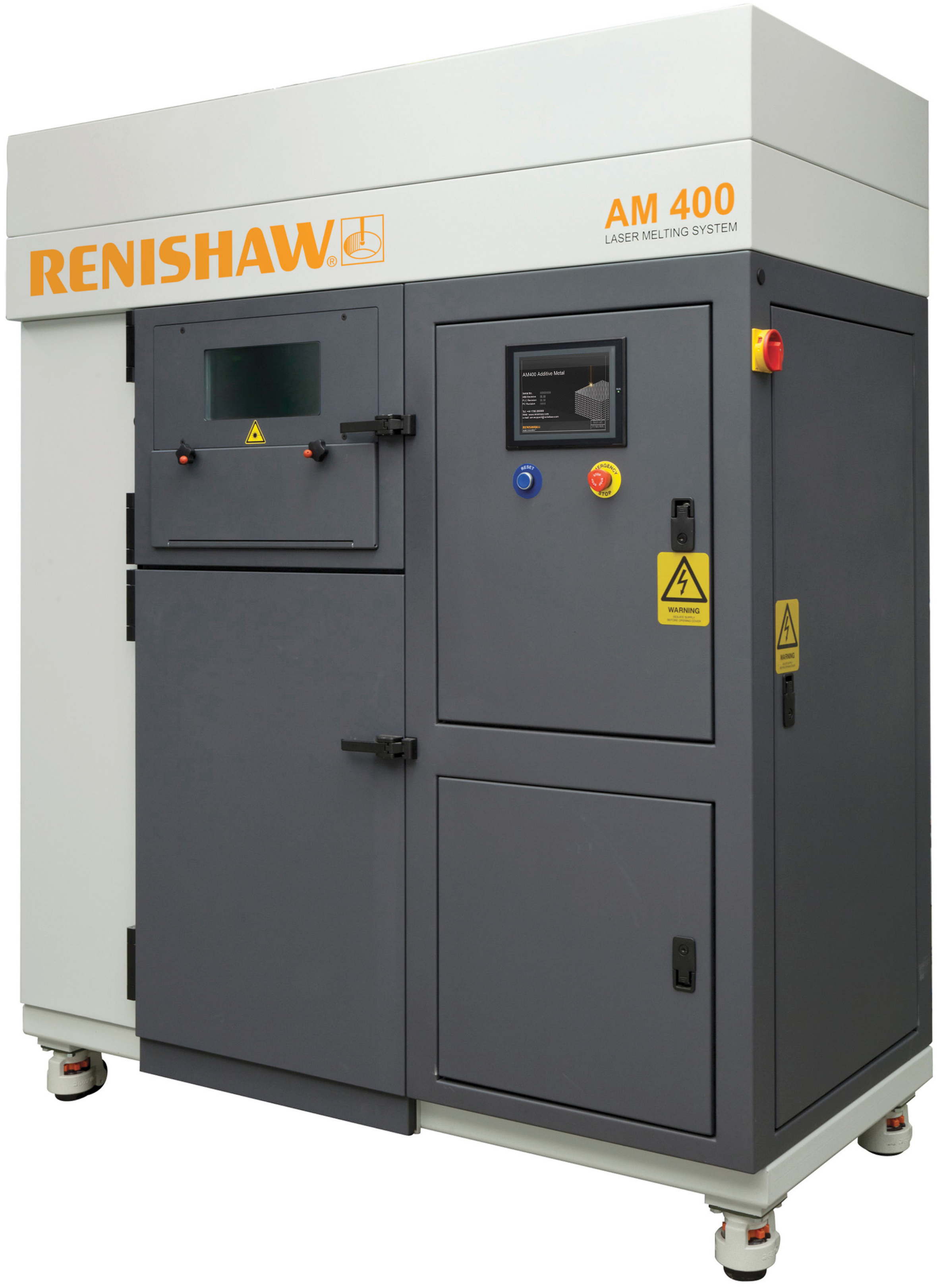

Figure 7: AM 400 additive manufacturing system 
by $54 \%$ and a $28 \%$ weight reduction, changing the material from aluminium to titanium alloy (Seabra, M. et al, 2016).

Although 3D printing technology provides designers with the opportunity of creating more complex structures than ever before; depending on the scale and size of a product rollout, the limitations of 3D printing technology also may hinder designers to using this technology (Conner et al, 2014). Industries however show an increased investment in this technology, promising a future where these limitations will erode.

\section{What are the challenges with $3 \mathrm{D}$ printing and SLM?}

The increased investment results in 3D printing technologies rapidly evolving and the challenges for designers today is about using these technologies, incorporating the design interpretation and printer limitations into their CAD files to streamline not only the design outcome, but also the waste material and post processing required for the end product.

Peter Beck from Rocket Lab explained that when companies use 3D printing technologies the preparation and optimisation is not the same as using traditional manufacturing processes. The printing is only one part of the process and the designing of an object, as well as the review post printing are important aspects to confirm whether the product represents the desired outcome (Sykes, 2015). Thomas (2009) describes in his study that the limitations of 3D printers themselves can result in the printed objects not representing the designer's intent.
The Wohler Report (2014) also recognises this outlining that more focus is today being given to the optimisation process to accommodate for this gap.

\section{The process}

To understand the challenges a designer faces when using 3D printing technology, the process of additive manufacturing needs to be understood.

The 3D printing process has five key steps designers need to be aware of. The process starts by preparing a 3D model using Computer Aided Design (CAD) software or a scan of an object, the CAD file is then run through specialised software that slices the model into cross-sectional layers, which is then fed to the $3 \mathrm{D}$ printer. The $3 \mathrm{D}$ printer then creates the object by printing layer by layer via the selective placement of material. Once the object is complete post-processing such as removing support structures and removing loose powder needs to represent the object's envisioned form (Wohlers Associates, 2014). The slicing of the model is a very important step as it decides on the direction of growth during the printing process and accuracy of the final object (Campanelli, Contuzzi, Angelastro \& Ludovico, 2010).

Significant efforts have been made by various researchers to establish additive manufacturing guidelines, however mostly unsuccessfully. The more successful researches only covered specific processes (Wohlers Associates, 2014). Other guidelines come from 3D printing companies such as Shapeways (2016), Sculpteo (2016) and Ponoko (2016) focusing on the digital design 
and how designers can improve their models as well as instructions on using different materials and other rules such as size limitations and file formats.

One of the more specific researches that specifically focused on SLM is Daniel Thomas's thesis (2009), which tried to identify specific design rules for printing objects using SLM. Thomas researched geometric design rules for mass-production with focus on improving productivity, quality and efficiency of the manufacturing process. Although the research suggests design rules, it does not review the changes to the design and impact on the aesthetics. Experimenting with stainless steel objects Thomas's research provides a set of design rules to allow for more predictable and reliable results when manufacturing parts with SLM, but lacks further experiments within the found limitations and case studies to assess the performance of the identified design rules.

\section{Pre-Processing}

The Wohlers report (2014) outlines the prebuild step of determining the support structures required for an effective print to occur. In particular support material is required for first layers and unsupported layers. In metal printing further support structures are required to fix the part to the base plate. This will minimise warping effects caused by the thermal stresses during the print. Without effective support structures an object may be damaged during or after the print. Depending on the 3D printer the skills and experience of how a platform is setup also plays a significant part in the success of the print outcome. RAM for example uses the software Magics to automatically add the supporting structure and slicing of the objects they produce for their customers. RAM advices that "all surfaces that are less than 30deg from horizontal will require support and in most cases this rule provides enough support" (RAM, 2016).

Kruth et al (2005) completed experiments printing objects in steel and bronze to identify limitations of Selective Laser Sintering and Selective Laser Melting manufacturing methods. The study found that there were limitations to the wall thickness limited due to the laser beam spot as well as the limitations in diameter due to the powder deposition impacting strength as well as the cool down period. These aspects were also important to ensure the accuracy of the object. Another finding was that to avoid curling due to thermal stresses, it needs to be ensured that the part is supported with the base plate.

The study by Nattapon Chantarapanich et al (2014) discussed the potential for the use of SLM within the aeronautical industry, producing complex three-dimensional honeycomb structuresinstainless steelotherwisenot possible with conventional manufacturing methods. The study discussed that the SLM machines should be within a vacuum environment to avoid any oxidation reaction. Other areas of interest were the grain size of the powder as well as the scanning spacing of the machine. They noted that the smaller the powder grain size, the more compact the part was. With regard to the scanning, they highlighted that an overlapping laser scanning track reduced the risk of any unmelted powder between the tracks. 


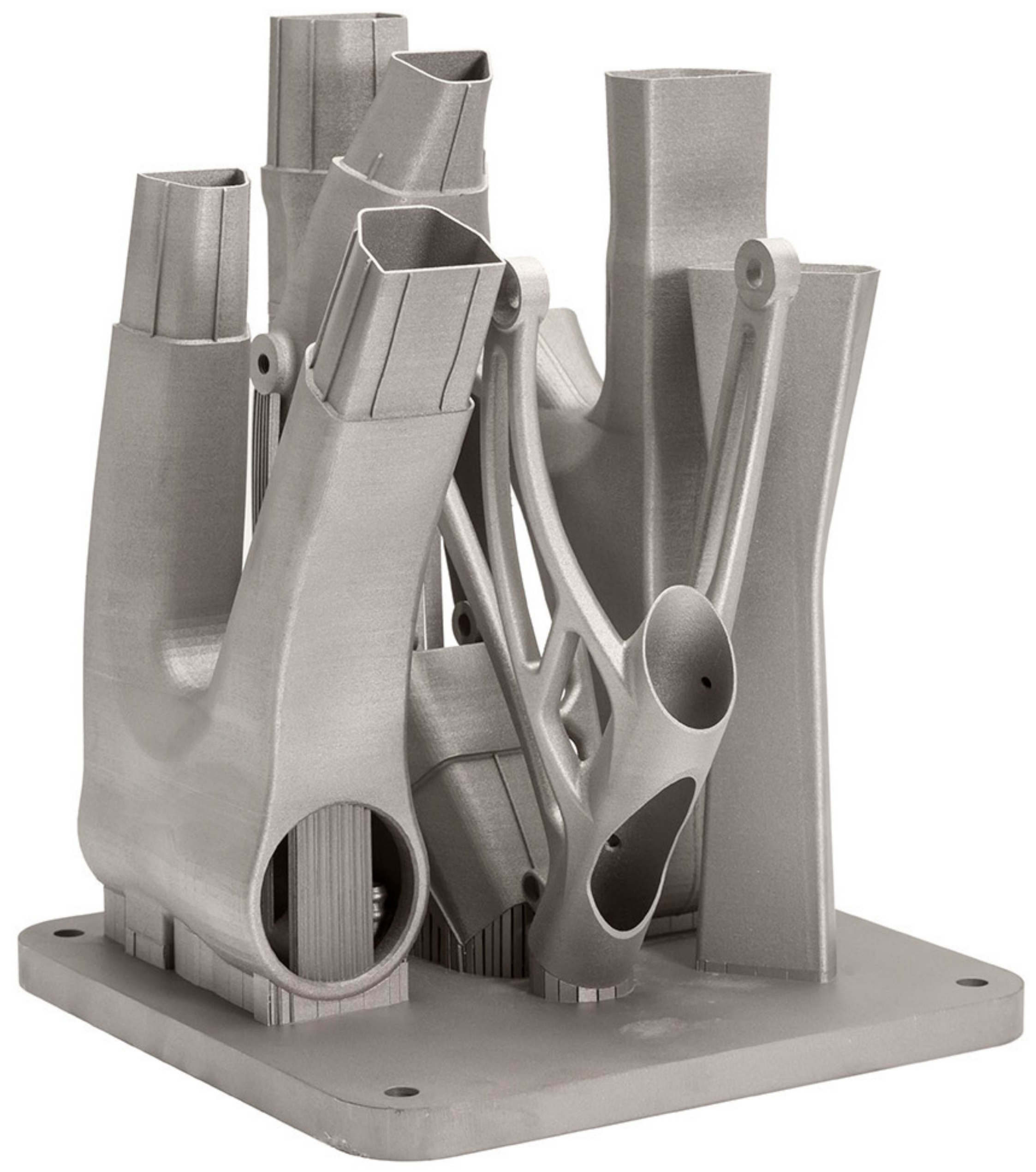

Figure 8:Titanium bike frame post process 


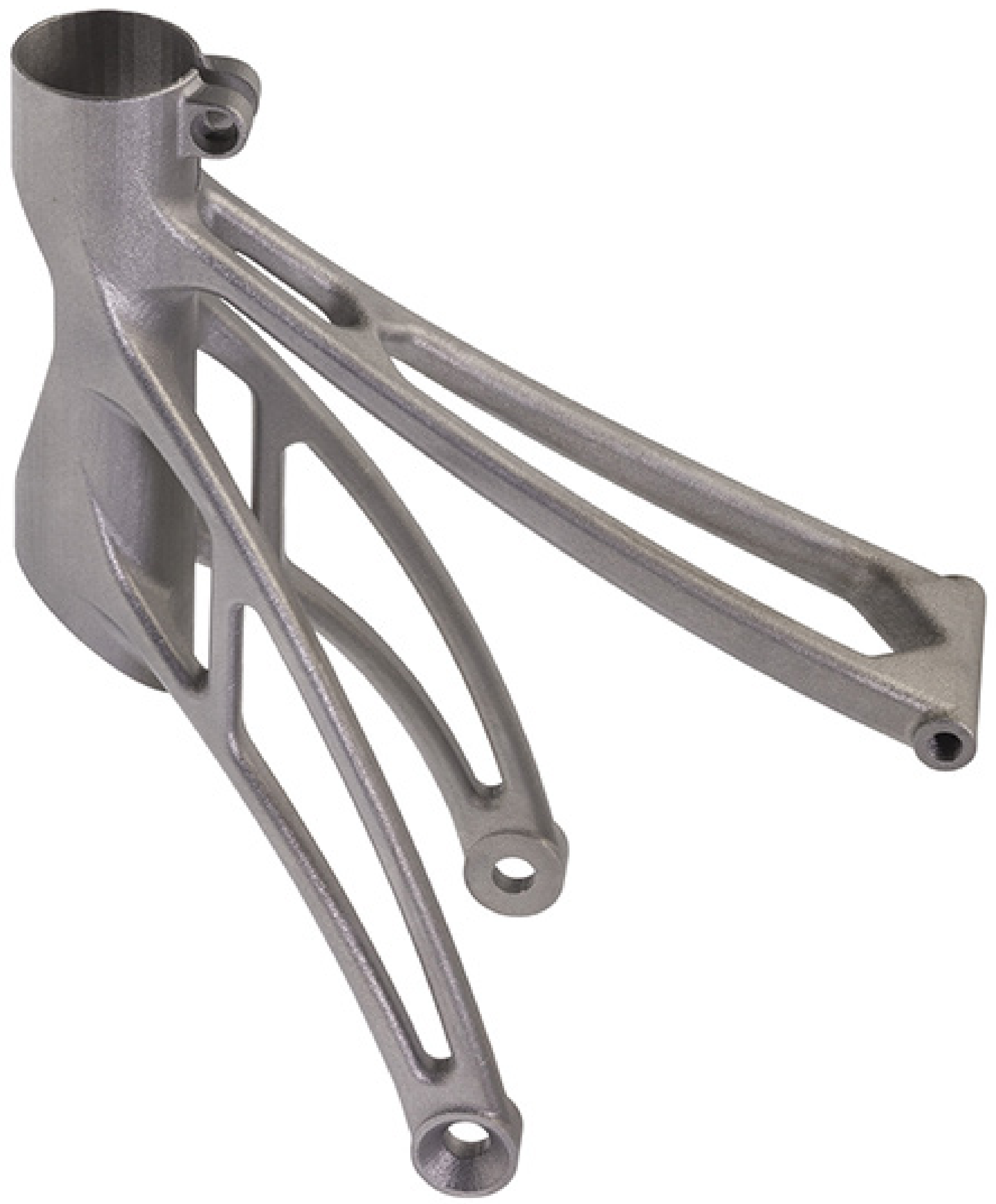

Figure 9: Topologically optimised seat post bracket 


\section{Post-Processing}

The Wohlers report (2014) state "postprocessing is a critically important aspect of $3 \mathrm{D}$ printing, but it is often overlooked or underemphasized" (p. 39). Companies that use the 3D printing capabilities like RAM are beginning to see the optimisation process to reduce post-processing activities as important as $3 \mathrm{D}$ printing itself due to post-processing steps increasing manufacturing lead times and costs. Designers are required to recognise where post-processing will be required to ensure that material is added in areas where it is required for post-processing to be streamlined. This includes requirements regarding surface finishes and tolerances so that refinements to the design can be made prior to the object being printed. As described the finished object then requires post-processing including removing the support structure and removing any metal powder and any waste material recycled. At RAM for example the excess material can be recycled up to 20 times (RAM interview, 2016).

\section{Quality and Reproducibility}

Lipsom et al (2013) provide design principles, two of which are relevant for this design research. The two principles are 'Less waste byproduct' and 'precise physical representation'. Spears and Gold (2016) describe that the difficulty with SLM printing lies with the part quality and reproducibility and states that in- process sensing capability is required to ensure the quality of the products. Campbell, Williams, Ivanova \& Garrett (2011) also confirm that the $3 \mathrm{D}$ printer output varies in quality and structural properties. Kurth et al (2005) found in their study on identifying the limitations of Selective Laser Sintering and Selective Laser Melting, the high potential for repeatability experimenting with steel objects, however also the "challenge is to reach high process accuracy" (p. 5). For SLM printing Campanelli et al (2010) also tested the dimensional accuracy printing of a particular part in steel. They found the accuracy to be good for nominal dimensions over $0.4 \mathrm{~mm}$. The inaccuracies were found to be lower for values under $0.4 \mathrm{~mm}$ due to getting closer to the laser spot diameter. The reports however did not discuss the impact the quality of CAD files and slicing of the model have as factors into the quality and final outcome of the product.

Other challenges with 3D printing are that it is not suitable for mass production at present in comparison to traditional manufacturing (injection moulding) and allows only a limit in size and material of the object (Campbell, Williams, Ivanova, \& Garrett, 2011). Lipson and Kurman (2013) also outline the limitations of some of the design and slicing software and different skills required as 3D printing technologies further evolve and improve in comparison to the traditional way of modelling and manufacturing. 


\section{Summary}

$3 \mathrm{D}$ printing is here to stay. The literature review highlighted thatwithincreasedinvestmentsin $3 \mathrm{D}$ printing technology by industry the limitations are rapidly disappearing. This is resulting in opportunities for designers with more design freedom and industry with new manufacturing methods. The review further highlighted that for designers taking up the opportunities 3D printing has to offer, the process and printer limitations need to be incorporated into the design. This includes adopting an optimisation process as part of the design phase to reduce waste and post-processing, saving time and money and achieve the best outcome. Further designers should also keep up-to-date with the latest software and printer technologies themselves as they rapidly evolve, which may influence design decisions and ultimately in the outcome of the end product. Designers should consider the guidelines by $3 \mathrm{D}$ printing companies as well as design rules set out for example by Daniel Thomas for SLM to reduce the iterations required to produce the optimal physical prints.

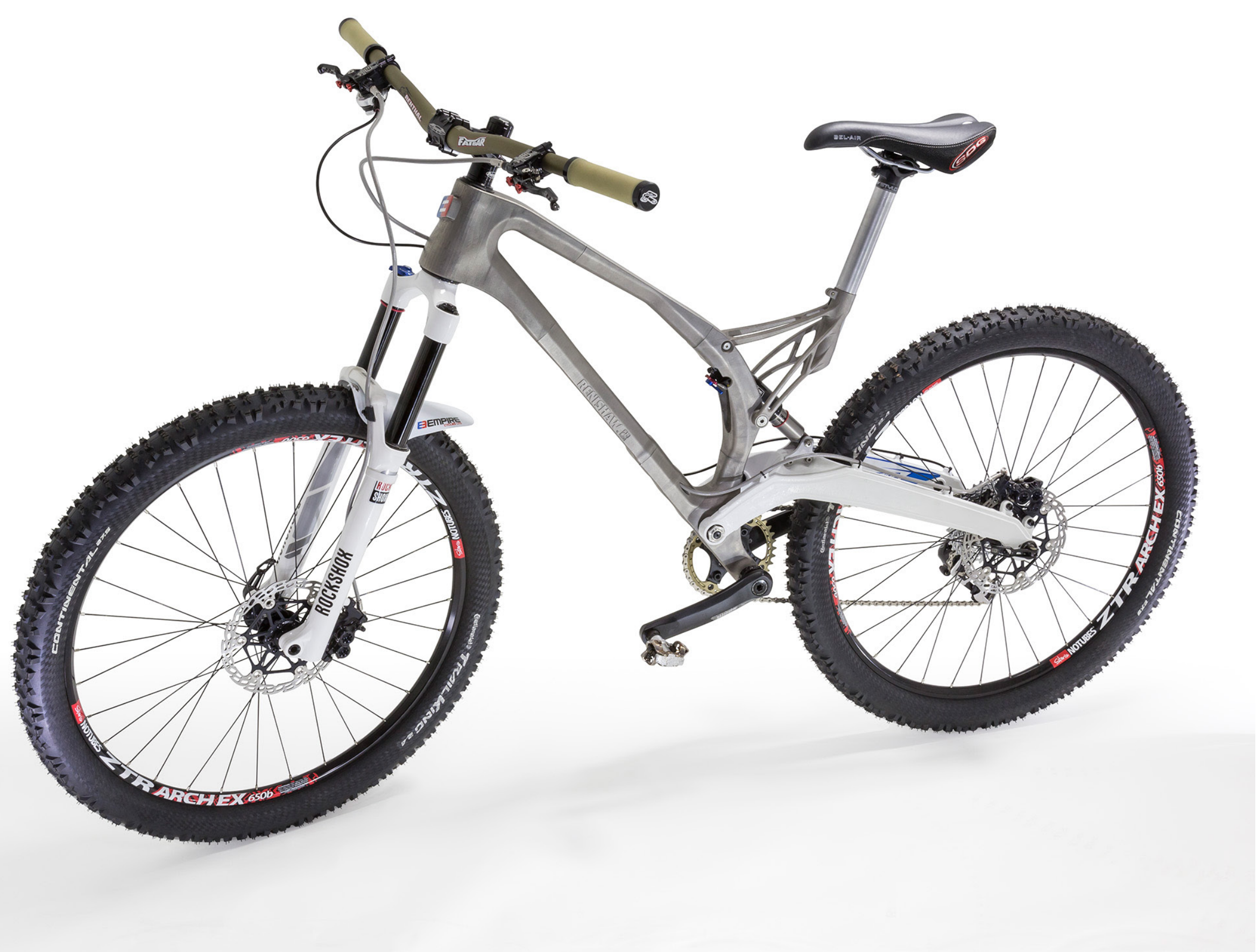

Figure 10: Complete bike with 3D printed titanium alloy frame. 
$-20-$ 
"We have come to realize that we do not have to turn design into an imitation of science, nor do we have to treat design as a mysterious, ineffable art. We recognize that design has its own distinct intellectual culture; its own designerly 'things to know, ways of knowing them, and ways of finding out about them".

Nigel Cross, Designerly ways of knowing (2007) 


\section{ME TH O D OLO G Y}

$\mathrm{T}$

he methodology used for this research is a mixture of qualitative and quantitative research.

The research is based on a case study to explore opportunities to streamline an existing product and compare the models from a qualitative perspective in terms of design intent and from a quantitative perspective the reduction in support material (Martin \& Hanington, 2012).

Cross's design method

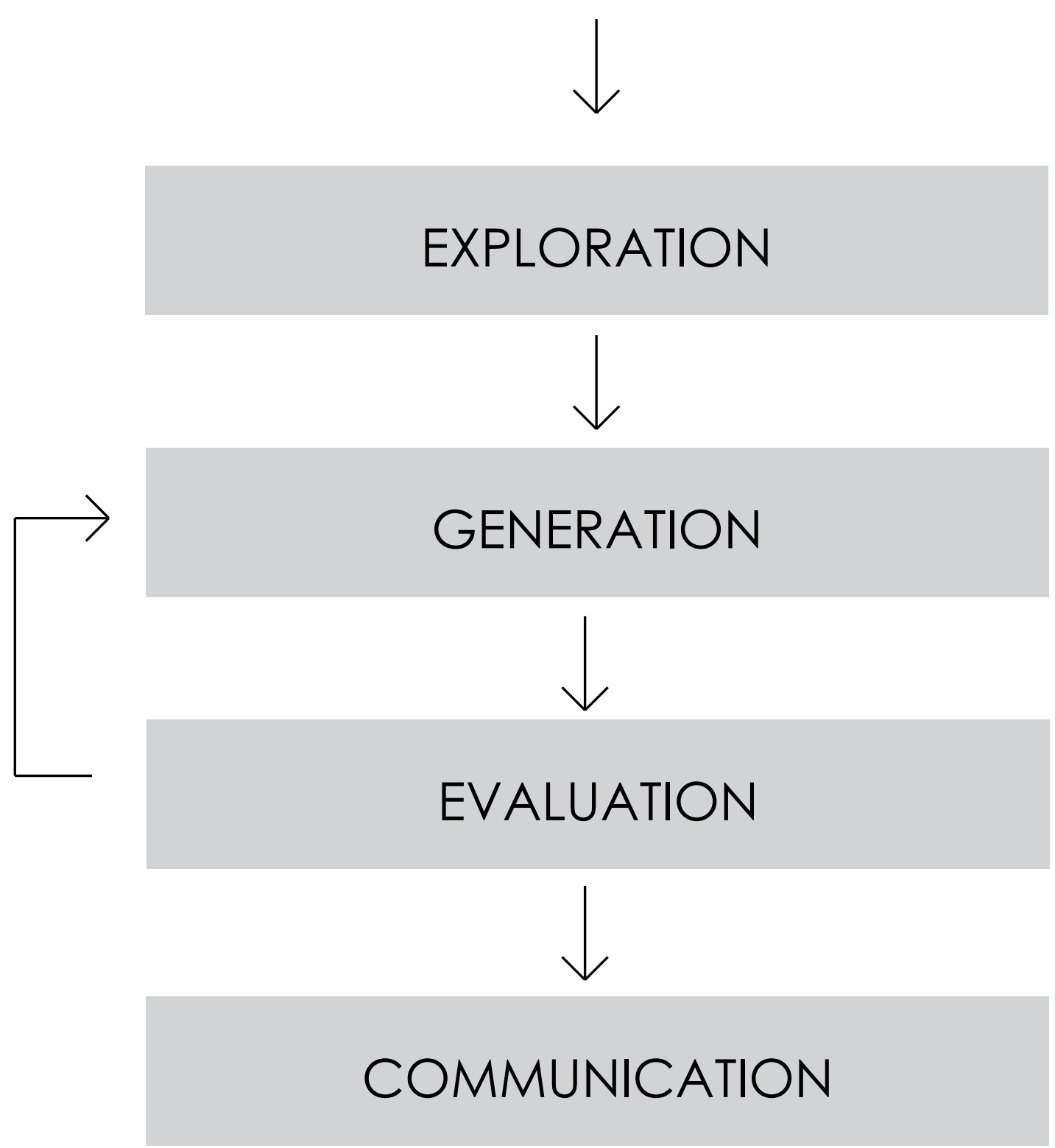

Figure 11: Cross's model 


\section{Taylored approach}

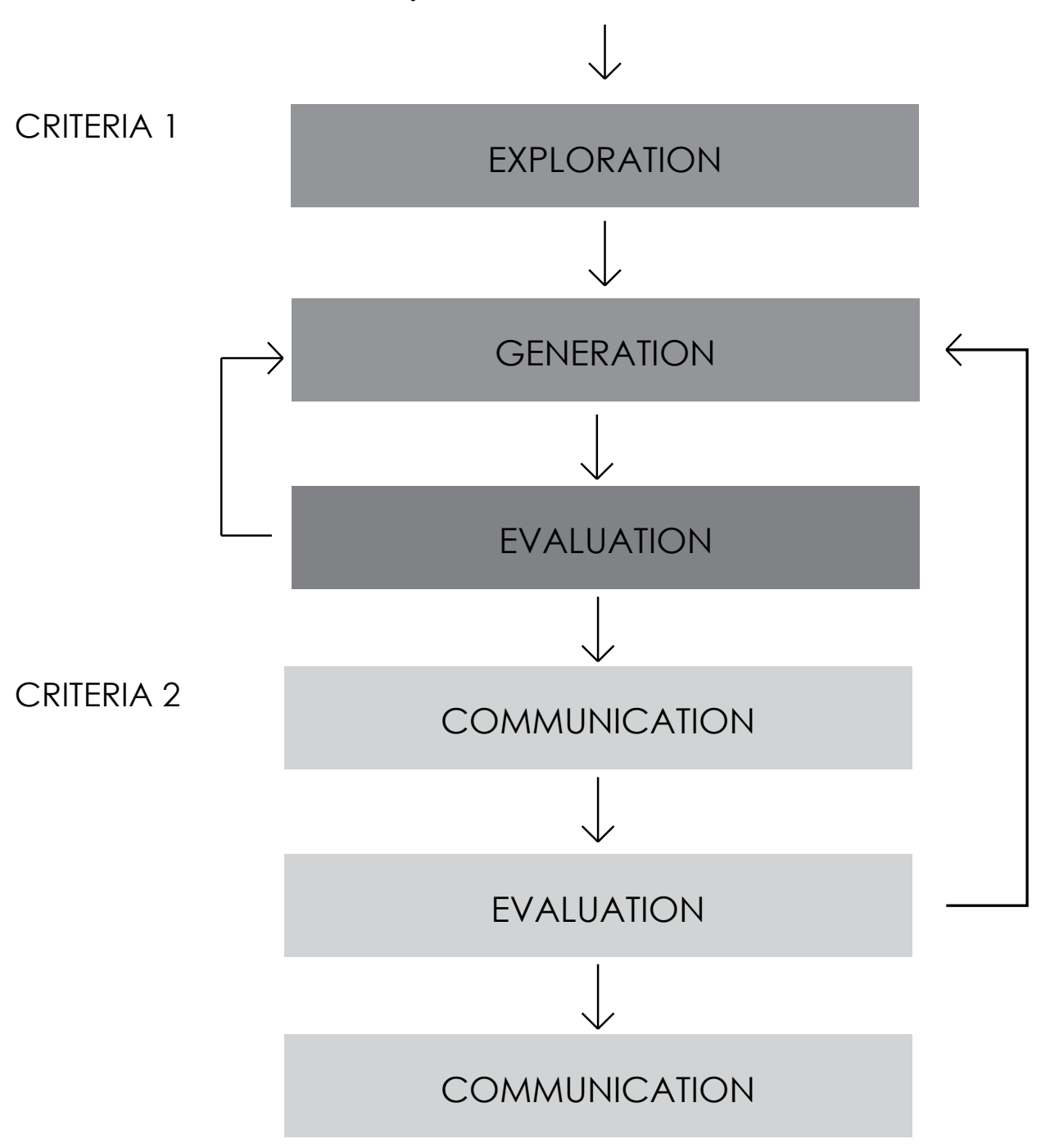

figure 12

\section{Interpretation of approach}

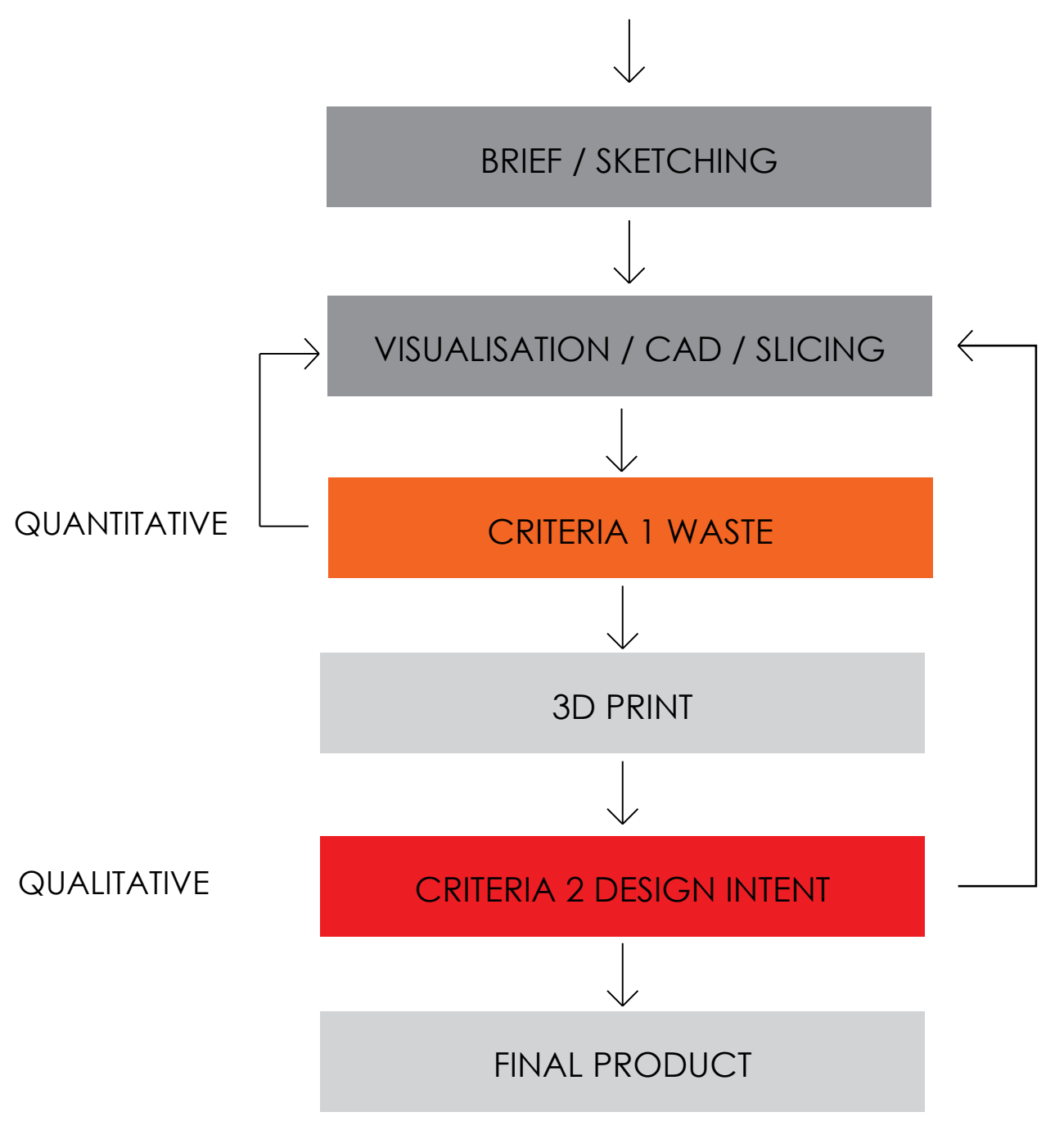

figure 13

Figure 12-13: Thesis approach 


\section{Approach}

This case study uses a problem-orientated model based on Nigel Cross's four steps: Exploration, Generation, Evaluation and Communication (Wynn and Clarkson, 2005). A tailored version of his framework has been developed to allow a number of added steps or sub-steps to be incorporated. Cross's method will be broken into two parts, one digital, the other physical. The sub-steps are procedural requirements, which will inform the communication stage, and which will then inform the analysis to this research. The following paragraphs provide further detail on each step and how they will be applied for this research.

\section{Exploration}

Cross's theory states that the exploration stage is the most poorly defined part of the design process. By this, he eludes that the designer's difficulties have a binary component, that is understanding the problem and finding the solution. Not only are design briefs sometimes vague but also have criteria that must be fulfilled and this will probably not be solved in the first concept (Cross, 2000). This step follows Cross's method closely, with the creation of ideas, sketches and overall concept of form. Input into the exploration step was also taken from primary and secondary design research to further inform the problem statements and constraints.

\section{Primary research}

Primary research was carried out by communication with Ross Stevens with a clear set of instructions for the design and material. An approach to a manufacturer was initiated and through personal communications via email and a face to face meeting, machine and process limitations were discussed.

\section{Secondary design research}

As part of the exploration step a secondary design research was completed to inform existing constraints and problems designers encounter using 3D printing technologies, but also gaps in existing knowledge on SLM with focus on thin walled 3D printed enclosures.

Searches of design databases were carried out using the Victoria university library links to ProQuest, JSTOR and the Design and applied arts databases. Personal collections of design books were also used to support the design decisions during this phase (Martin \& Hanington, 2012). In particular, one research paper written by Daniel Thomas (2009) included a set of geometric design rules for SLM that were used to inform design decisions. The design rules were used as a benchmark against the case study file to check the validity of findings both in the design research and the case file that was developed. 


\section{Generation}

Cross forms his intention of generation by using it as an internal visualisation of the problem. He intends this step as a process of iteration and modification to the design but not ready to be communicated to the outside world.

By using this same process, multiple iterations will be constructed and measured against criteria set down in the design brief.

The generation process has two aspects to it that, while both are CAD programs have different roles in this step. In the first part of the approach, the generation side will be created using Solidworks as the primary design program, the second part of the approach will be Materialise magic's, which will be used specifically to determine the support structure.

Figure 14: Model 3.0

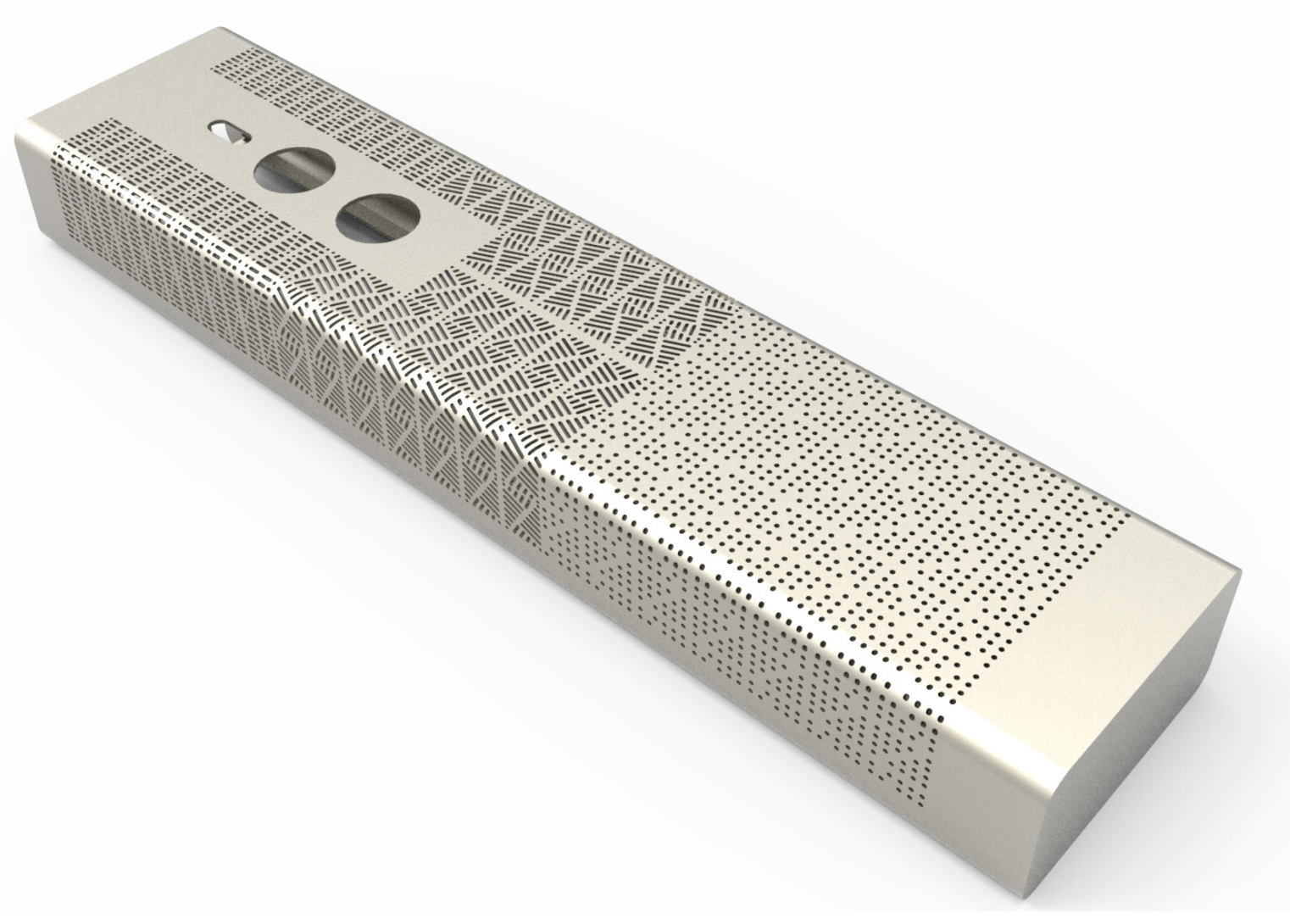

\section{Evaluation}

To evaluate using Cross's method would entail looking at only the design through the lens of the designer by separating the process of design from the process of making. However, using a tailored approach, the physical will also be evaluated as seen from a manufactured object as both digital and physical play a role in the process of creating. This is done to validate ideas that have come from the digital realm and brought into the physical. To evaluate both digital and physical stages, the criteria used are waste and design intent.

\section{Communication}

Communication is by far the most important and the most difficult part of designing that confronts a designer. Whether it is by drawing (which was the most common way to transfer ideas from designer to manufacturer at the time Pye wrote his book 'The Nature of Design') 
or more prevalent at the time of this writing (3 dimensional models). This section is again split into two distinct categories as seen in the tailored approach.

\section{Digital/ Materials magic}

The first communication stage gate will be the digital file that has passed through the first evaluation of the criteria. Slicing software is a critical point of design when creating an object to be $3 \mathrm{D}$ printed with the SLM process. However, the name does not tell the whole truth to the steps involved when going through this process. The software also calculates the amount of support material needed to allow the object to print without falling over. This is one of the key parts to SLM printing as the more support material that is required for a part, the more post processing is needed for the part to meet with the designer's intention.

This stage will be shown graphically using data taken from Materialise magic and assessed against the proceeding model iterations.

\section{Physical / Renishaw}

The second communication method will be a physical 3D print using a Renishaw SLM additive manufacturing machine (Renishaw, 2016). The company engaged was Rapid Advanced Manufacturing (RAM), uses the following process:

- $\quad$ Powder bed fusion process: Renishaw SLM machine AM250

Heat treatment: To release thermal stress that has built up in the part

- $\quad$ Post processing of support material: The removal of any unwanted material

(note, in some cases support material cannot be avoided, see Thomas design rules.)

Communication of these steps will be used in the analysis of this research to determine if both criteria were achieved. Only when the first criteria are met then the second physical part can be carried out. If the second criteria are not met, then the process regenerates back to the generation stage to begin again. If both criteria are met, then the product has satisfied the design brief. 
" $3 D$ printers work in the same manner to traditional laser or inkjet printers, rather than using multi-coloured inks, the $3 D$ printer uses powder that is slowly built into an image on a layer-by-layer basis".

Barry Berman, 3D printing: the new industrial revolution 


\section{D PRINTING PROCESS}

$\mathrm{T}$ his chapter describes the 3D printing process, such as how 3D printing works, and includes a description of the process used and the reasoning behind why this method of production was chosen.

3D printing utilizes an additive manufacturing process where objects are built on a layer-by layer process through a series of cross sectional slices. All additive manufacturing (AM) machines use CAD software to run calculations on thousands of cross sectional slices of individual objects and use this data to determine the exact geometry and configuration on how each layer will be constructed (Berman, 2012).

The CAD software chosen for this study was Solidworks by Dessault Systems, due to its ease of use and prevalence of use in the manufacturing sector. Paired with this is Materialise Magics, a slicing software used to prepare the CAD data into a machine readable format.

The best analogy would be to take a hot glue gun and squirt the hot glue on to a surface, then repeating this on top of the previous line, slowly building up on itself and creating a wall. This is the essence of additive manufacturing, placing material in the position designers want, not taking material away, which happens in traditional subtractive manufacturing like milling an object out of a solid block of material. The process chosen for this study is selective laser melting (SLM), which is a powder fusion based manufacturing technique. This process development was created based on selective laser sintering (SLS), which partially melts the powered material causing it to stick to its neighbour and form the desired object. SLM takes that one step further by fully melting the material into a molten pool, binding the material closely together and fusing it into a solid object.

The SLM process has an added advantage when paired with specific alloys such as titanium64 (titanium mixed with $6 \%$ aluminium and $4 \%$ vanadium), which allows the minimum width to walls to be $0.4 \mathrm{~mm}$. This is important as using less of the material means less cost and waste which is a factor in most designs. 


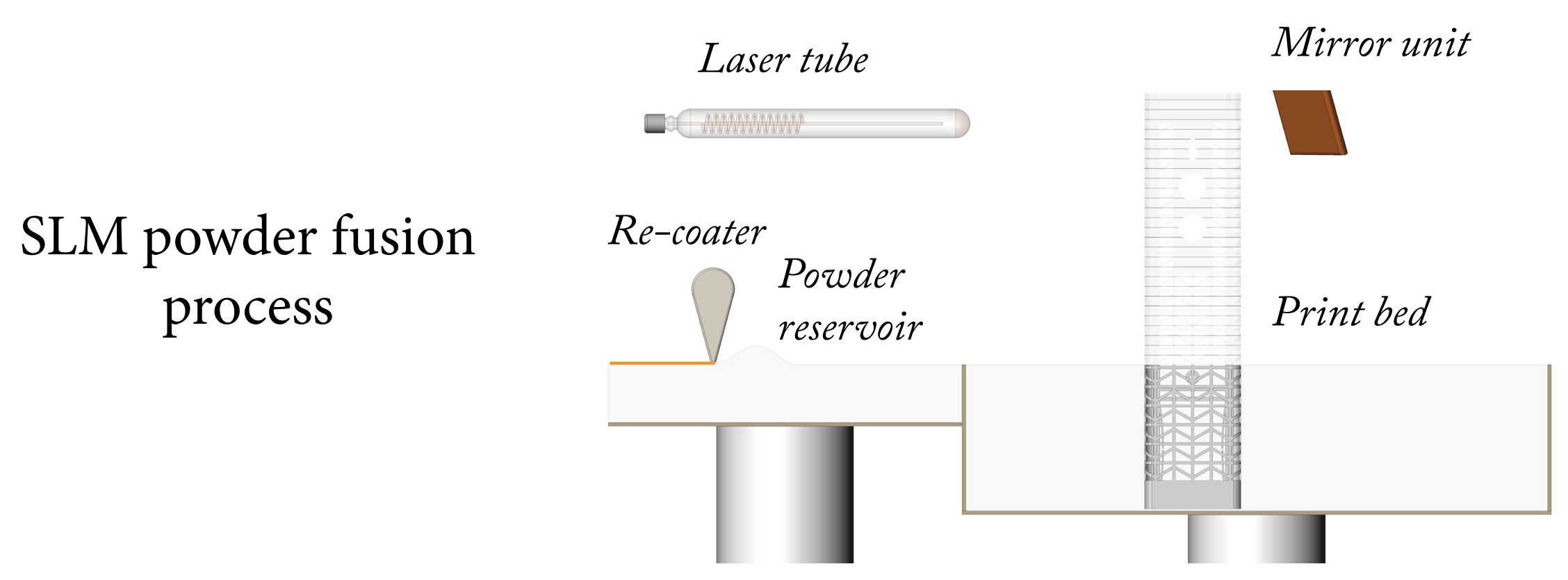

figure 15

Powered material (Ti64) is taken from the powder reservoir by the pre-coater and spread evenly accross the print bed.

Once the powder is in place, a scanning laser is directed onto the material via the mirror unit, tracing the form of the the desired object.

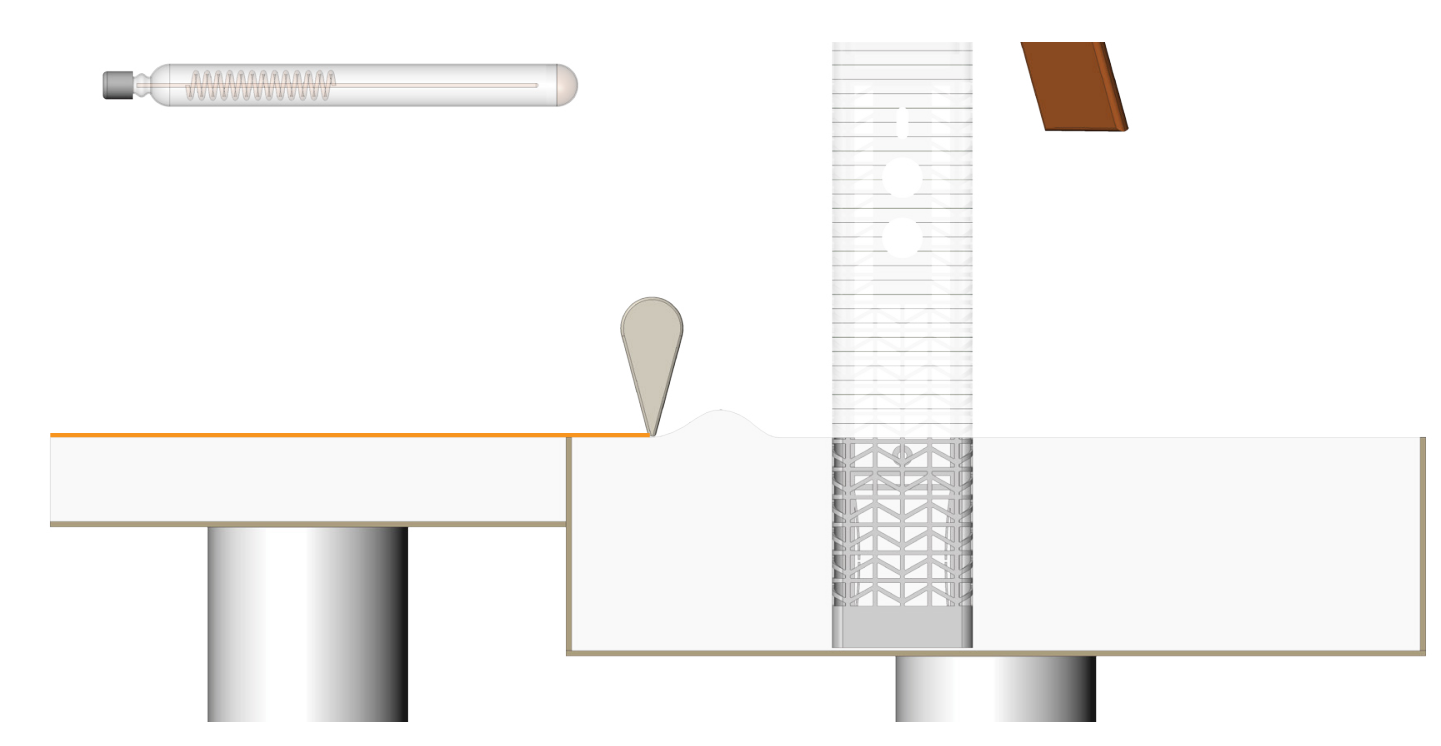

figure 16

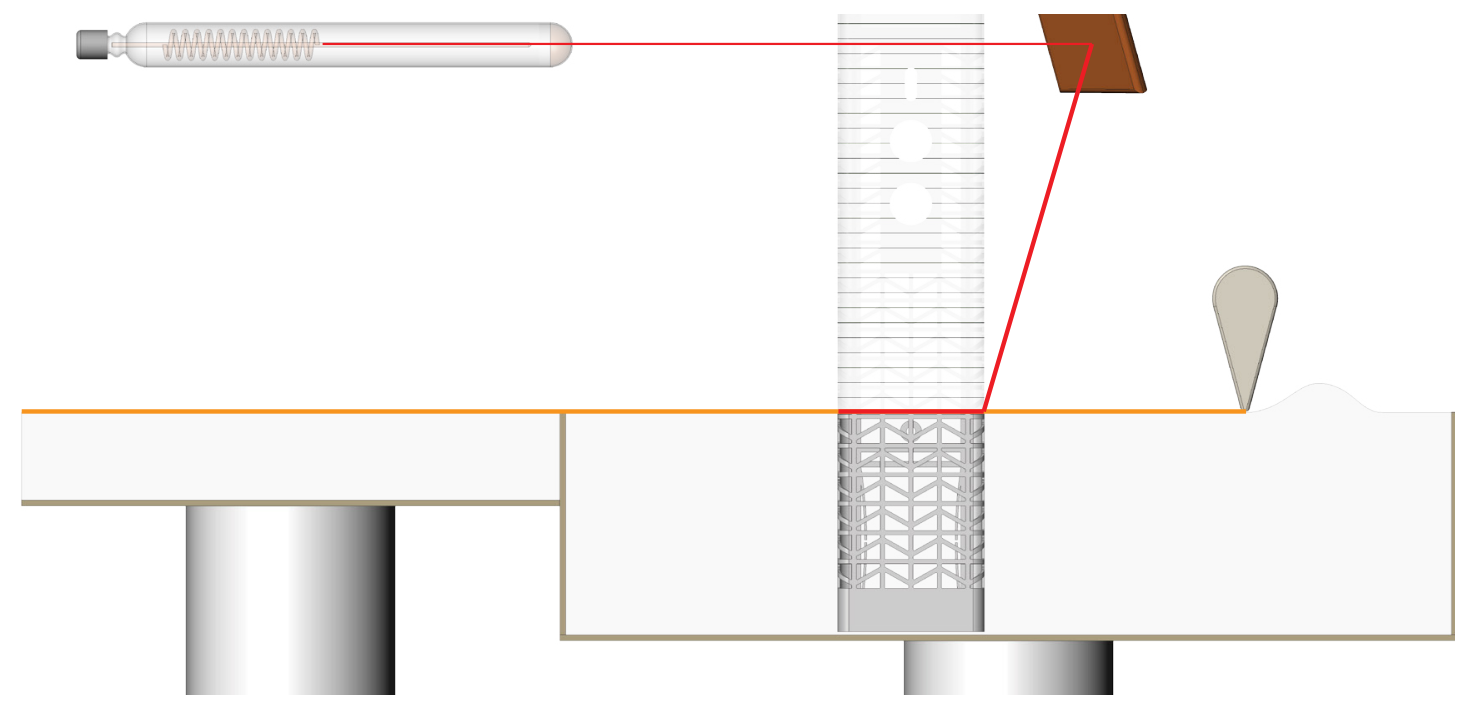

figure 17 


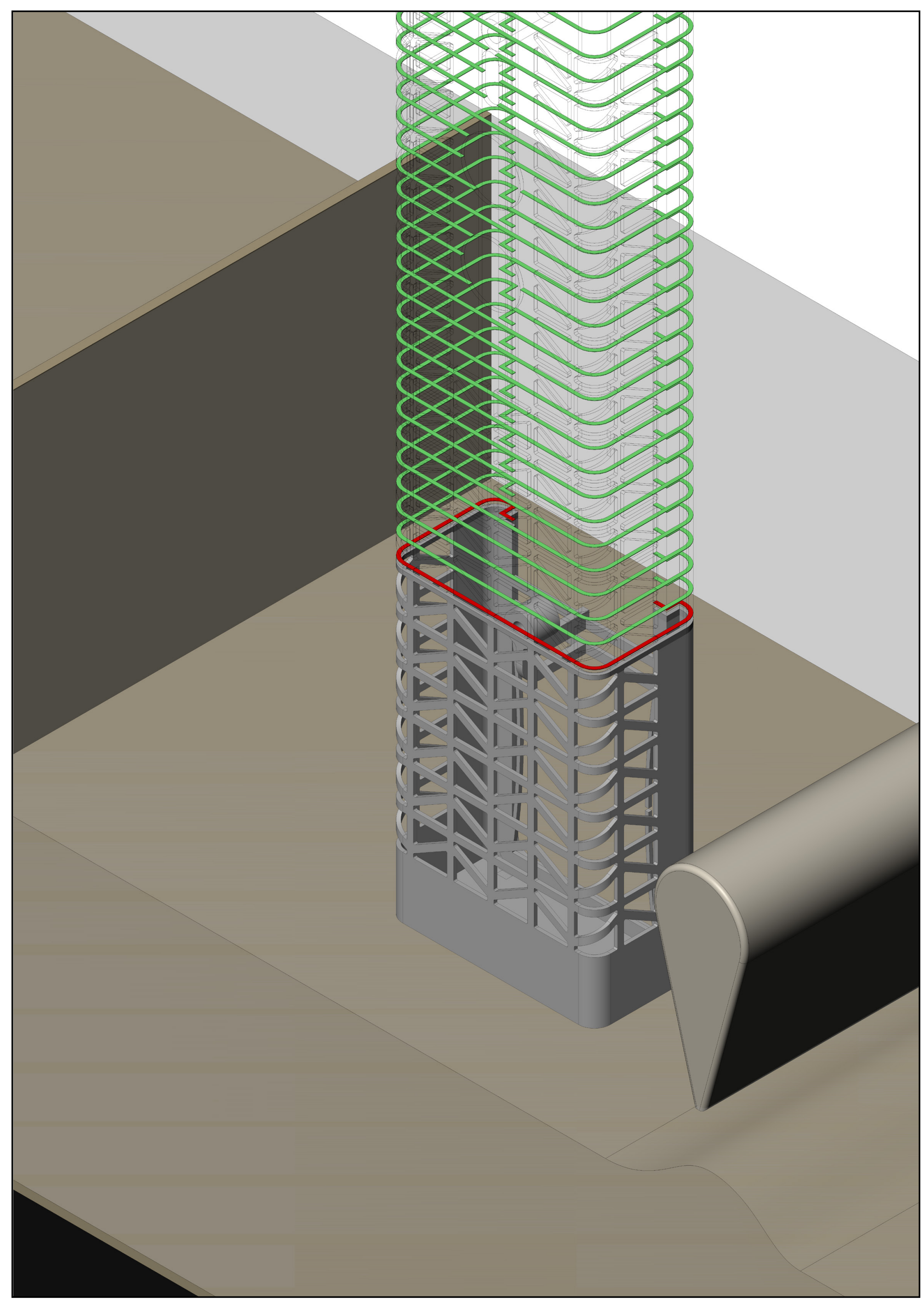

Figure 18: 3D CAD form fused with underlying model structure (red), forming 99\% solid object. 
$-31-$ 
$-32-$ 
"A 3D printer without an attached computer and a good design file is as useless as an iPod without music"

Lipson and Kurman, Fabricated (2013) 


\section{DESIGN REQUIREMENTS}

$\mathrm{T}$

his chapter describes the experimental planning, such as machine requirements, and includes a description of the design criteria, how the criteria informed experimental iteration and machine data. Finally, this chapter describes the reasoning behind each experimental iteration and how design criteria were used to produce a successful outcome.

\section{MACHINE LIMITATIONS}

Machine limitations are the main set of effect the case study model.

conditions that first have to be addressed as these The secondary research machine design rules are non-negotiable and are key to understanding were carried out on a MCP SLM Realizer the evaluation criteria for each iteration and the 250. The material used in this study was $316 \mathrm{~L}$ decision processthatinformsthenextexperiment. Stainless Steel (Thomas, 2009).

These limitations have been retrieved from both The SLM machine this thesis was carried out primary and secondary research through email, on was the Renishaw M250 and the material face to face conversations with manufactures, used was Ti64 titanium alloy. It must be noted books and online sources. After the machine that machine limitations are specific to each limitations have been understood, design criteria individual machine.

were developed following the design brief. This study will outline only design limitations that

\begin{tabular}{|l|l|}
\hline 1 & Minimum of $0.4 \mathrm{~mm}$ wall thickness. \\
\hline 2 & Minimum of $0.3 \mathrm{~mm}$ size between features. \\
\hline 3 & Minimum of $30 \mathrm{deg}$ for no support material. \\
\hline 4 & Down side surfaces over must be over $0.8 \mathrm{~mm}$ for removal from build platform. \\
\hline 5 & Max $7 \mathrm{~mm}$ holes without support material in the $\mathrm{z}$ orientation. \\
\hline 6 & Min $1 \mathrm{~mm}$ hole without support material in the $\mathrm{z}$ orientation. \\
\hline 7 & Max $0.7 \mathrm{~mm}$ hole on flat surface. \\
\hline
\end{tabular}




\section{Nesting with SLM}

It must also be mentioned that the process of nesting parts plays a role in 3D SLM printing. Parts are placed digitally on the print bed to maximize the amount of objects to be produced at one time. However, with hinged and interlocking parts the literature (Thomas, 2009) states that parts must use support structures to prevent movement and to support walls and overhangs with angles less than 30 degrees from collapsing. This points to hinged or interlinked designs that should not be able to be printed with the SLM process such as chain-mail. However, there does exist examples of SLM printed chain-mail witnessed by myself at the RAM production center in Tauranga. In correspondence with them, it is possible to create unsupported interlinking parts, however their response was "The chain-mail you refer to was designed and developed by us over a period of time. It contains some very critical areas of design to make it work and that IP is not in the public domain". (RAM, 2016)

More research into this is advisable, but is not in the scope of this research.

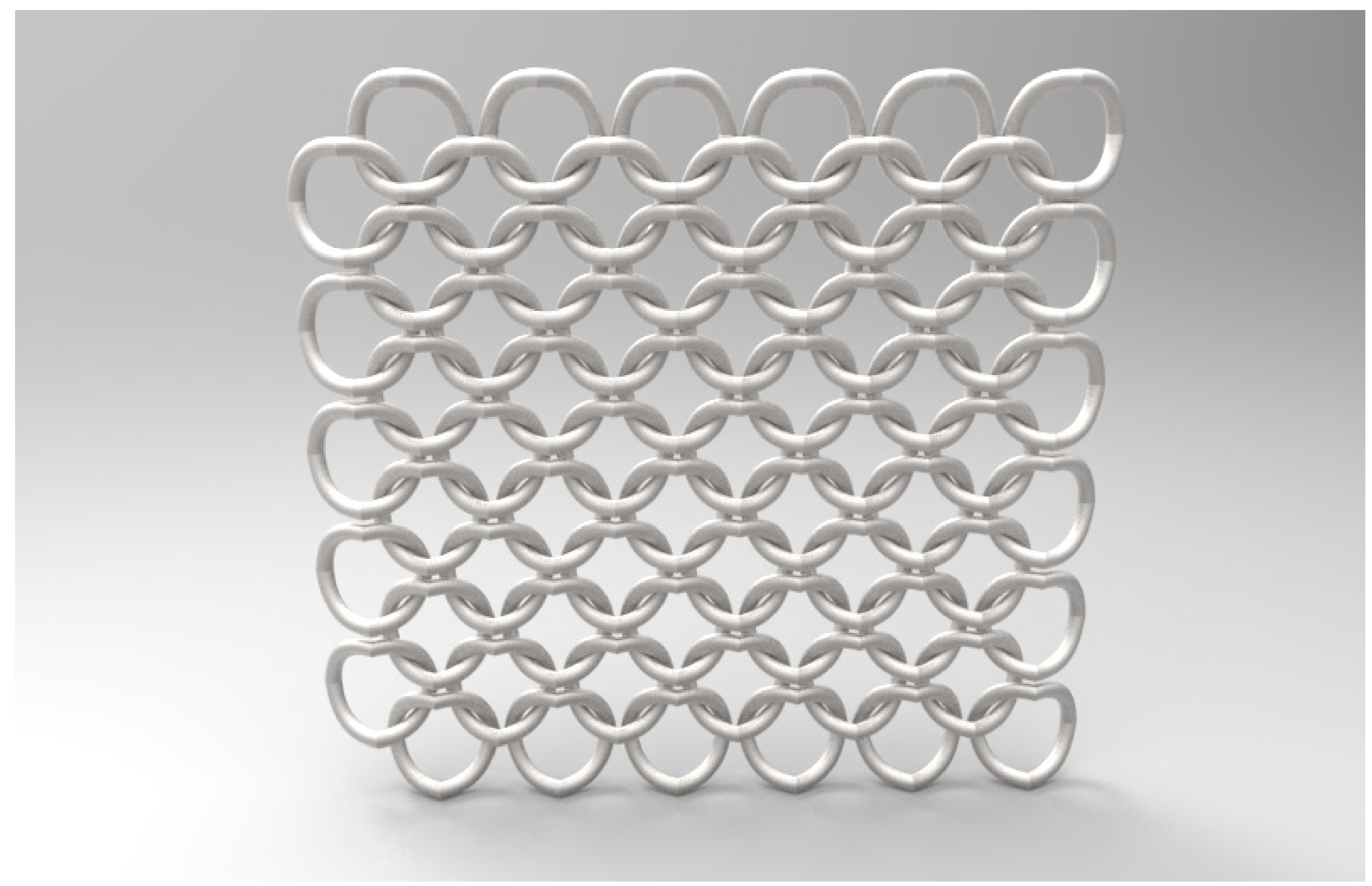

Figure 20: Nested parts designed in CAD 


\section{DESIGN CRITERIA}

This section of the study explains the criteria used with each experimental iteration and how these criteria are used to assess the desired outcomes of the iteration process.

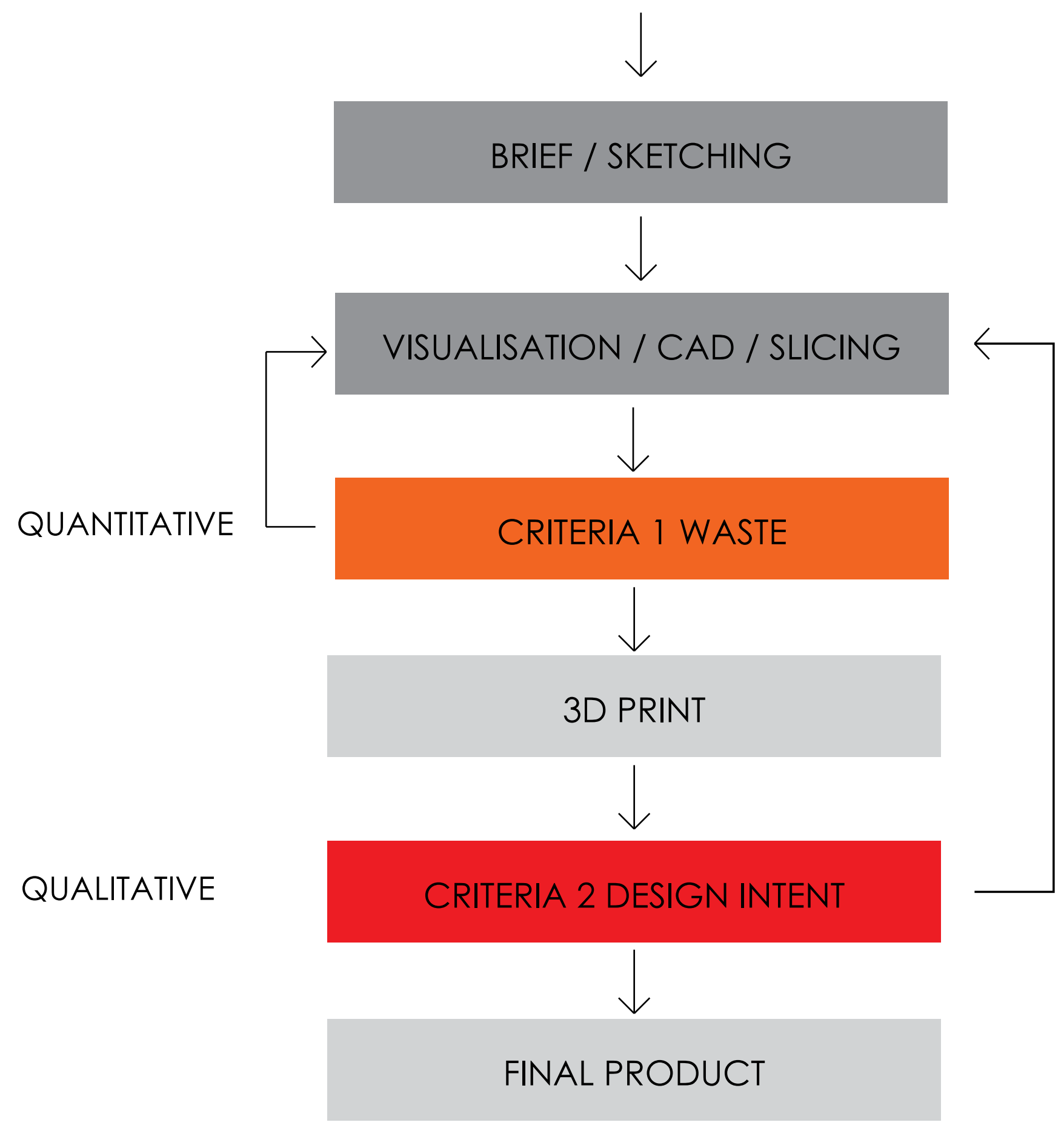

figure 21 


\section{CRITERIA 1: WASTE}

Additive manufacturing has made it possible to phase out potentially polluting excess waste from traditional manufacturing supply chains when dealing with the disposal of old tooling (die's and moulds) and swarf created by CNC machining. The contrast between the conventional method of subtractive manufacturing (removing material from a blank) and additive manufacturing (adding to the build with layers of material) are obvious as the additive process does not produce the amount of waste as a by-product as drilling, cutting or turning on a lathe.

As Morrow et al (2007) describes it:

By utilizing only, the amount of material needed for the product, additive manufacturing technologies have the potential to reduce the life cycle material mass and energy consumed relative to conventional subtractive techniques by eliminating engineered scrap, while also eliminating the use of harmful ancillary process inputs (p. 1).

The first criteria used will be assessed against the model iteration using the slicing software Materialise magic. Support material generated by the software is automatically placed onto the model using the machine rules outlined in this chapter. An assessment is made of the iteration to determine how geometry can be modified to decrease the amount of support material, thereby reducing the amount of waste that will be removed in post processing. The amount of material removed is a success for this stage.

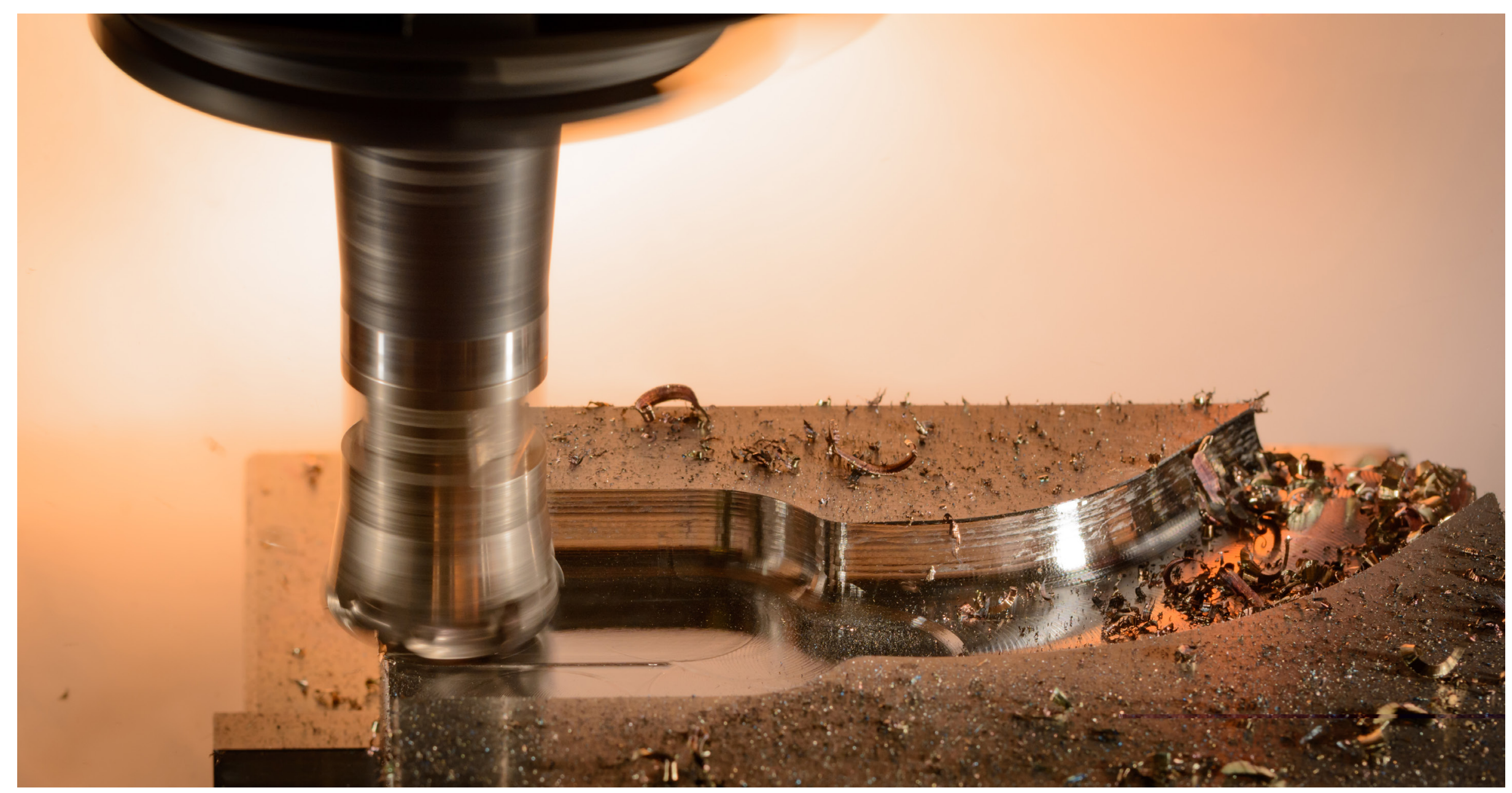

Figure 22: Milling cutter 

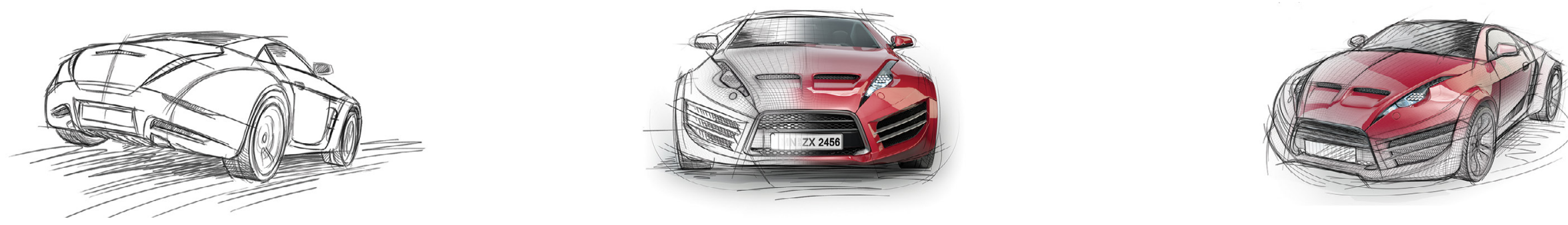

Figure 23: Sketch drawing of a sports car

\section{CRITERIA 2: DESIGN INTENT}

At the initial point of the design phase, industrial designers visualise the object and place their own viewpoint on the problem considering the constraints, freedoms and context. The outcomes that a designer usually delivers is a range of sketches, 3D models and colour pallets that inherently convey the design ideas that he or she envisaged. These steps encapsulate and solidify the design intent and are then qualified into a formed product ready to begin iteration.

Mengoni and Germani (2007) explains:

The design of aesthetic products is a set of complex and iterative decisional processes which involve different skill and which are influenced by multiple factors such as the evolution of taste, marketing requirements, ergonomic satisfaction, technical design constraints and manufacturing constraints. Numerous design iterations and aesthetic errors are due to the difficulty to understand and preserve the design intent from the first conceptual phases to the following engineering developments (p. 1).

The second criteria used is wholly subjective in its aims, where the overall design of the iteration is assessed against the preliminary design. The objective of this criteria is to match design features such as lattice shape, internal functional geometry and walls as close to the preliminary design as possible. This stage is qualitative as aesthetics and personal preference like lattice design are taken into consideration and success is determined by the designer. 


\section{EX P ERIMENTA L I T E R A T ION}

Combining machine limitations and design criteria into a checklist of steps to inform the design process and aid the process of CAD creation. These steps are applied from the initial sketch through to the final $3 \mathrm{D}$ print. If more than $80 \%$ of all criteria are passed then the model would be considered a success.

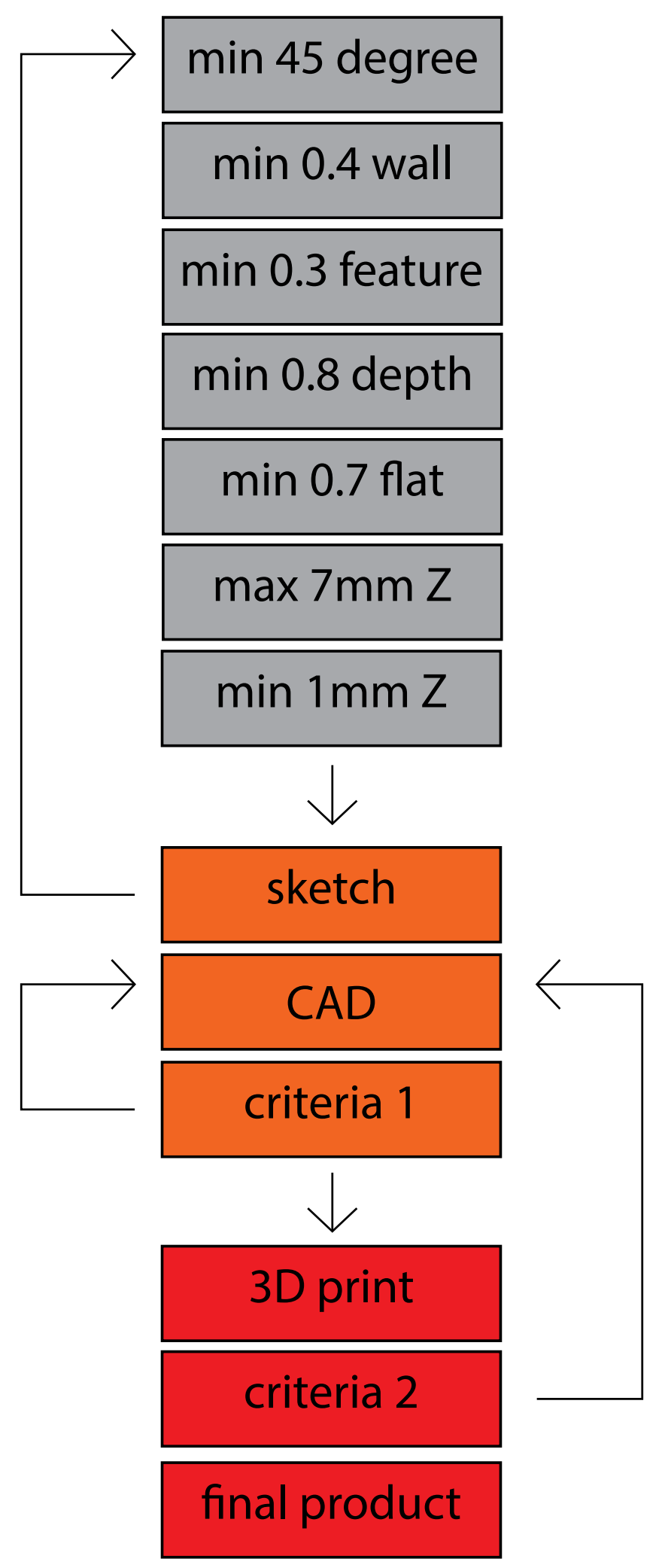

Figure 24: Experimental iteration checklist. 
-40- 


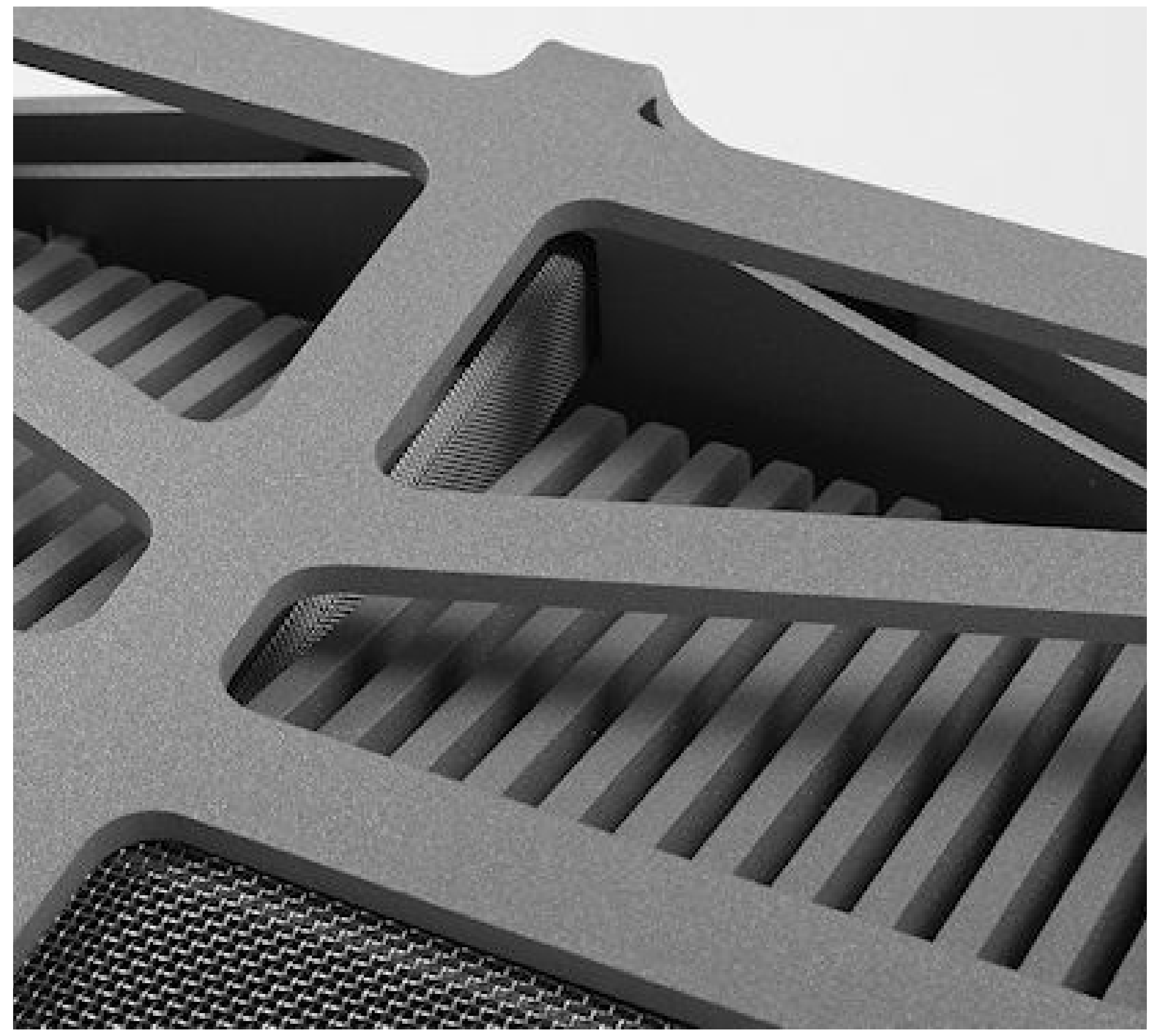

Figure 25: Reference Class A Monoblock «pureaudio. 


\section{P RE L I M I NA RY D E S I G N}

$\mathrm{T}$ he precursor for the design of the remote control comes from a reference class A monoblock, designed and made by pure Audio New Zealand using traditional manufacturing methods. The challenge that was given to me had a number of qualities that had to be met including:

1. To recreate the aesthetic direction of the preamp using additive manufacturing processes

2. Make the structure as thin as possible to reduce cost and waste

3. Make the structure as strong as possible to retain structural integrity

4. Make the CAD file fit to be reproduced without any further design changes
Using the aesthetic direction of the cut out forms, the preliminary design was created in the parametric design program Solidworks using a pre-defined shape and lattice structure. The lattice takes its form from the triangular shapes left after laser cutting the blank monoblock sheet, which is then bent into its final form. These decisions were made due to the interior electronics module and battery pack. Further considerations are taken into account regarding the physical machine limitations of the process, including:

5. Build angle from the horizontal must not be less than 30 degrees to avoid excess support material

6. Material must have an adequate thickness to avoid bucking during cooling period

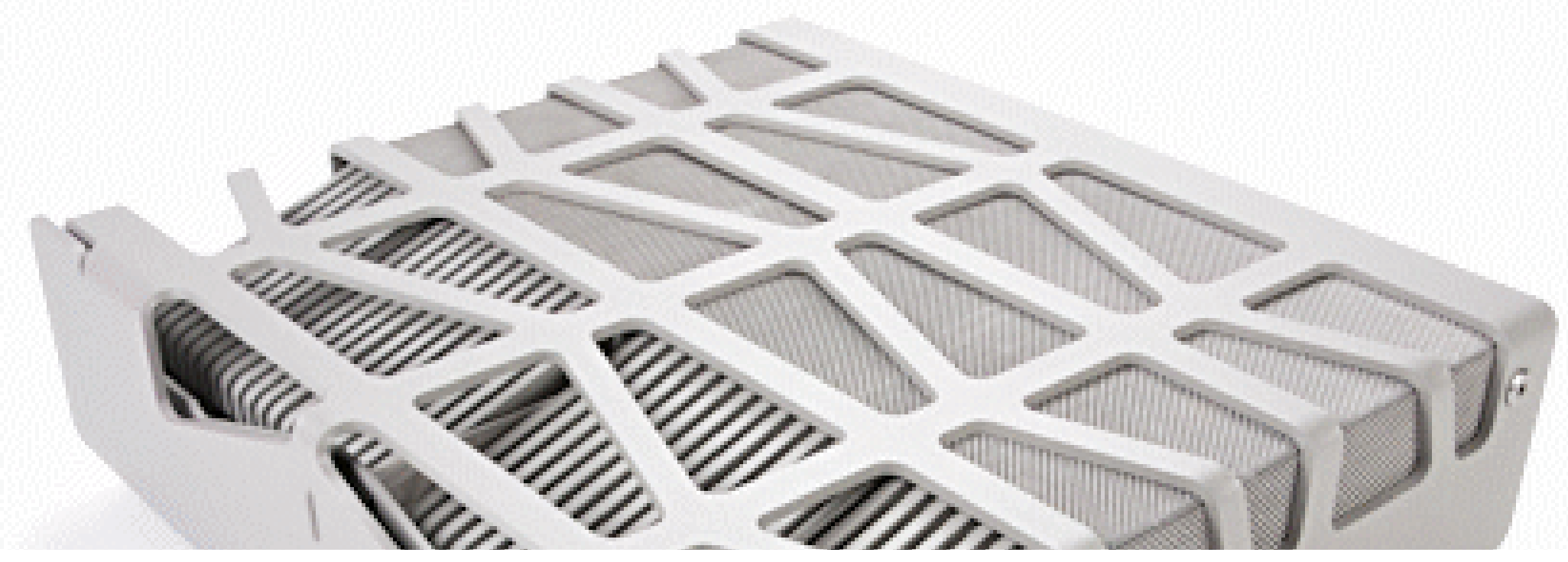




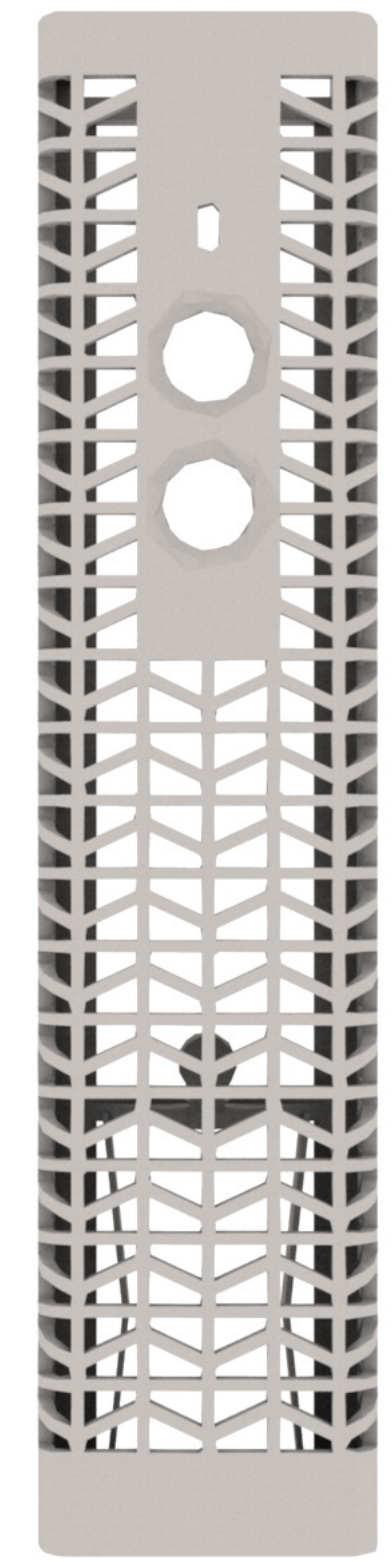

figure 27

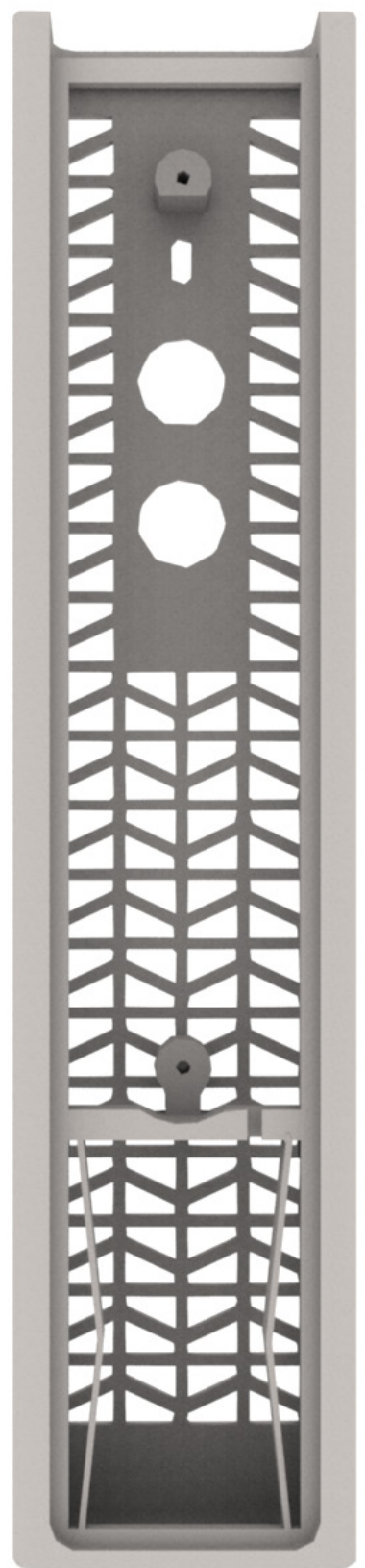

figure 28

\section{0}

\section{Original design}

\author{
The original design was developed in \\ the software Rhino then taken over into \\ Solidworks.
}

Height: $212 \mathrm{~mm}$

Width: $47.5 \mathrm{~mm}$

Overall wall thickness: $2 \mathrm{~mm}$

Mass: 42.70 grams

Cost:

Nylon - $\$ 61.45$

Stainless - $\$ 219$

Titanium - $\$ 1003$ 


\section{1 \\ Updated CAD}

The up-dated CAD model was redesigned with some geometry being changed as deemed superfluous and wall thickness reduced.

Height: $212 \mathrm{~mm}$

Width: $47.5 \mathrm{~mm}$

Overall wall thickness: $1 \mathrm{~mm}$

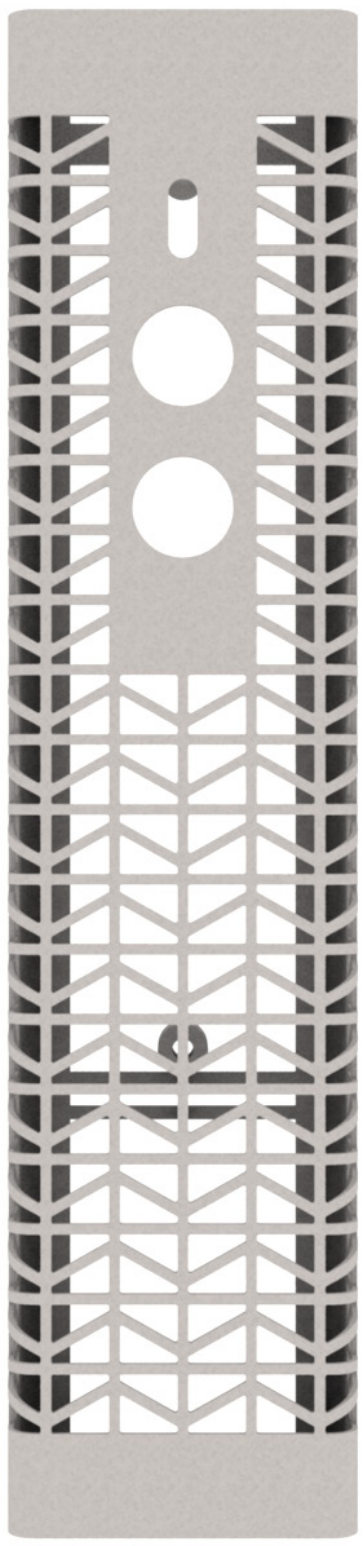

figure 29

Mass: 15.74 grams

Cost:

Nylon - \$57.95

Stainless - \$126.99

Titanium - \$ 369

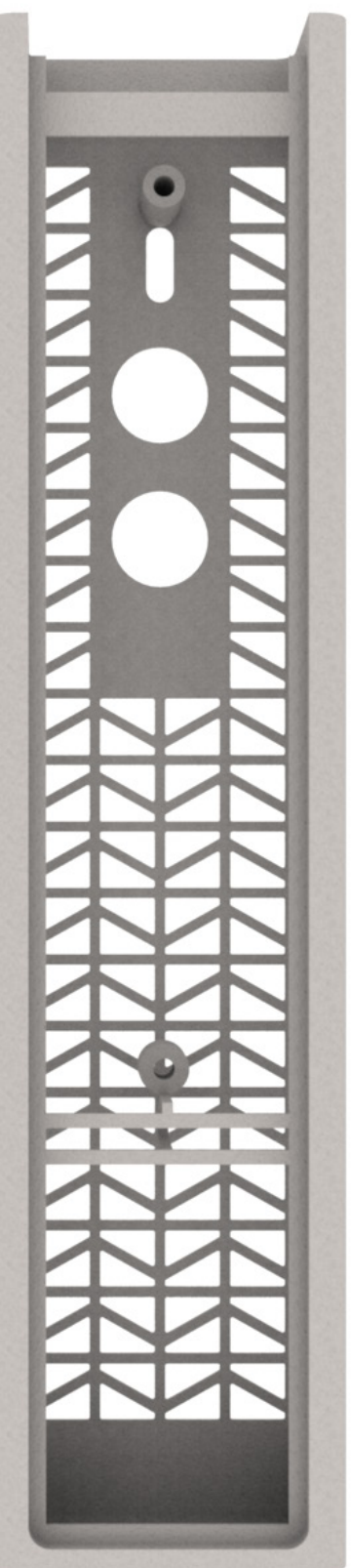

figure 30 


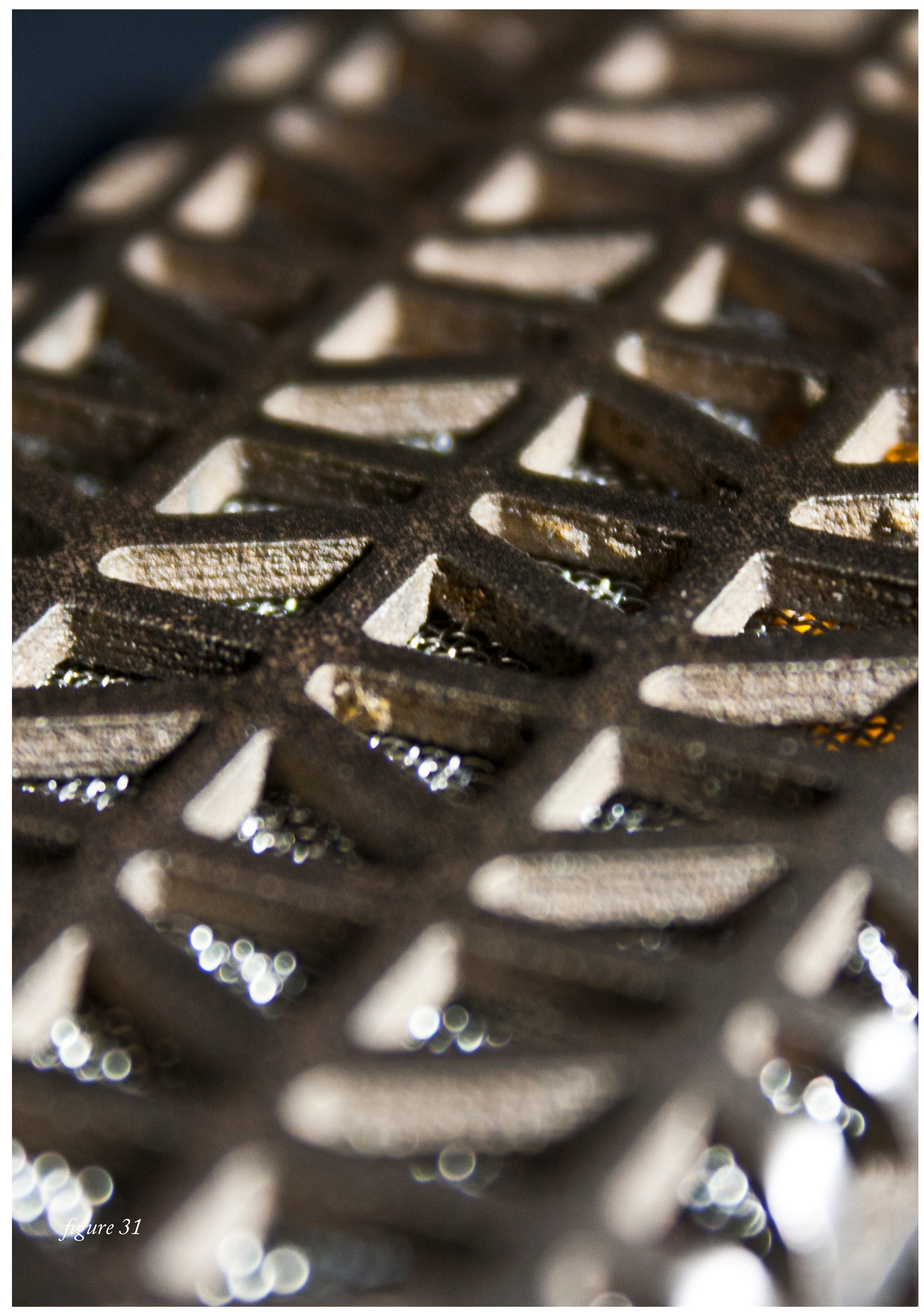

Figure 31: Model 1.3 with stainless steel inner mesh 


\section{E X P E R I M E N T S}

This chapter will show the experiments that were carried out in this study such as material choice and removal of support material in the digital space. This will also include an approximate cost comparison of each iteration both in the material used and the final material choice (titanium). All material experiments were created by Shapeways and used the selective laser sintering process. 


\section{1}

\section{Nylon White}

Hight: $212 \mathrm{~mm}$

Width: $47.5 \mathrm{~mm}$

Overall wall thickness: $2 \mathrm{~mm}$

Volume: 17.18

Cost:

Nylon - \$ 61.08

Stainless - $\$ 175$

Titanium - \$ 403
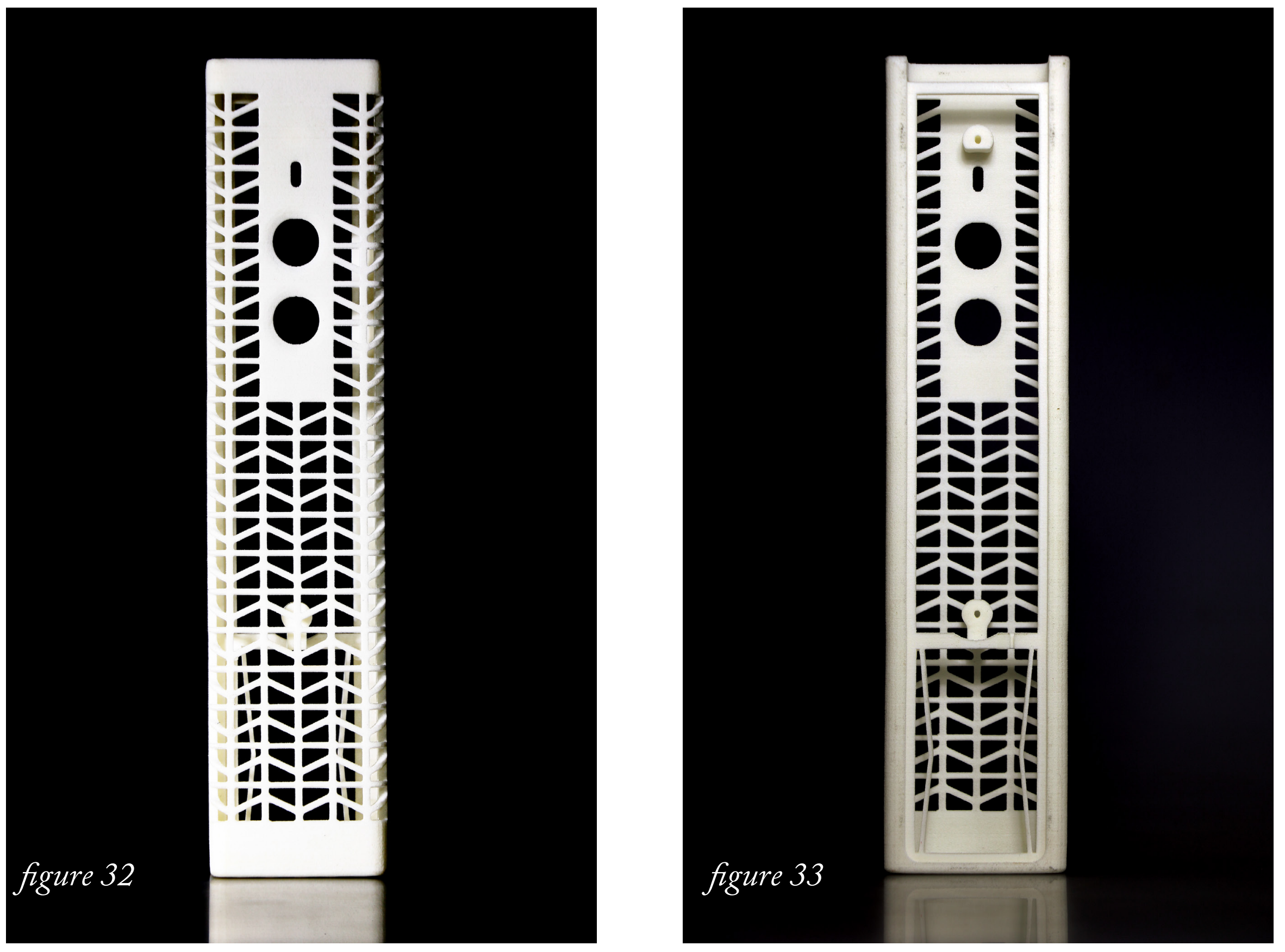


\section{Nylon Black}

Hight: $212 \mathrm{~mm}$

Width: $47.5 \mathrm{~mm}$

Overall wall thickness: $1 \mathrm{~mm}$

Volume: 15.77

Cost:

Nylon - \$ 61.08

Stainless - \$ 84

Titanium - \$ 370
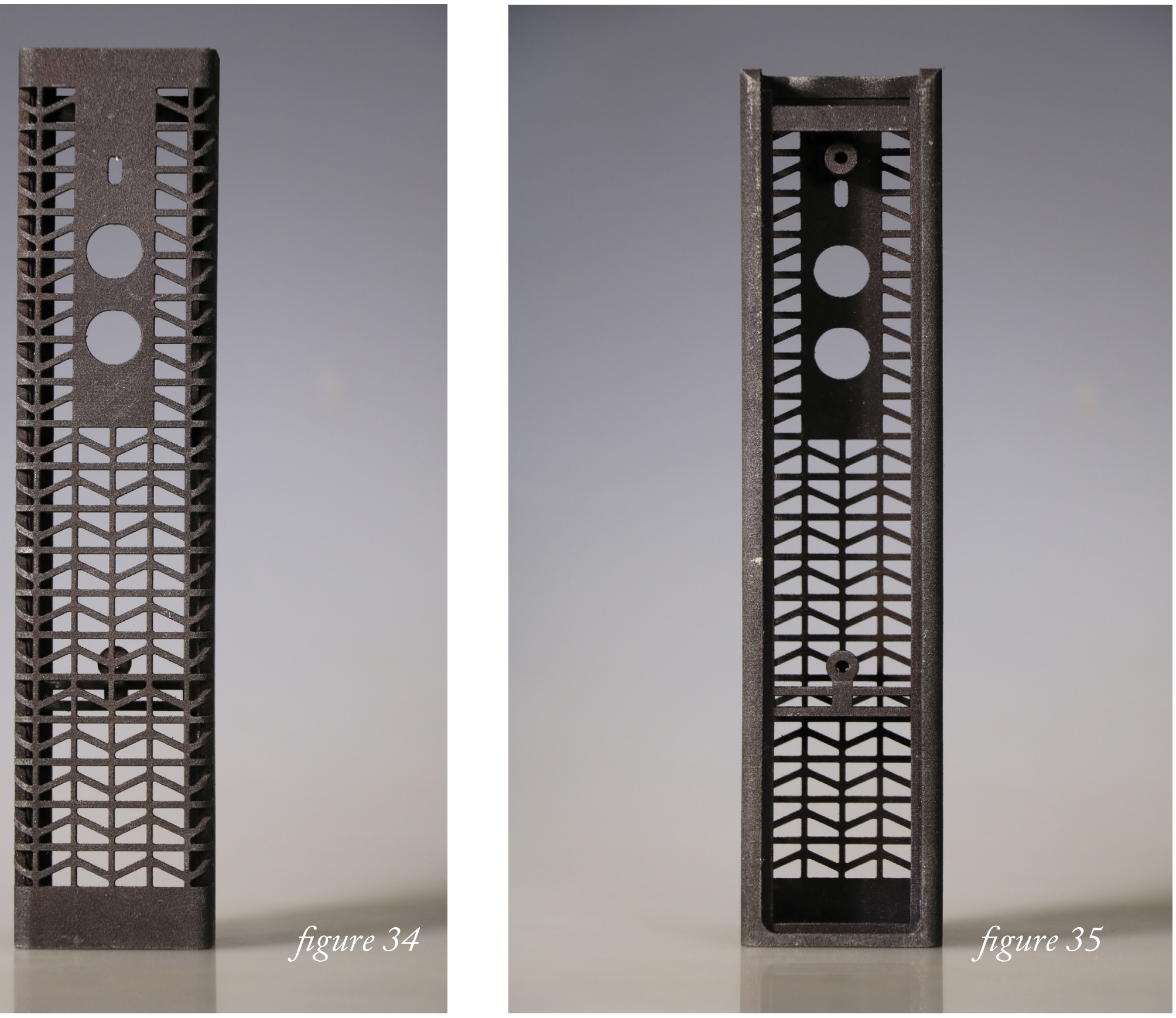


\section{3}

\section{Stainless Steel}

Hight: $212 \mathrm{~mm}$

Width: $47.5 \mathrm{~mm}$

Overall wall thickness: $2 \mathrm{~mm}$

Volume: 17.18

Cost:

Nylon - \$ 61.08

Stainless - \$ 175

Titanium - $\$ 403$
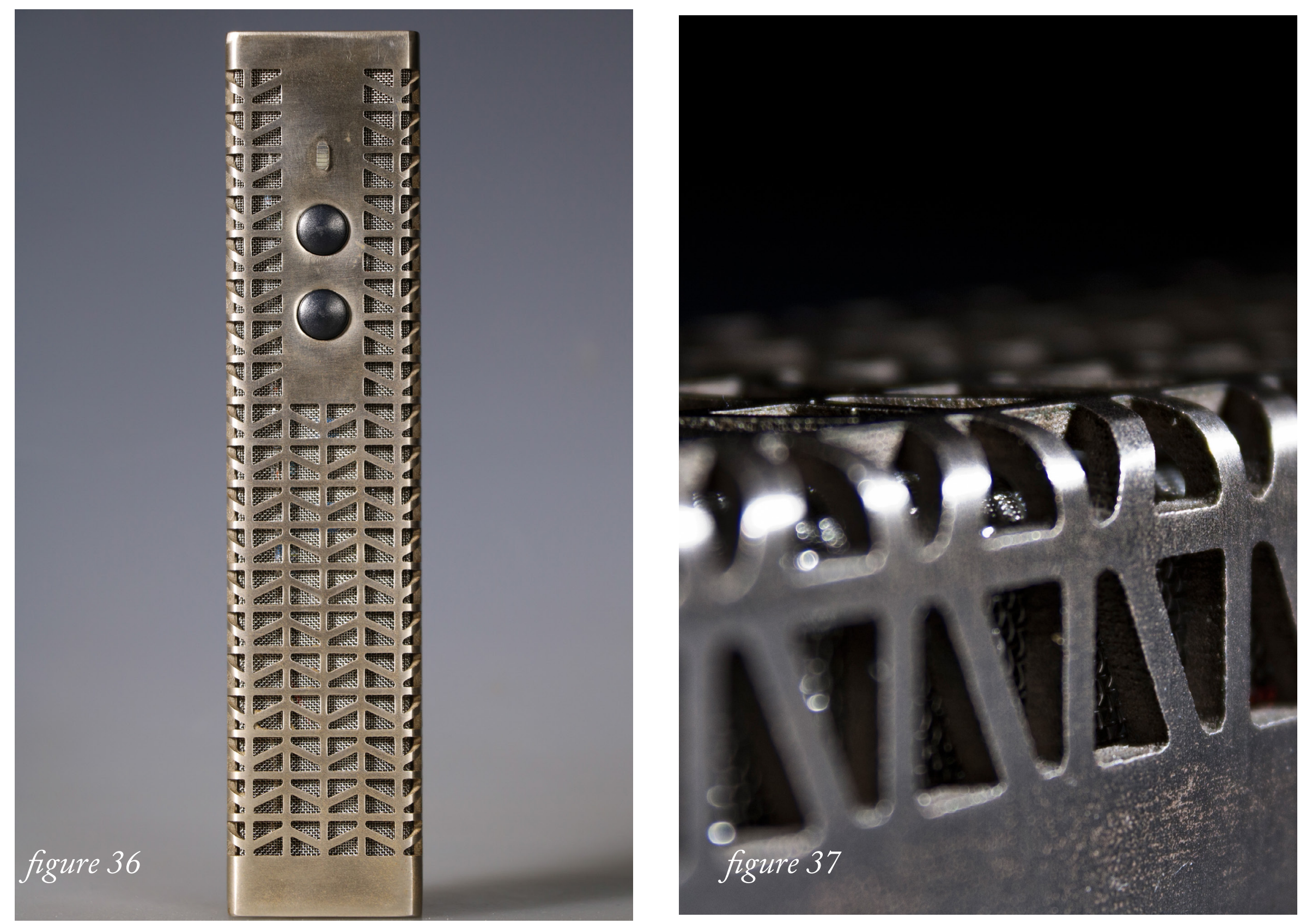

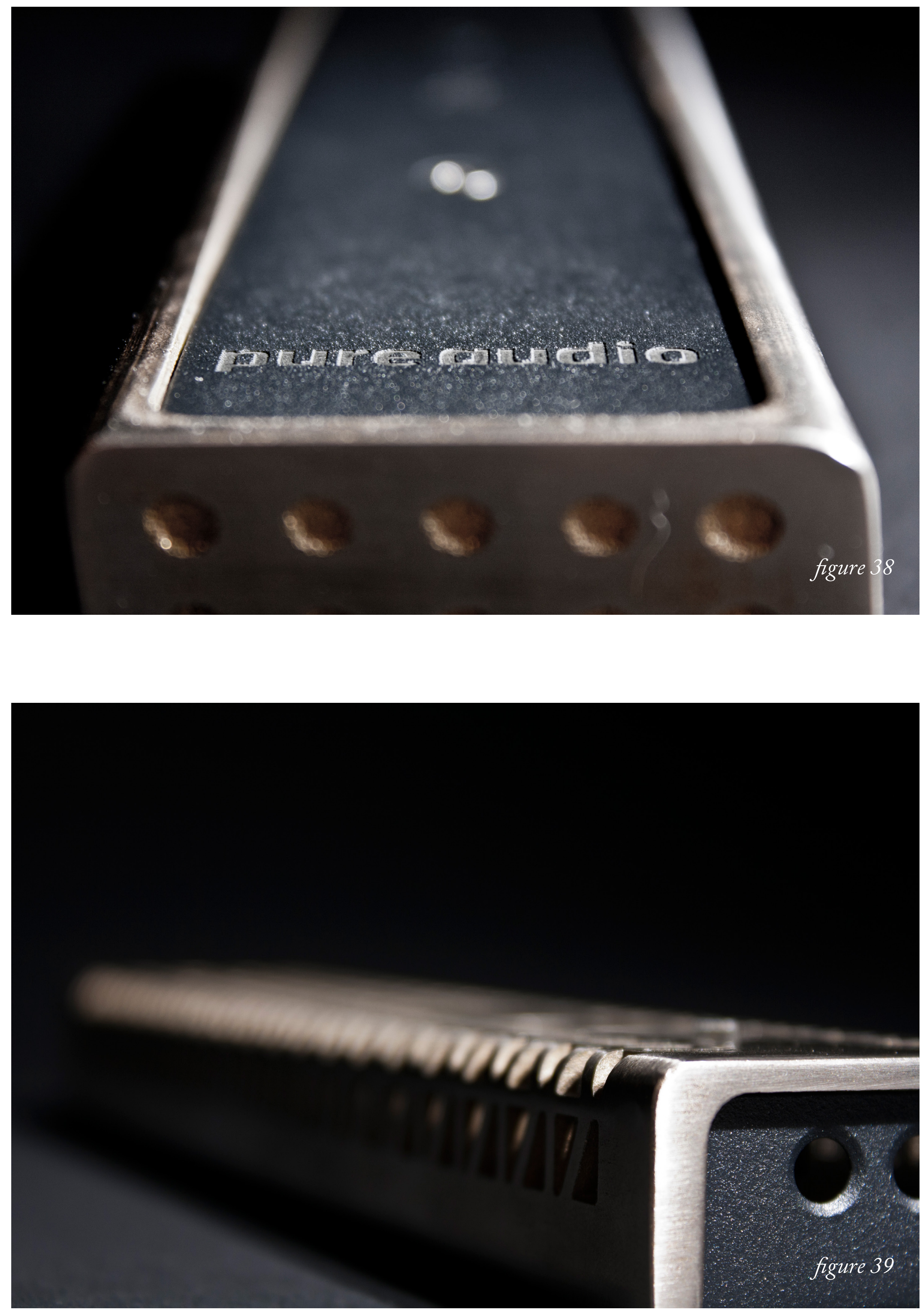

$-50-$ 


\section{Support removal}

The removal of support material (sections in red) is one of the prime intentions of this thesis. The support is generated by the slicing software Materialise magics and can only be partially influenced by the designer when it is generated. The material is added to the design when the software identifies sections of geometry that exceeds the design parameters set within the program. Individual 3D printing machines have different sets of parameters, for instance SLS and EBM settings differ from SLM due to machine limitations.

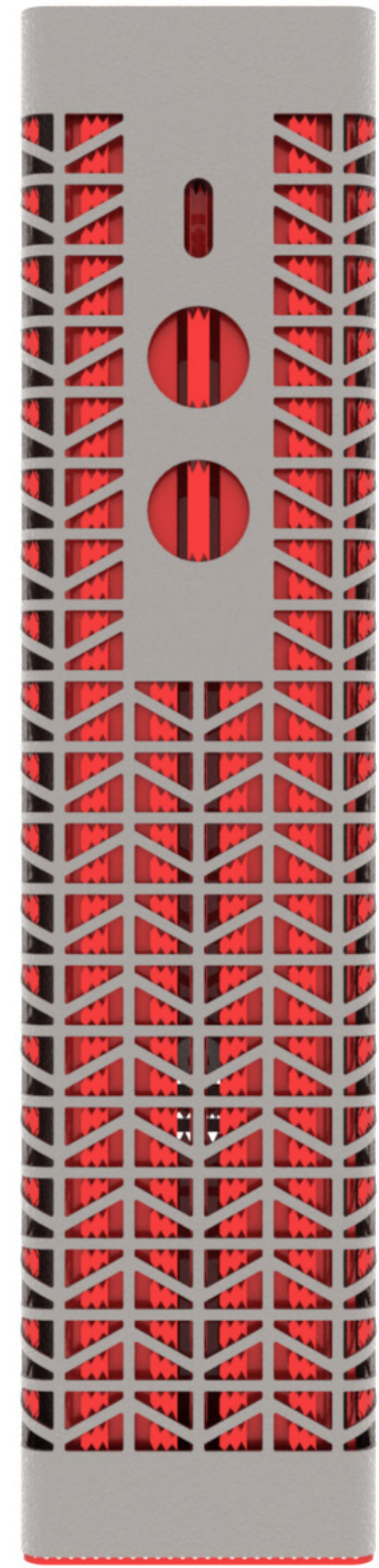

figure 40

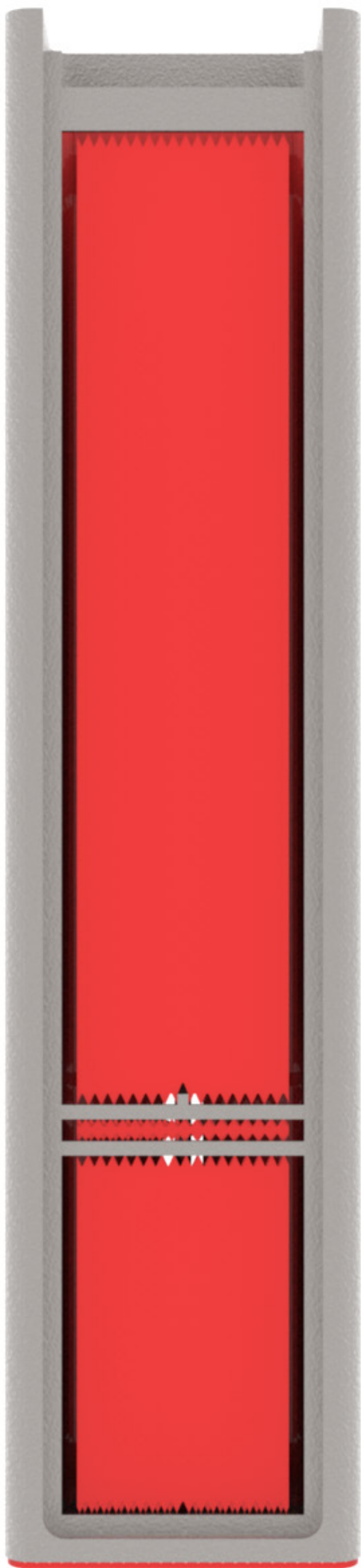

figure 41

Figure 40-41: Front and rear view of support material 
Streamlining the design of CAD geometry is the one of the main solutions to excessive support material. Another is orientation of the part.

When loading the digital file into a $3 \mathrm{D}$ printer, the user can orientate the part to best fit their design needs. However, if a designer wishes minimal surface artifacts, parts are loaded to present the smallest flat surface to the build platform to prevent surface artifacts form damaging the finish.

Physical removal of support is both lengthy and risky. In the case of titanium prints, the support material is the same as the finish part, titanium. When designing fine, thin walled parts of lattice structures, a part can be damaged or destroyed if utmost care isn't taken.

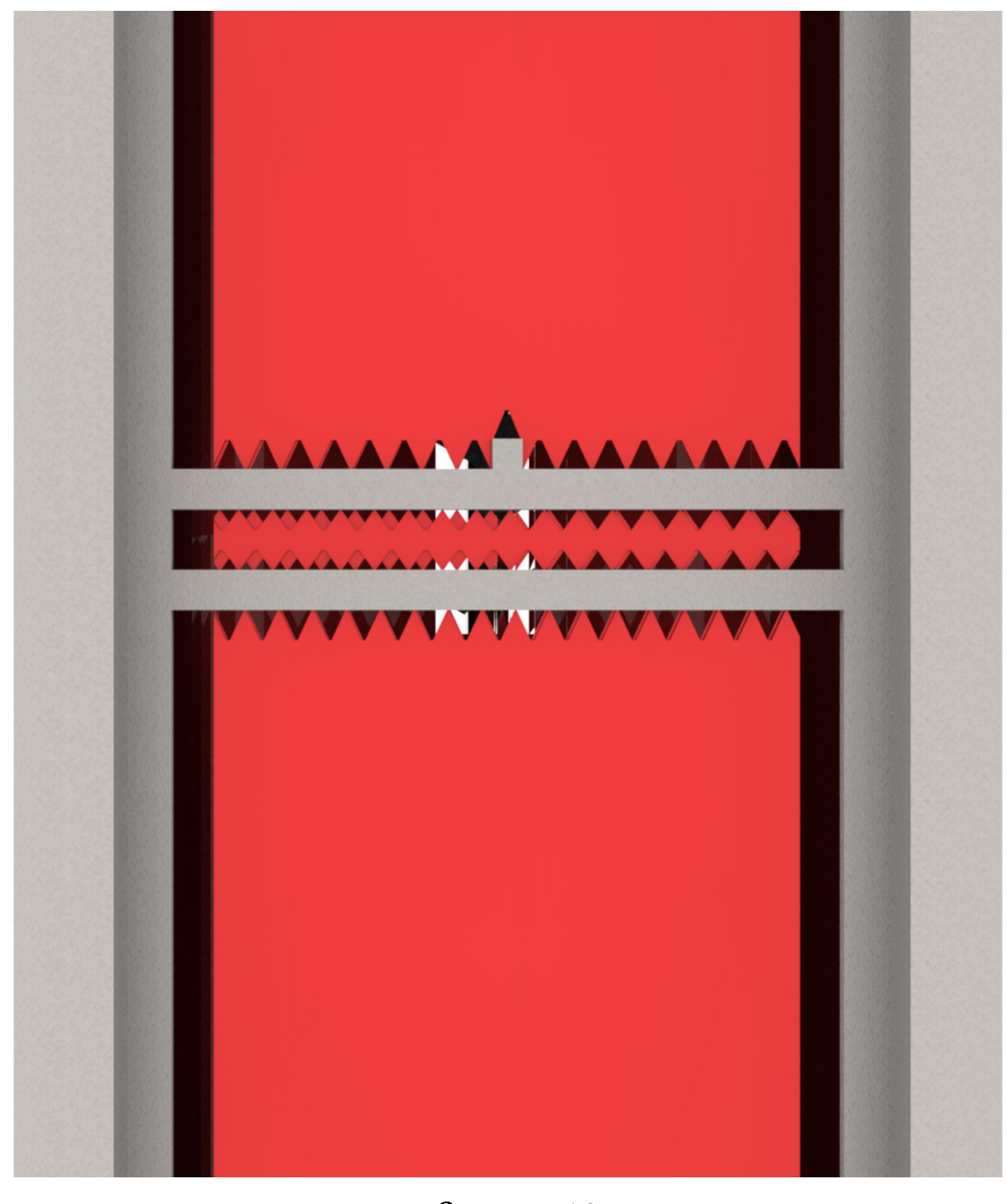

figure 42

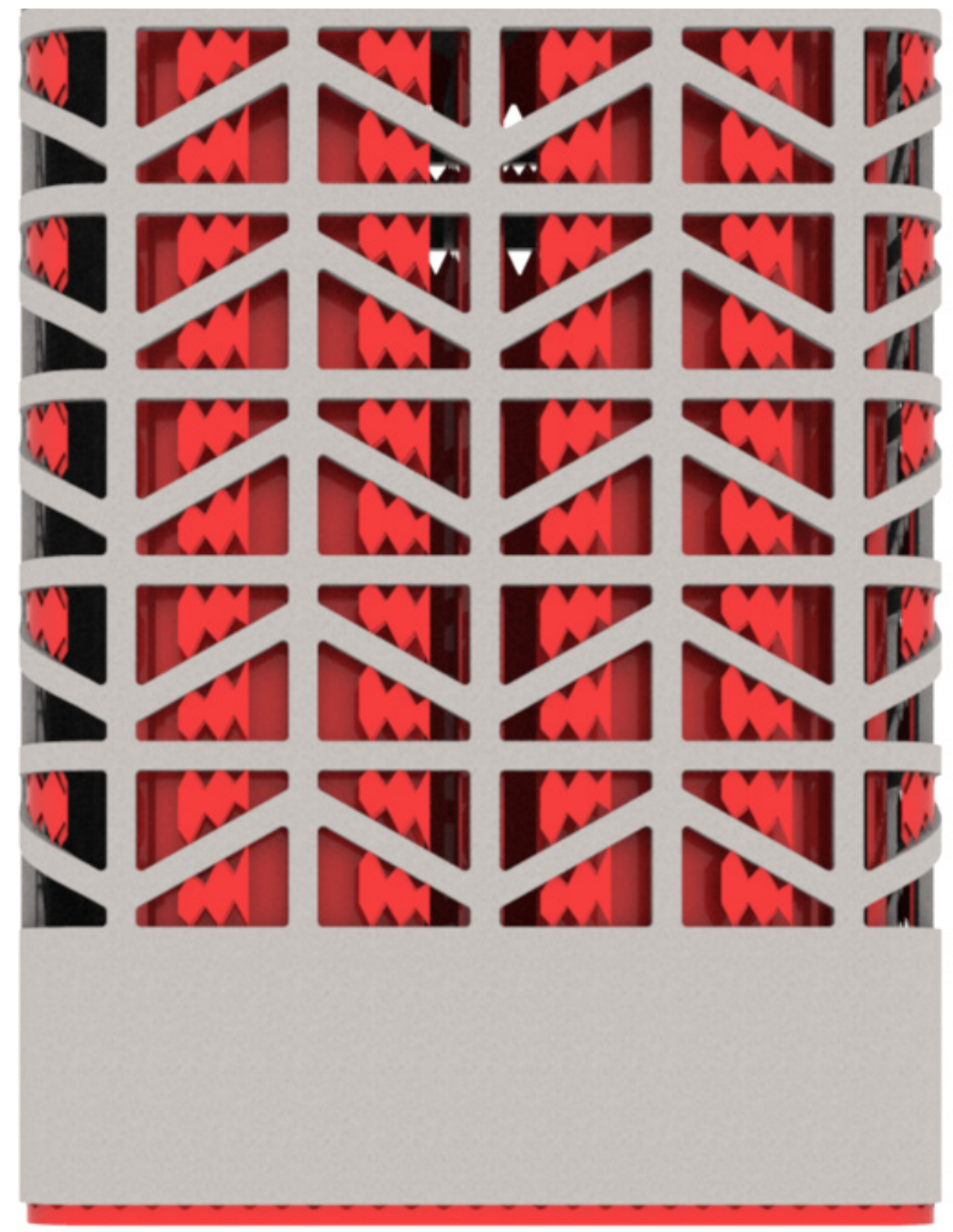

figure 43

Figure 42-43: Close up view of support material 
$-53-$ 
-54- 


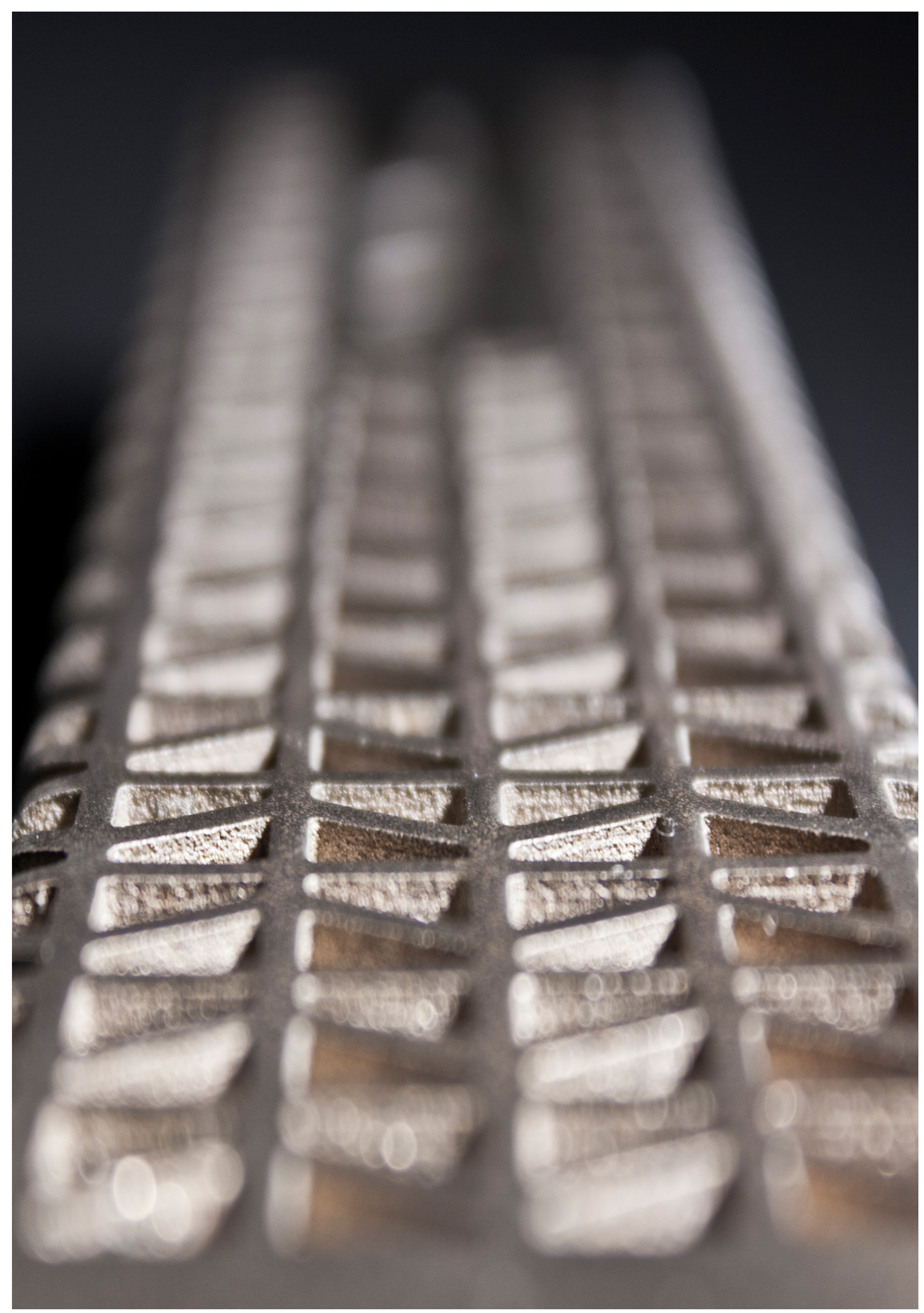

Figure 44: Model 1.3 Stainless Steel

$-55-$ 


\section{DESIGN ITERATIONS}

$\mathrm{T}$ his chapter describes the iteration process, such as the steps taken on each design and includes an analysis on all printed parts measured against the iteration criteria. This section also includes a cost breakdown on materials and processes.

The intention of these iterations is to improve design techniques generated from the original design 1.0. To achieve this a list of requirements was established in the criteria phase to validate the success of each iteration. After each design is printed, these criteria can be used to inform the next iteration by visually analyzing any deviations from the digital file. A judgment call will be made on individual aspects of the model and fed back into the criteria. Discrepancies such as the conforming of the CAD file to machine limitations or $7 \mathrm{~mm}$ hole size without support material can be easily rectified with each preceding iteration.

As the SLM printing process has a lead time of three to four weeks, only a limited selection of iterations were printed. Also the cost per print in titanium 64 required only the essential models were manufactured to keep costs at a minimum.
All prices for Nylon were retrieved from the Shapeways website and all prices for ti64 were calculated using the volume of the object times the price per gram. These latter prices are only an approximation as the company involved retains all IP rights to its costing scale.

Costing

Nylon white:

$\$ 1.50 /$ part

$\$ 0.28 /$ material $\mathrm{cm} 3$

$\$ 0.21 /$ machine $\mathrm{cm} 3$

$1.50 \times$ Volume $\times 0.21 \mathrm{~cm} 3=$ total

Nylon black:

$\$ 2.50 /$ part

$\$ 0.28 /$ material $\mathrm{cm} 3$

$\$ 0.21 /$ machine $\mathrm{cm} 3$

$2.50 \times$ Volume $\times 0.21 \mathrm{~cm} 3=$ total

Titanium:

$\$ 23.50 \mathrm{~cm} 3$

23.50 x Volume 


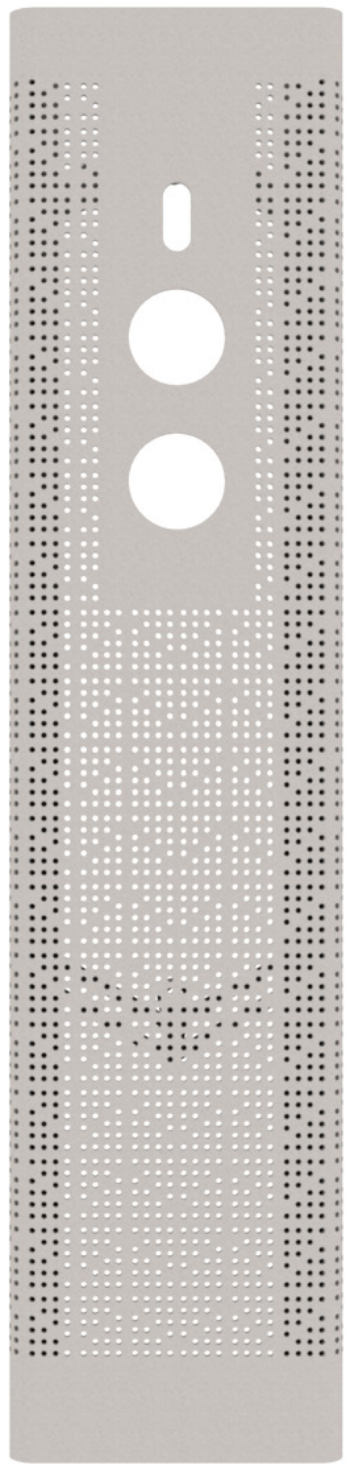

figure 45

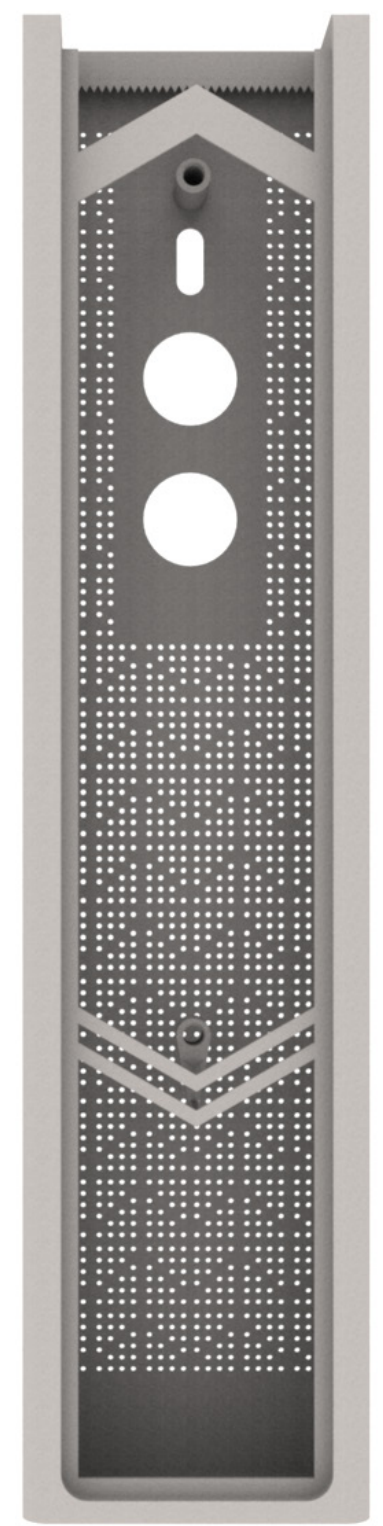

figure 46

\section{0}

Height: $212 \mathrm{~mm}$

Width: $47.5 \mathrm{~mm}$

Overall wall thickness: $0.8 \mathrm{~mm}$

Volume: $18.44 \mathrm{~cm}^{3}$

Cost:

Nylon - \$56.80

Stainless - $\$ 98$

Titanium - \$ 433

The intention for this iteration is the angling of all flat surfaces in the model to lessen the impact of support material. This iteration is mainly an exploration on how the main structural beams and cross members react to different geometry when applied in the slicing software Magics.

The lattice on the surface follows the same triangular form of the original but without flat edges. 
The downward facing flat surfaces were designed with a saw tooth aesthetic as the angle of the teeth does not exceed the 30 degree tolerance.

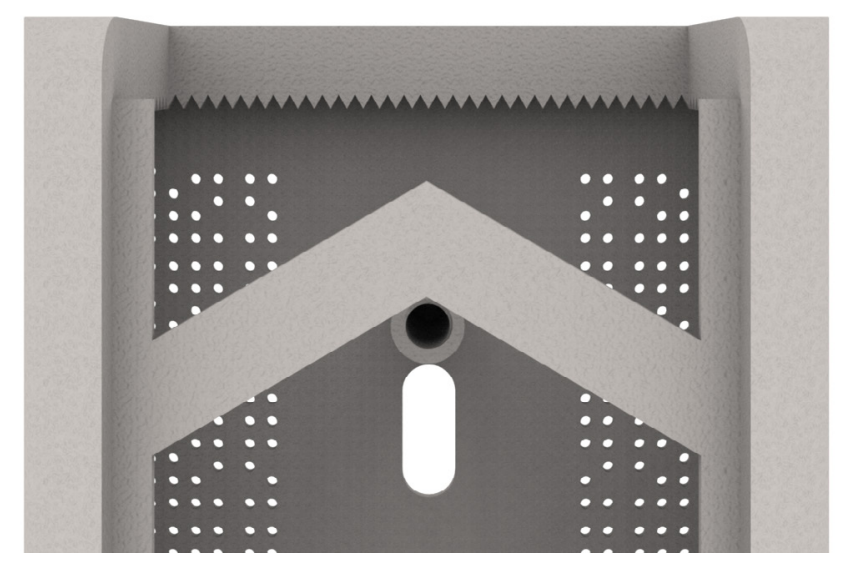

figure 47

The angled cross members were an attempt to design around flat surfaces where bracing was thought to be needed for structural stability. However in later iterations this bracing was removed as the toughness of the material was not fully realized at the time of design.

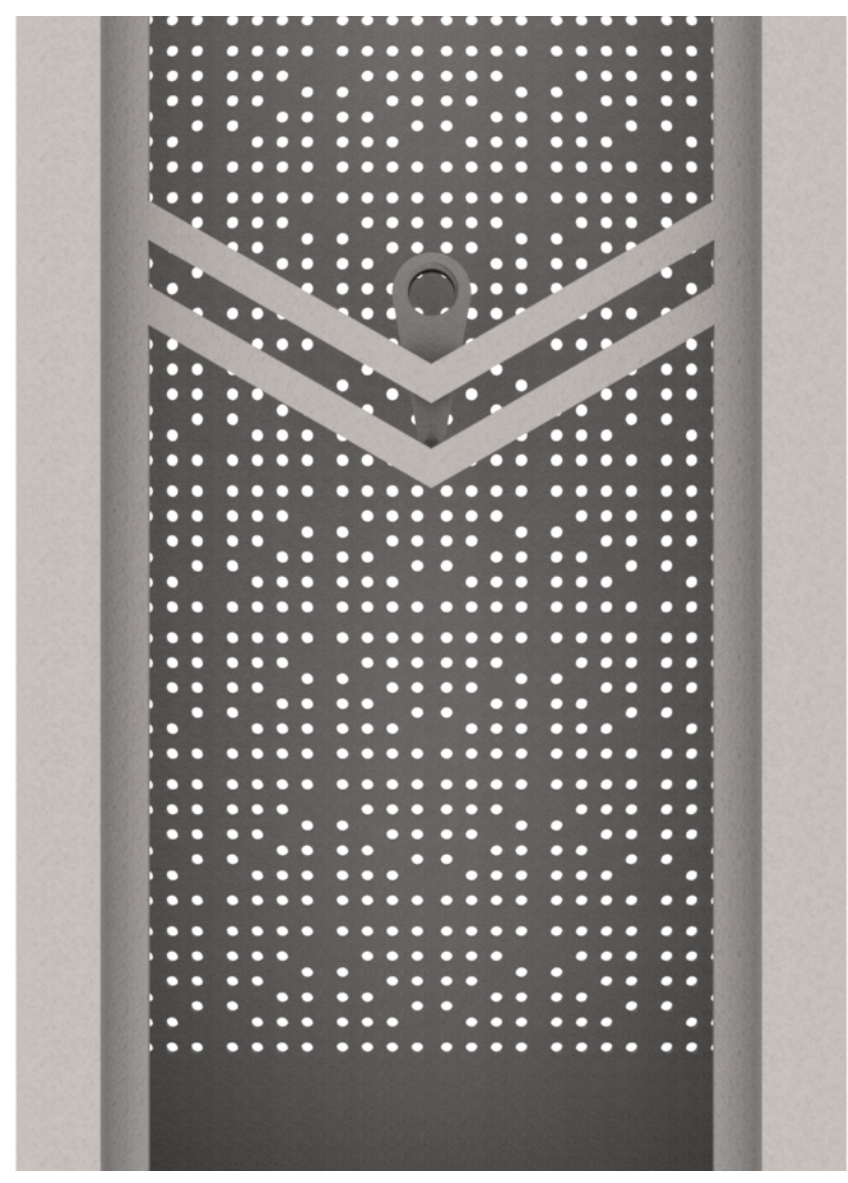

figure 48

In cross section, the geometry of the model appears hollow. The model is designed this way to remove the maximum amount of material without changing its outward appearance. 


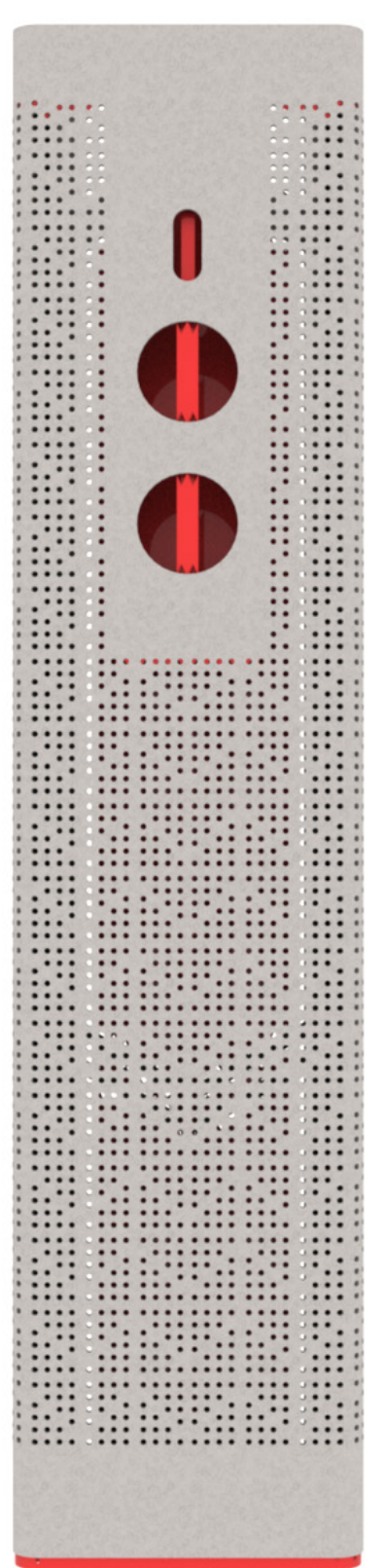

figure 50

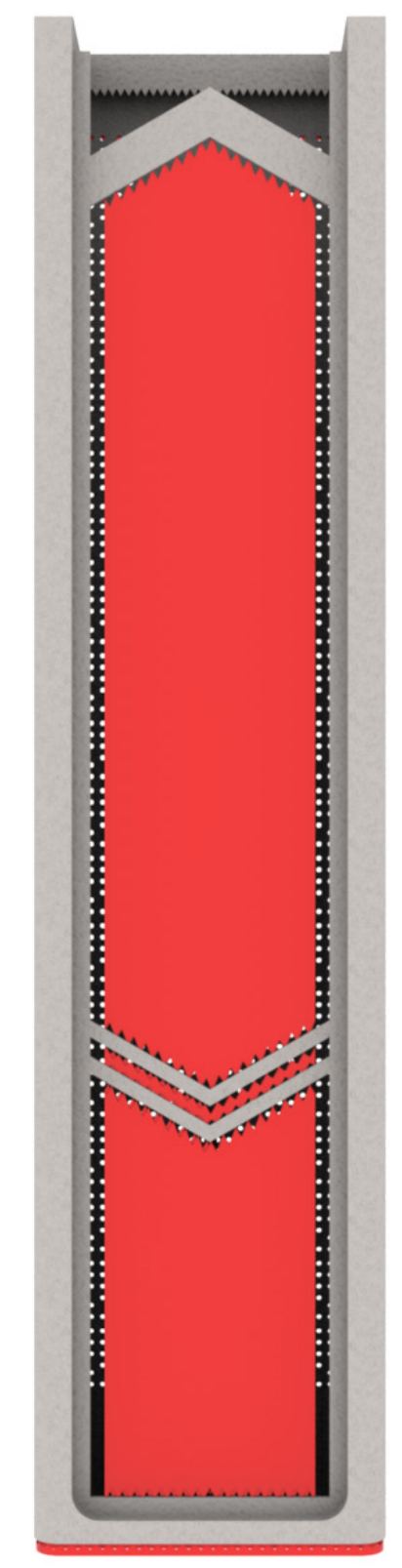

figure 51
The last stage of the modeling process is calculating the amount of support material that the model will be printed with. As this is the first in the series of iterations, the confidence level of support material reduction was not high. However in the front elevation (left) there is minimal material in the surface lattice, holes and base of the model. This is crucial as removal of any support material leaves surface artifacts such as pitting and scuff marks which would not be desirable on the exterior.

The rear of the model still contains a substantial amount of support material. The experiment with angling the cross braces did not have the desired effect of minimizing material. This material is only in the void between cross members in the $\mathrm{Z}$ axis and does not fill the depth of the model. 


\section{1}

Height: $212 \mathrm{~mm}$

Width: $47.5 \mathrm{~mm}$

Overall wall thickness: $0.8 \mathrm{~mm}$

Volume: $19.43 \mathrm{~cm}^{3}$

Cost:

Nylon - \$ 54.96

Stainless - \$ 103

Titanium - \$ 456.00

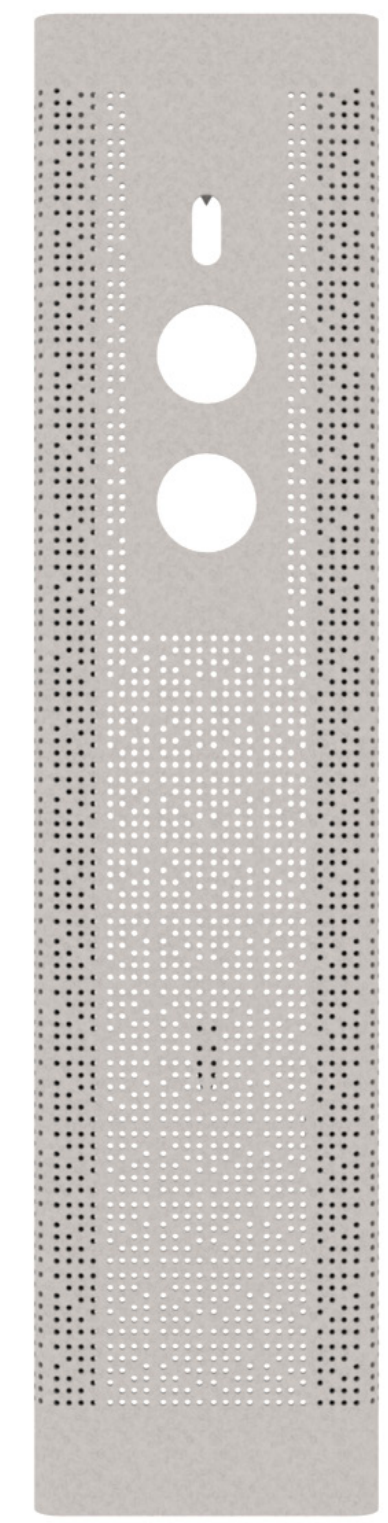

figure 52

Using the findings from iteration 2.0 a design decision was made to remove all flat cross bracings. This was done to streamline the design as the original case model was designed without knowledge of what process and material would be used. The removal of the cross bracings simplified the placement of the lower screw bracket which in turn gave easier access for fitting the electronics board.

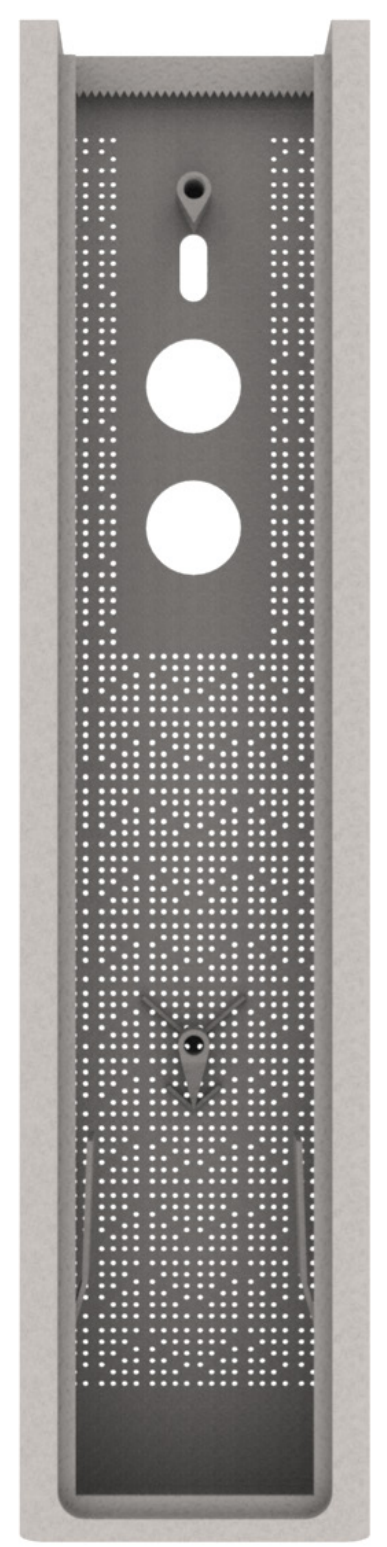




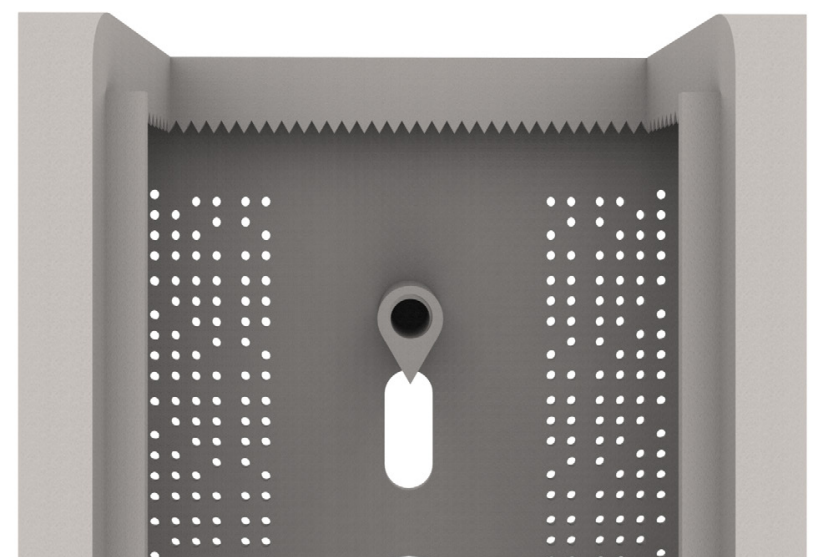

figure 54

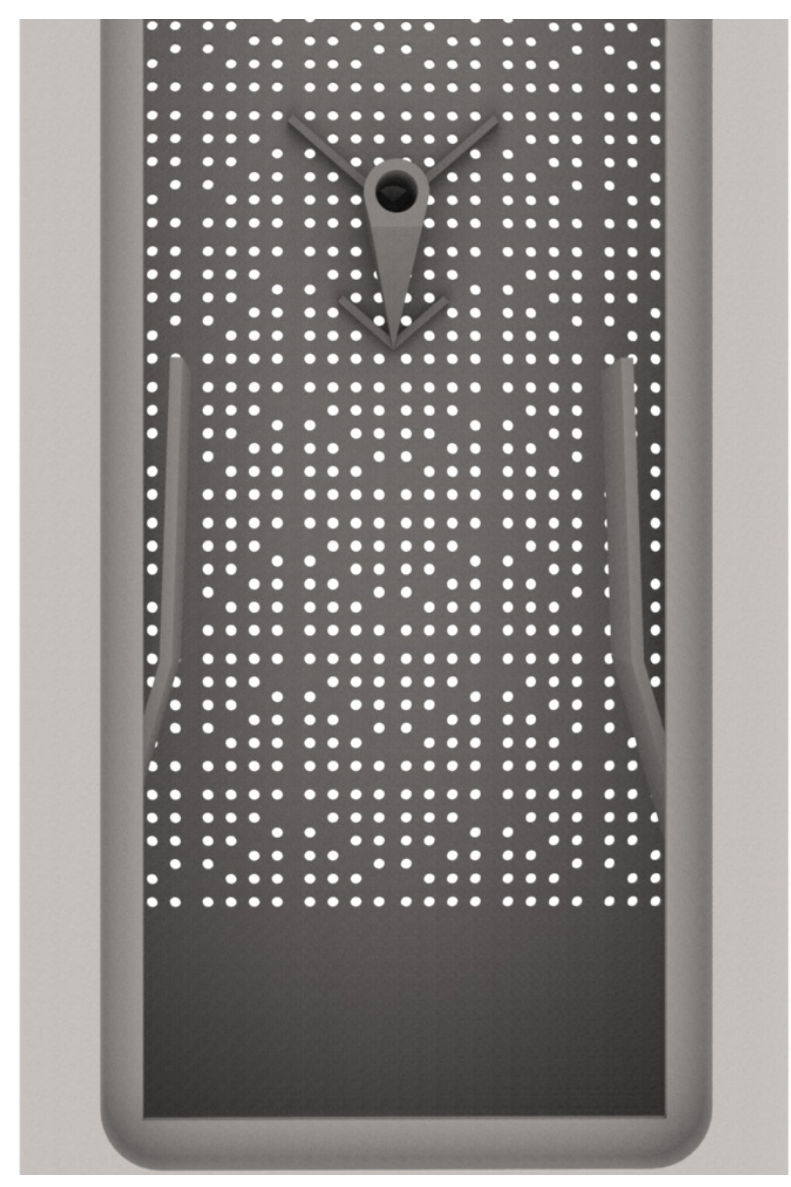

figure 55
The upper section from the rear is now cleaner without the angled cross member and the upper screw bracket is now free from overhead obstruction. The downward facing top surface retains the saw tooth configuration in accordance with the design rules.

At the lower section of the model, the removal of the braces allowed the lower screw bracket to be directly fixed onto the shell of the model. This gave the bracket added support as this part will have high torque applied to it.

In the cross sectional view, both screw brackets can be seen fixed onto the shell of the model. Also, springs were added along the sides to secure the battery pack.

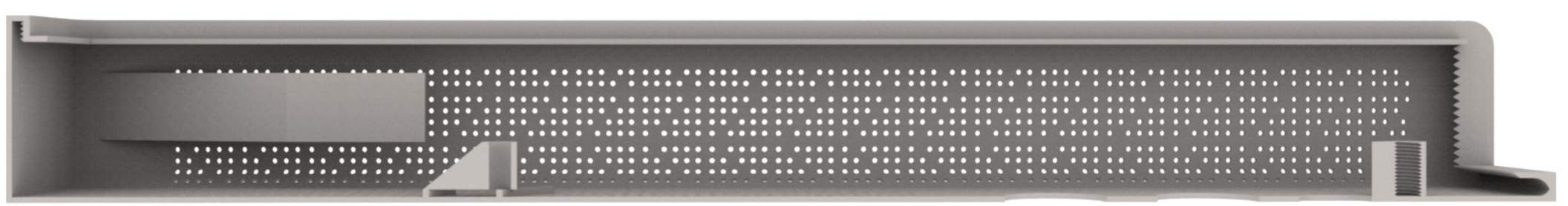

figure 56 
With the removal of the cross members, when the slicing software was run on this iteration, a large portion of the support material was removed. The areas that still required support were the hole regions and the base of the model. With this the most likely level of support removal without jeopardizing the structural integrity of the model, the decision was taken to concentrate on the lattice structure until the first model was printed.

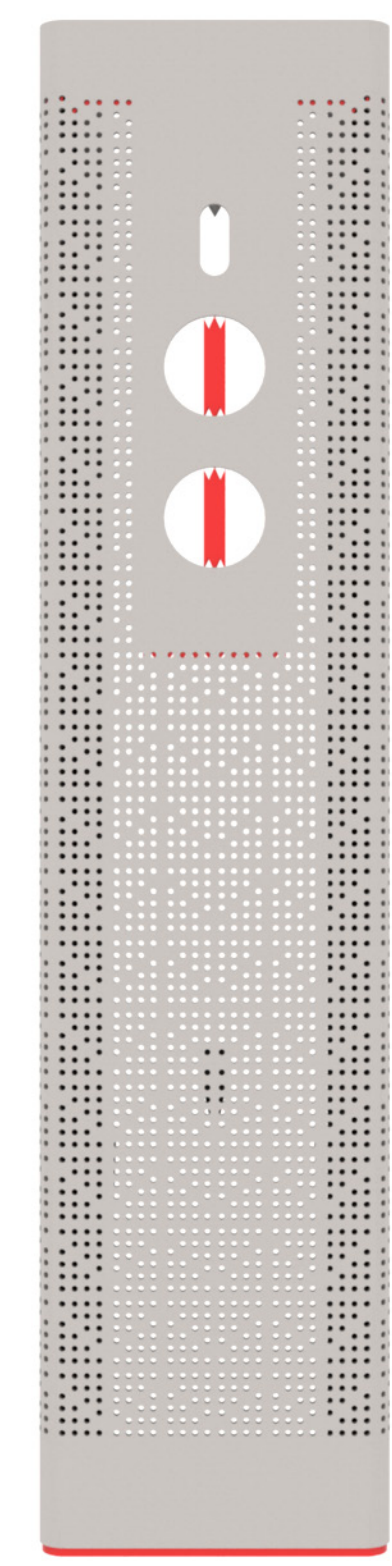

figure 57

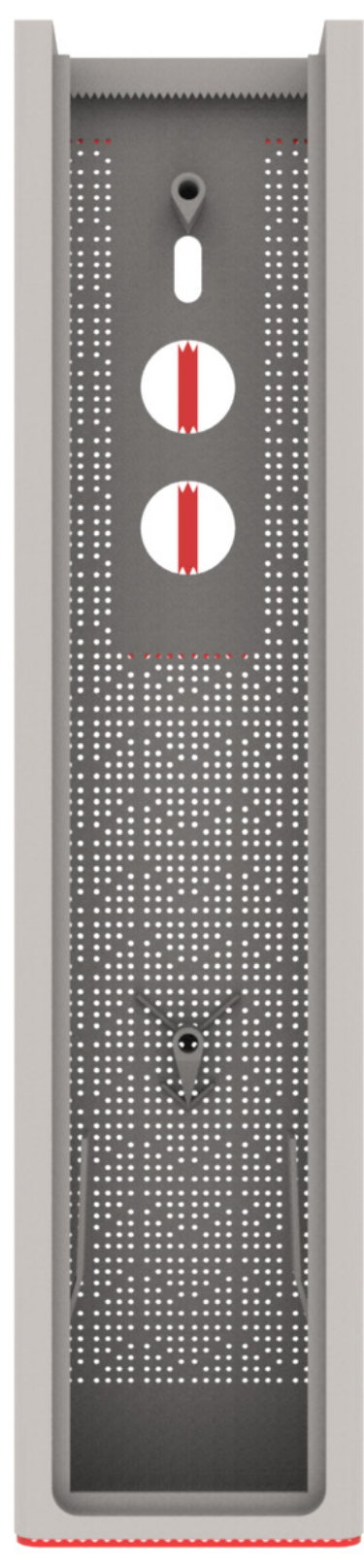

figure 58 


\section{2}

Height: $212 \mathrm{~mm}$

Width: $47.5 \mathrm{~mm}$

Overall wall thickness: $0.8 \mathrm{~mm}$

Volume: $16.99 \mathrm{~cm}^{3}$

Cost:

Nylon - \$ 54.27

Stainless - \$90.98

Titanium - \$ 399

\section{figure 59}

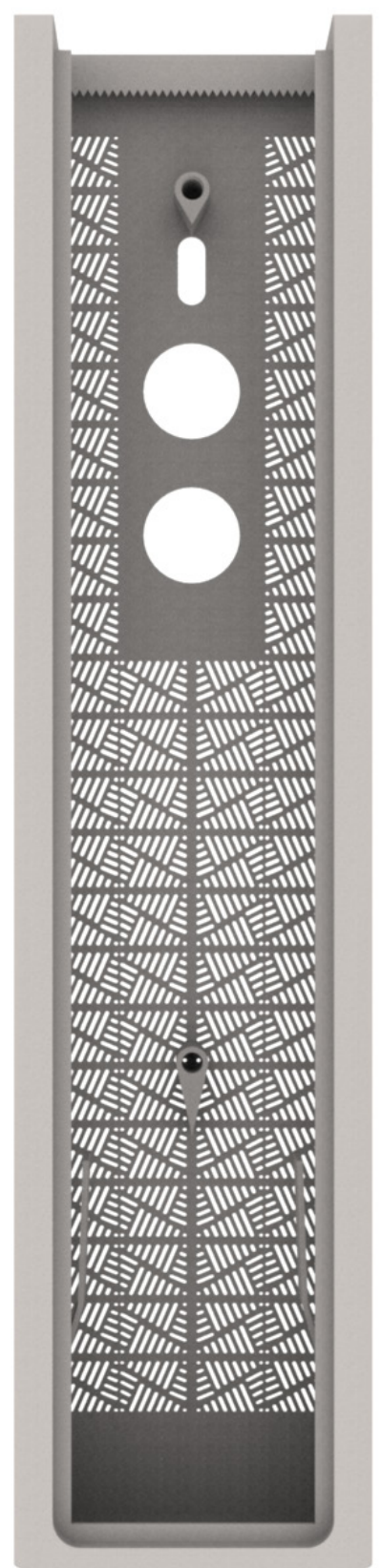

Iteration 2.2 has an array of 50 degree slots running in a triangular pattern. This lattice forms a compact barrier between the top surface and the electronics board beneath. The 3D printed stainless steel iteration has a fine mesh interposed between the lower surface and the board. By designing a tighter weaved lattice, this mesh can be factored out meaning less parts to the overall development. At this point in the iteration process some conditions can not be met due to design constraints.

figure 60 


\section{3}

Height: $212 \mathrm{~mm}$

Width: $47.5 \mathrm{~mm}$

Overall wall thickness: $0.8 \mathrm{~mm}$

Volume: $17.07 \mathrm{~cm}^{3}$

Cost:

Nylon - \$ 54.29

Stainless - \$91.37

Titanium - \$ 401

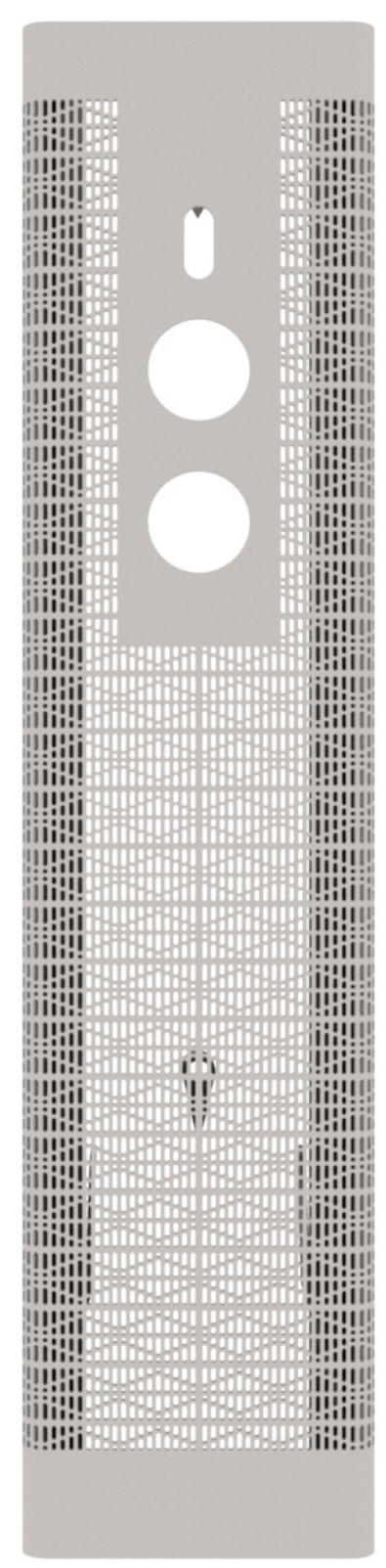

Taking aesthetic learnings from iteration 2.2, model 2.3 retains the tight lattice surface. However the lattice slots are running vertically figure 61 while still retaining the design intention of the model.

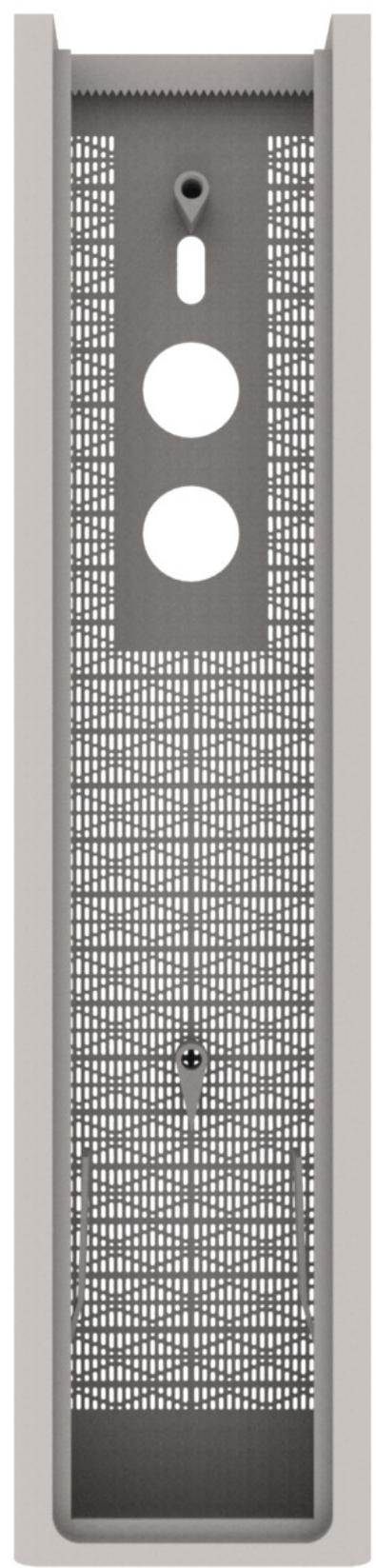

figure 62 


\section{4}

Height: $212 \mathrm{~mm}$

Width: $47.5 \mathrm{~mm}$

Overall wall thickness: $0.8 \mathrm{~mm}$

Volume: $17.31 \mathrm{~cm}^{3}$

Cost:

Nylon - \$ 49.91

Stainless - \$92.58

Titanium - \$ 406

figure 63

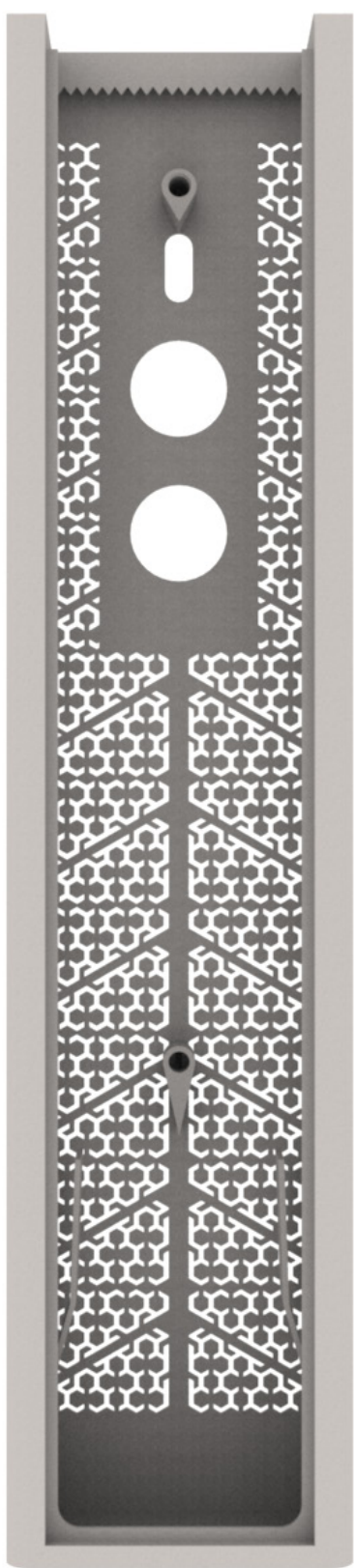

Iteration 2.4 was used to explore the hexagon as an alternative to a slotted lattice surface. The lattice was envisioned as being quite large in its construction however the wider gaps between each section would have enabled particulate matter to fall through and potentially damage the electronics beneath.

figure 64 


\section{5}

Height: $212 \mathrm{~mm}$

Width: $47.5 \mathrm{~mm}$

Overall wall thickness: $0.8 \mathrm{~mm}$

Volume: $17.49 \mathrm{~cm}^{3}$

Cost:

Nylon - \$49.98

Stainless - $\$ 93.48$

Titanium - \$ 411

Following on from 2.4, 2.5 uses the same hexagonal design but with a substantially tighter lattice. The downside to this design is its increasing gain in volume, which in turn

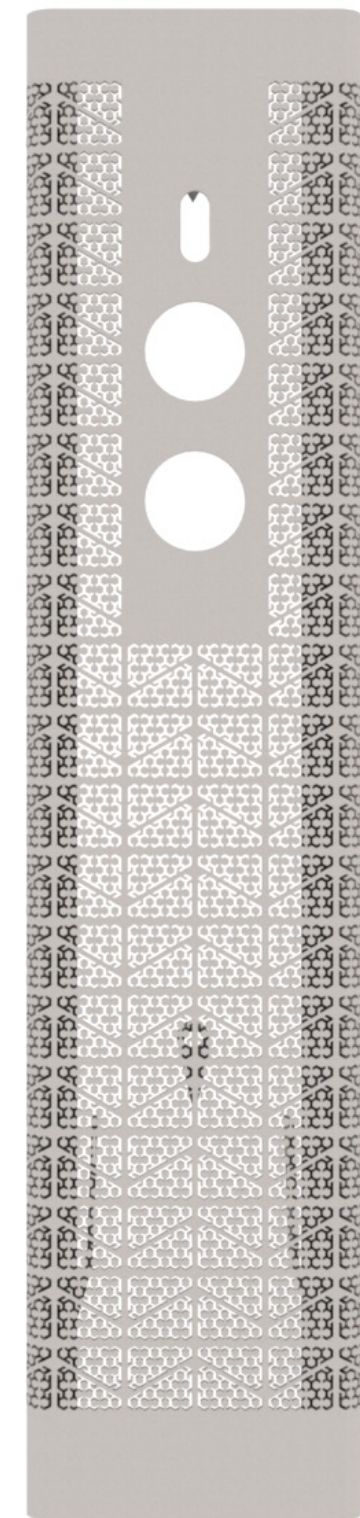

figure 65 drives up price.

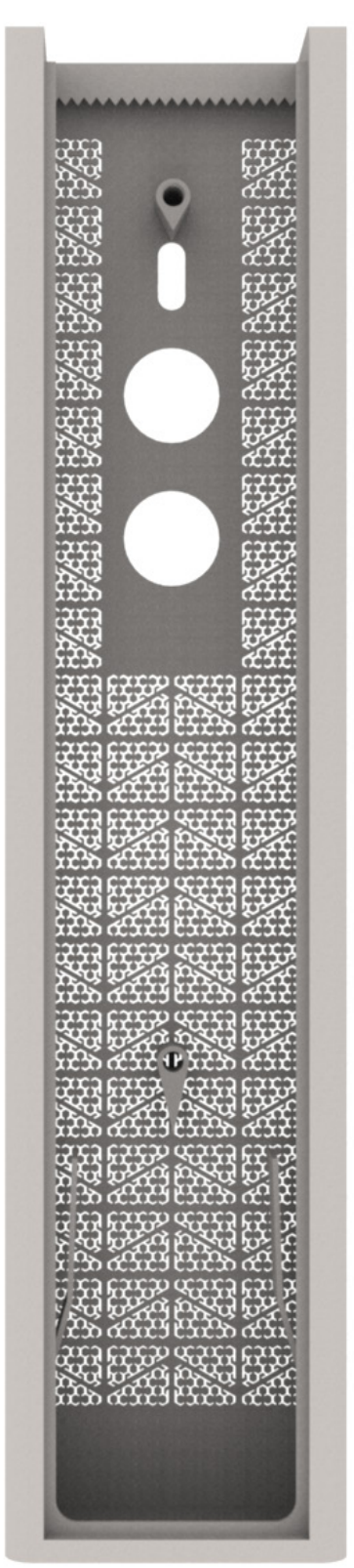

figure 66 


\section{0}

\section{Combination Lattice}

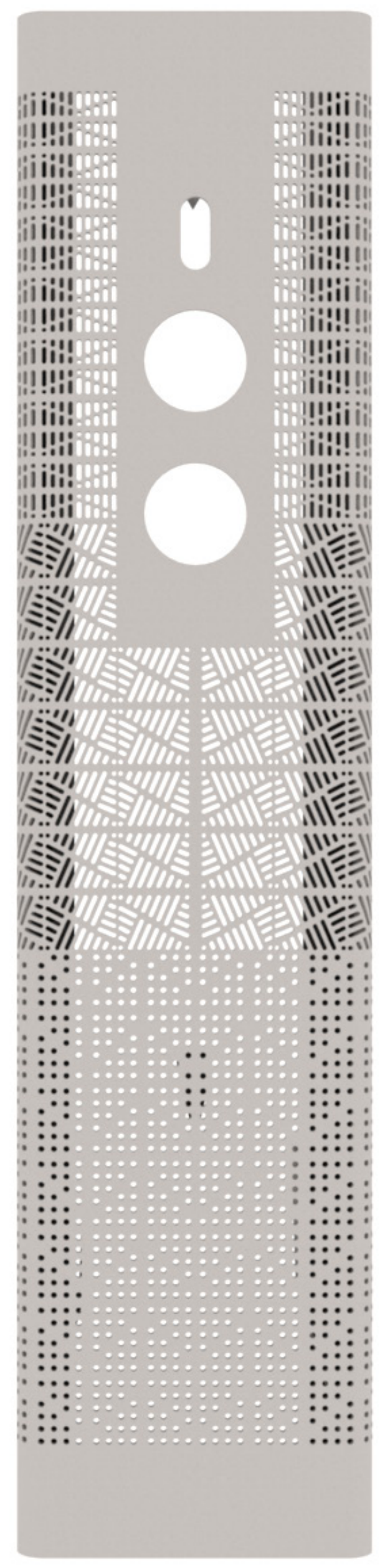

figure 67
Height: $212 \mathrm{~mm}$

Width: $47.5 \mathrm{~mm}$

Overall wall thickness: $0.8 \mathrm{~mm}$

Volume: $18.99 \mathrm{~cm}^{3}$

Cost:

Titanium - \$ 448

The combination lattice was chosen to be the first SLM 3D print. This decision was made to gain understanding firstly about the process and secondly to have a mixture of surface geometries with which an informed aesthetic choice could be made for the final developed design.

\section{Chosen lattice}

Circular

Slot at 50 degrees

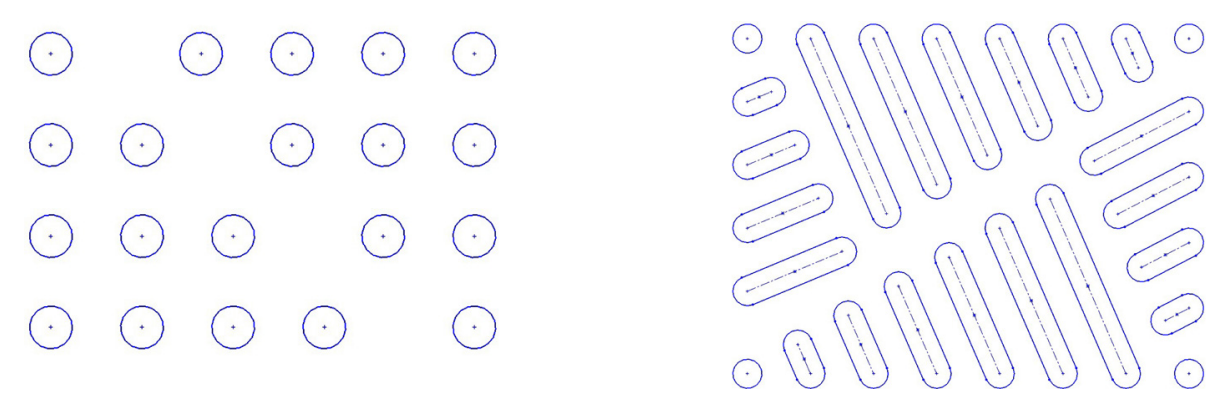

Horizontal slot

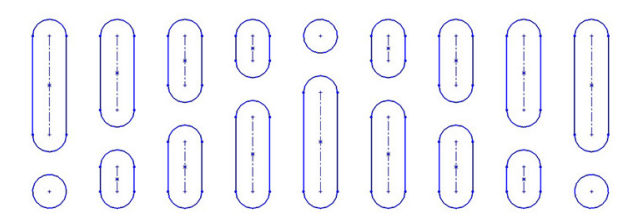




\section{Physical prints}

The image below shows iteration 3.0 in the front, side and rear elevations. As shown, the amount of buckling throughout the part is a factor of poor heat dissipation through the build and cooling phases. The discoloration on the top of the part was cause by the material possibly over heating at the end of the build cycle.

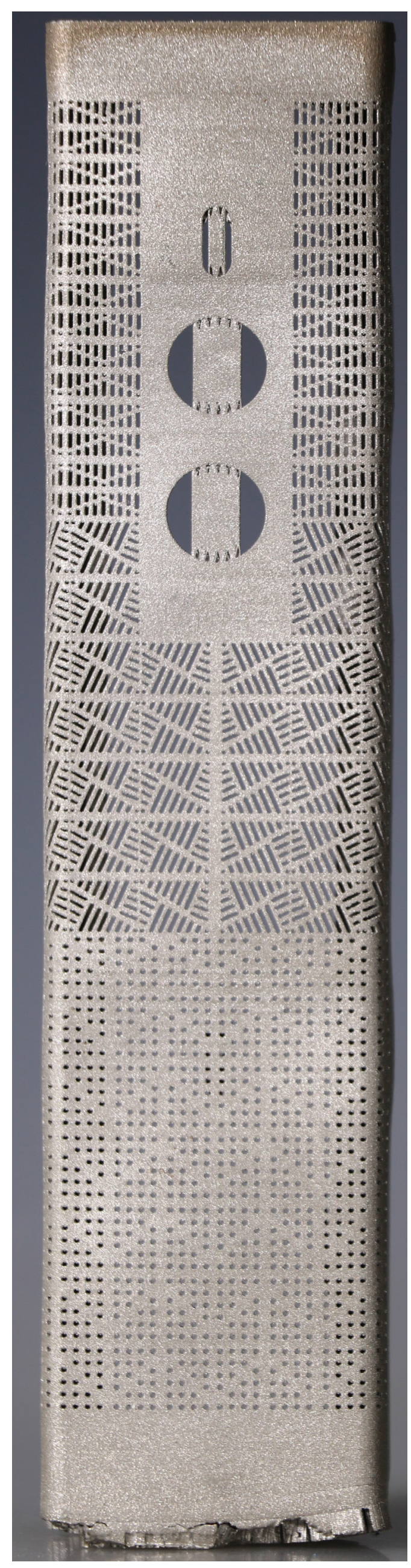

figure 68

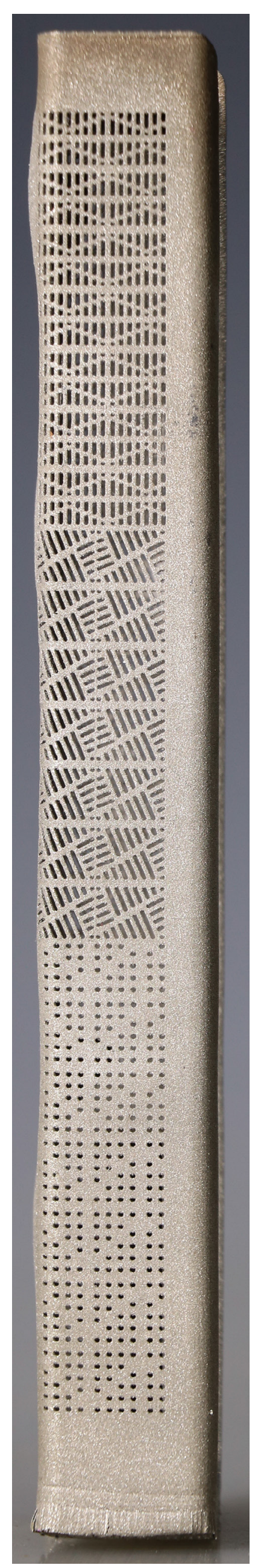

figure 69
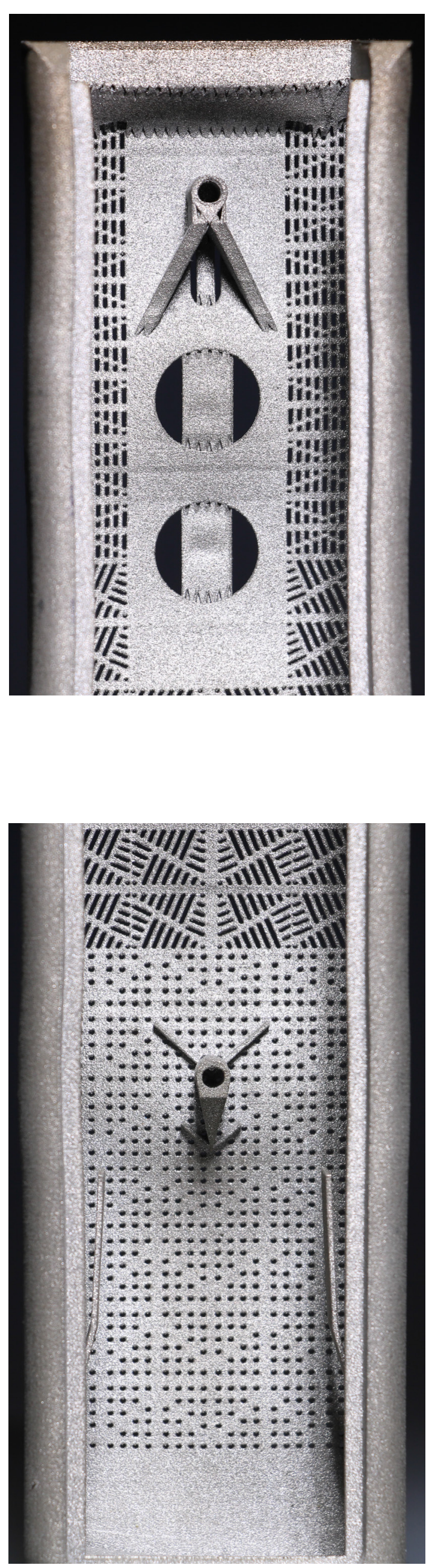

figure 70 
View from the open ended section of the part showing the level of detail as the view focuses further down. The damaged section at the end of the part was caused by its removal from the build platform. Increasing the depth of material at the end will offset this.

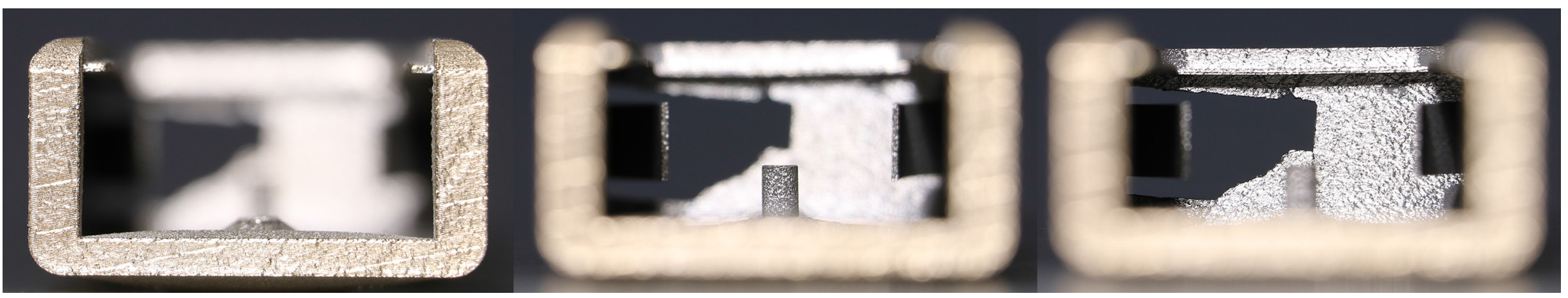

\section{figure 71}

The bottom left image shows the amount of buckling through the length of the part. This is caused mainly by poor heat dissipation during the build process and the cooling phase.

The bottom right images shows the damage to the end of the part from removal from the build platform. It is noted that the part has lifted somewhat during the build process, this may be attributed to not enough material on the bottom to 'fix' the part in place.

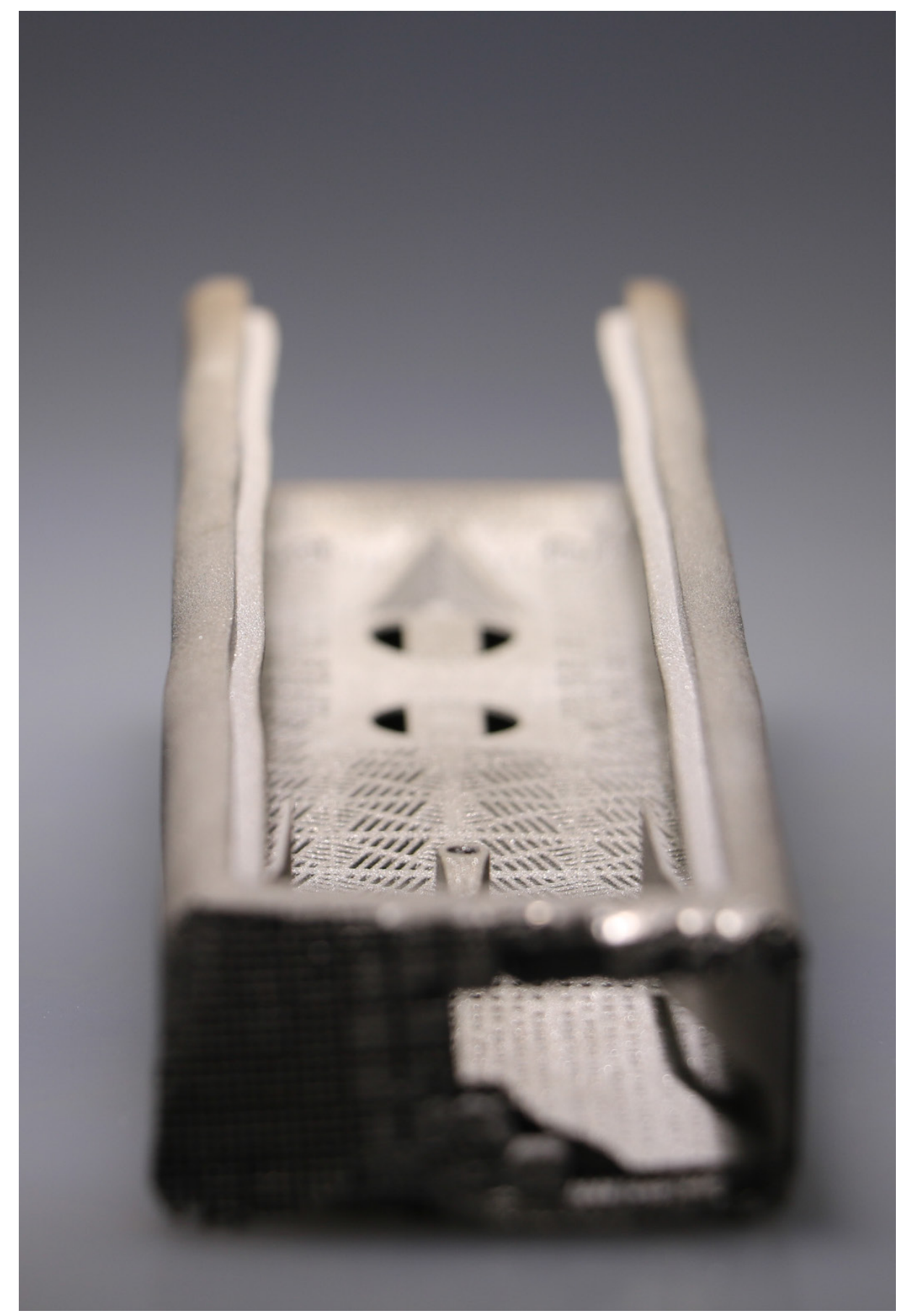

figure 72

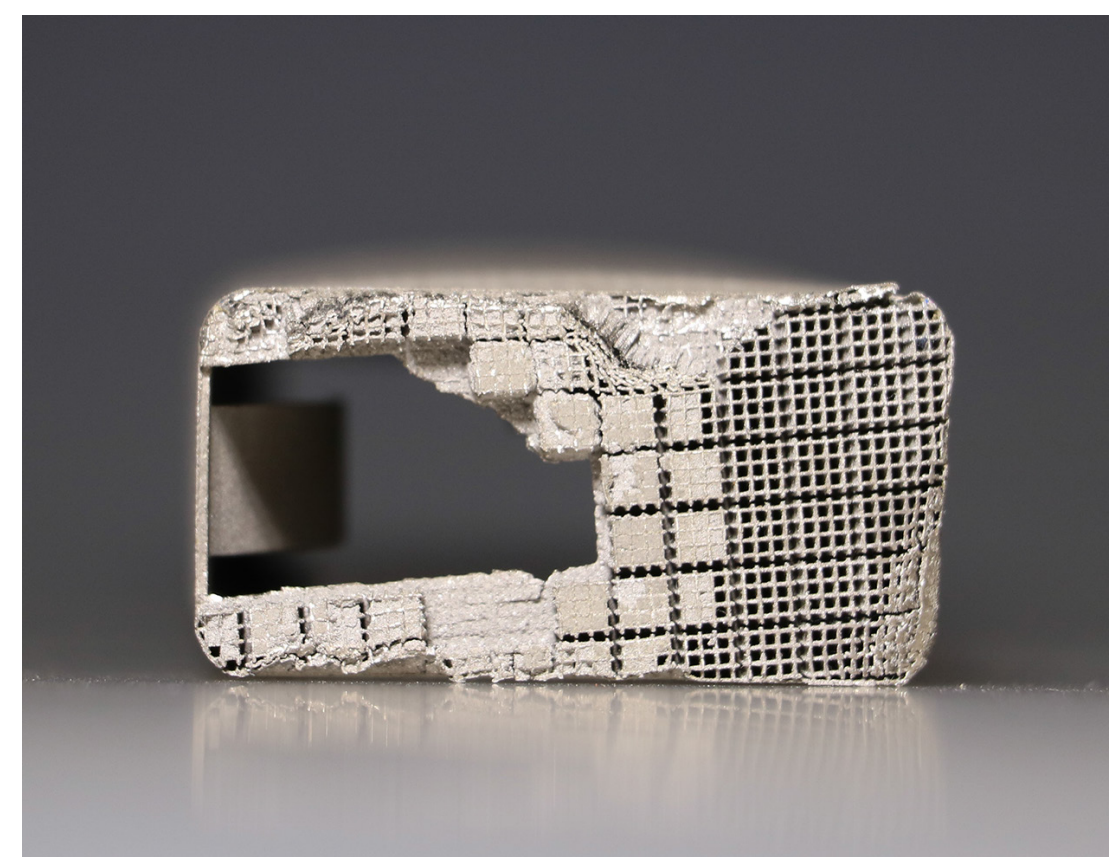

figure 73

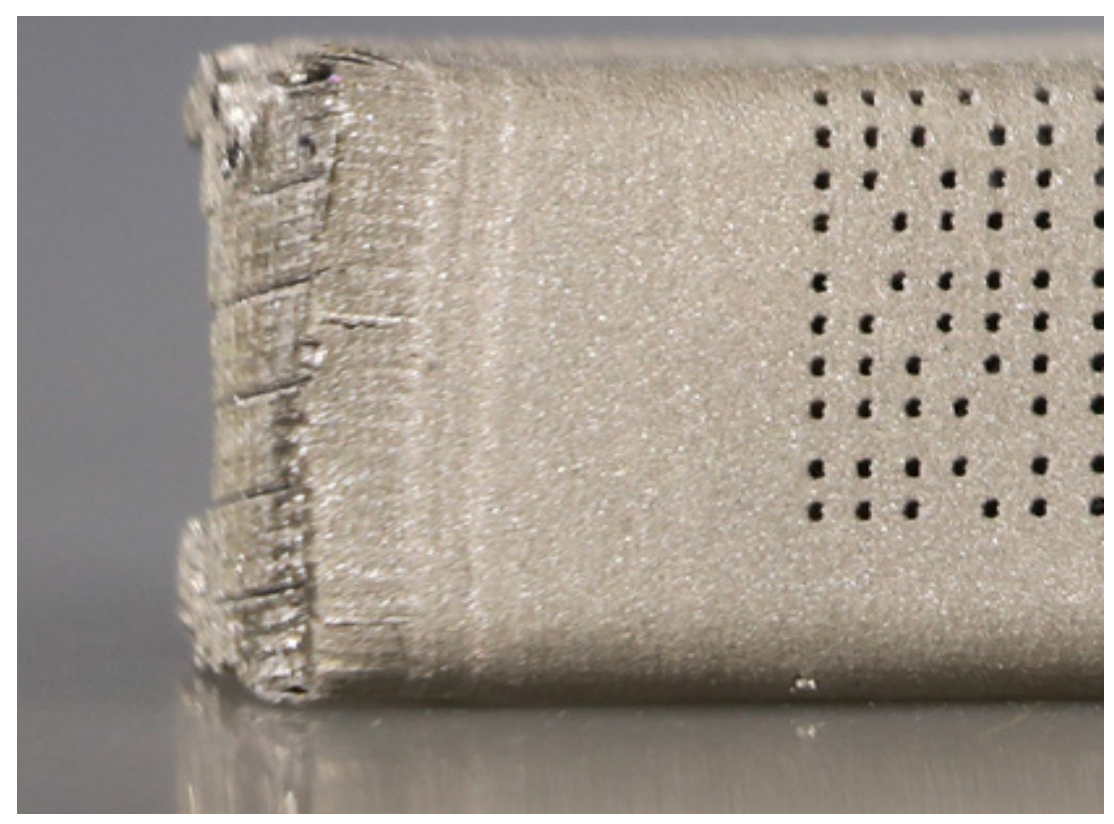

figure 74 


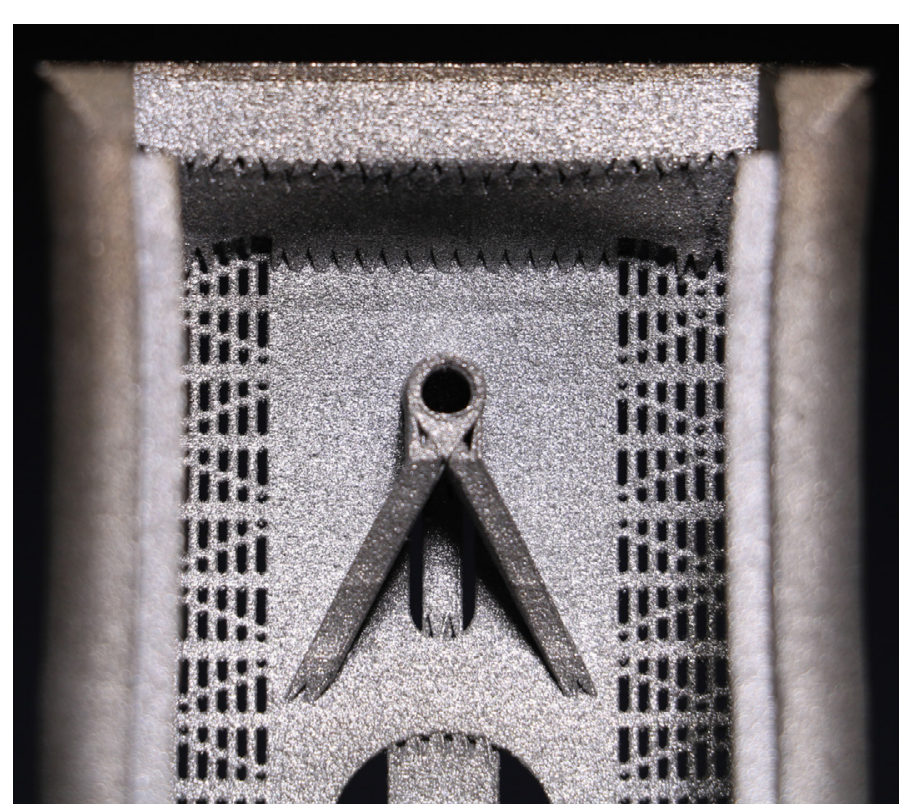

figure 75

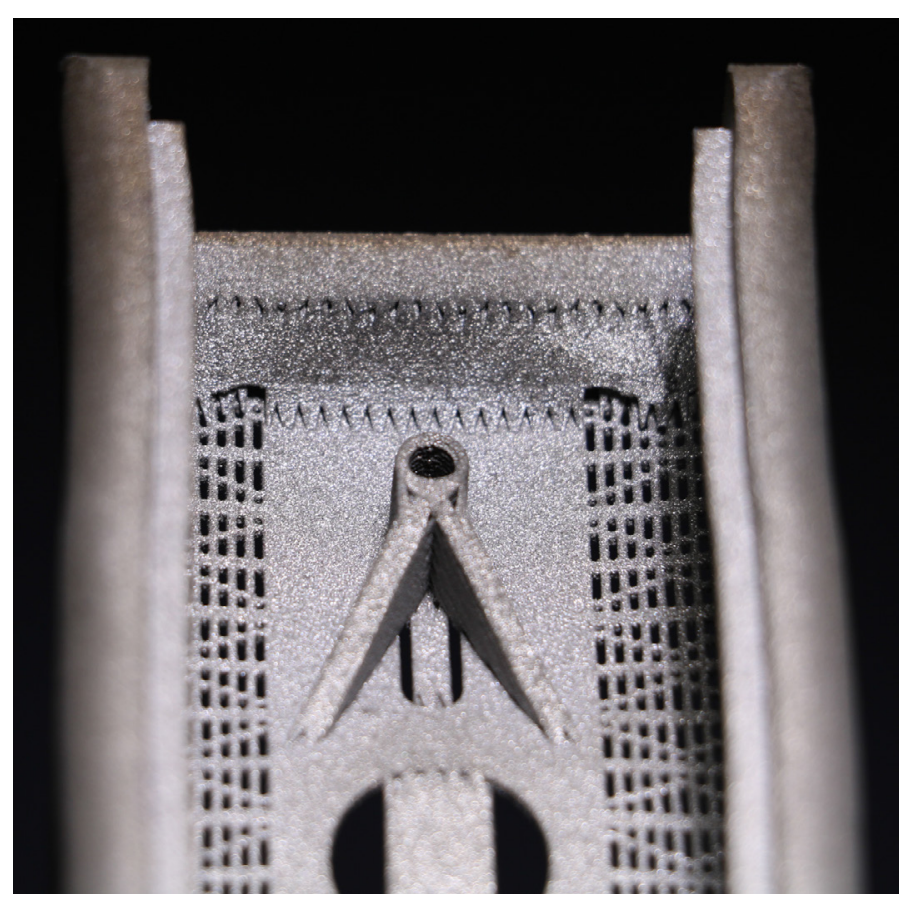

figure 76

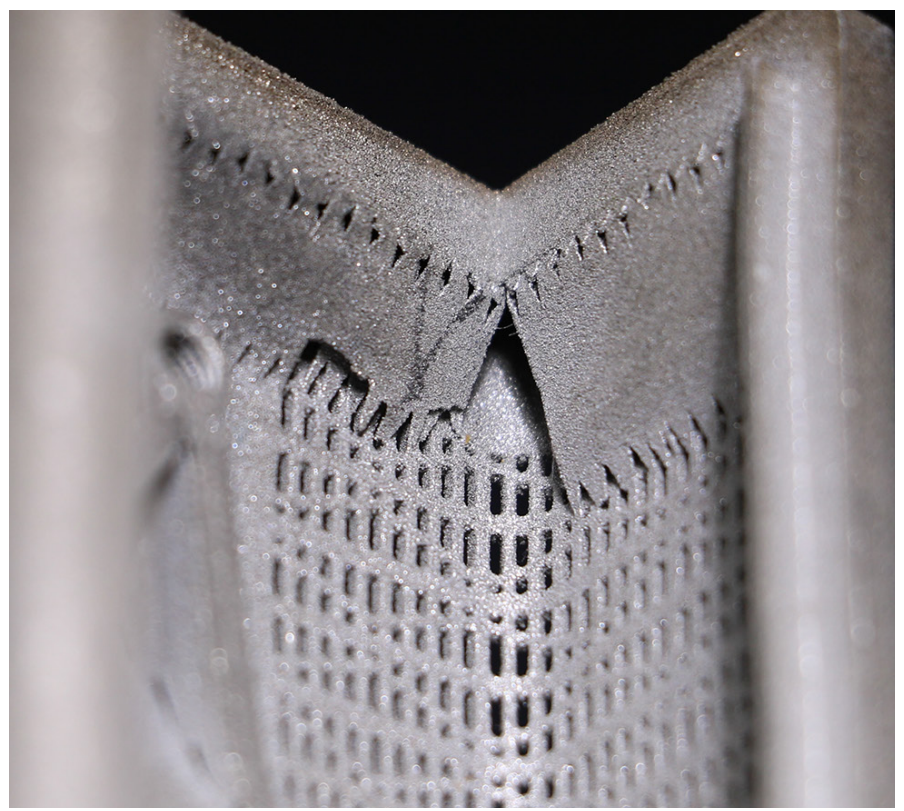

As seen in the corner section of the part, the support material has started to encroach on the surface lattice. If this is not designed out of the part it will have a negative effect when the material is removed. The titanium support material is extremely difficult to clear from a lattice structure such as this and damage could occur which will affect the overall aesthetic.
The buckling attributed to the build and cooling phases can be clearly seen on the vertical beams. This buckling moment did not only cause this but also affected the front surface of the model to an extent that the part can be considered a failure. However as the buckling was seen to have propagated in a sequence of ripples, strengthen of the part with a series of struts will be used. 


\section{Evaluation}

There are a number of points that needed to be addressed after this iteration was printed. The list below explains some of these problems and the possible design solutions.

1. It was found that the minimum downward facing surface does not contain enough material to allow it to be removed safely from the print bed after printing. The minimum depth will be increased to $1 \mathrm{~mm}$ to allow for a safe margin.
2. Due to the distortion of the part by heat dissipation, an array of support beams will be added to the next iteration to strengthen the structure.

3. The hole sections that are over $7 \mathrm{~mm}$ in the $Z$ direction cannot be changed as this is a design requirement needed for the control buttons. 


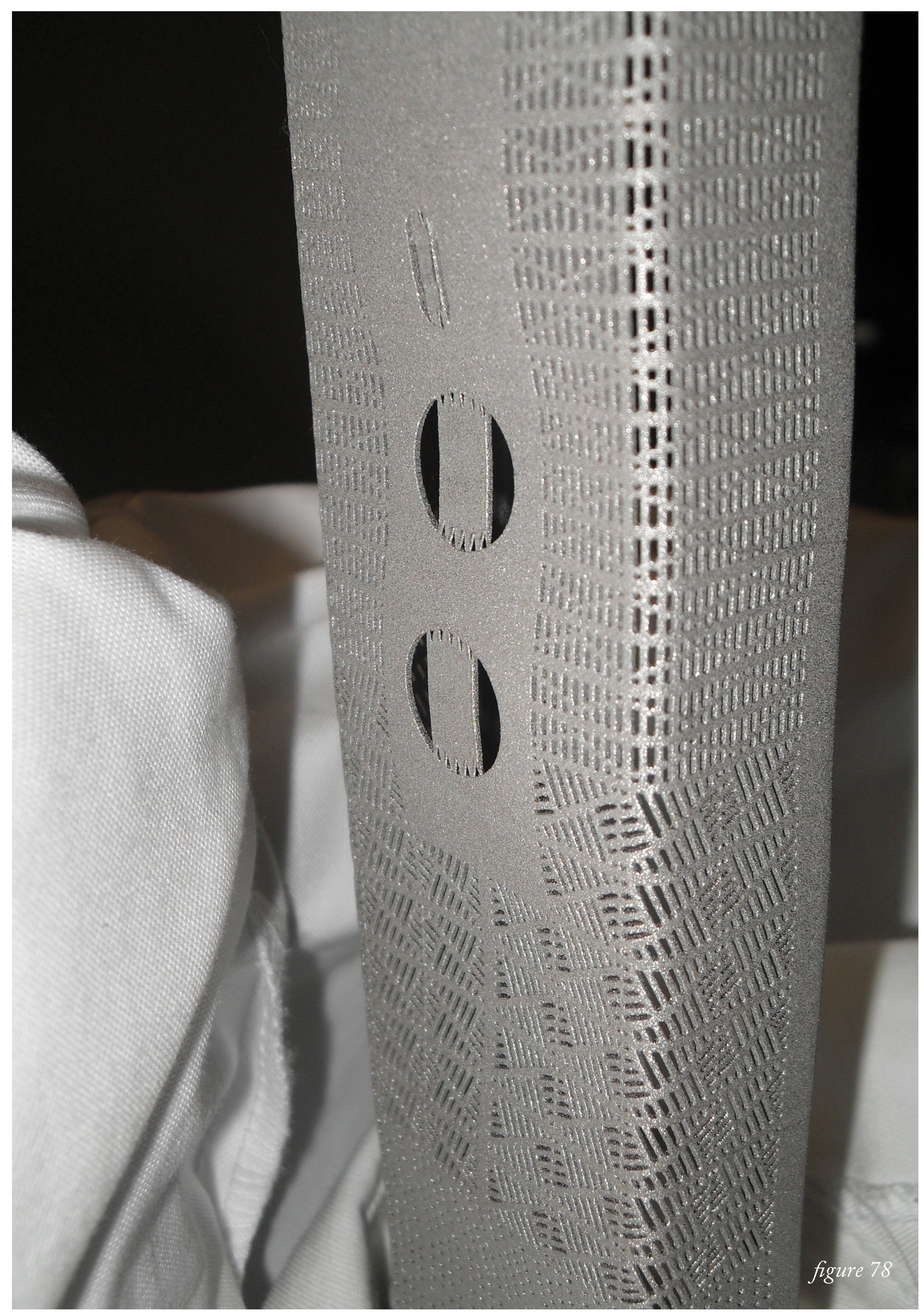

Figure 78-79-80: Finished part before removal from SLM machine 


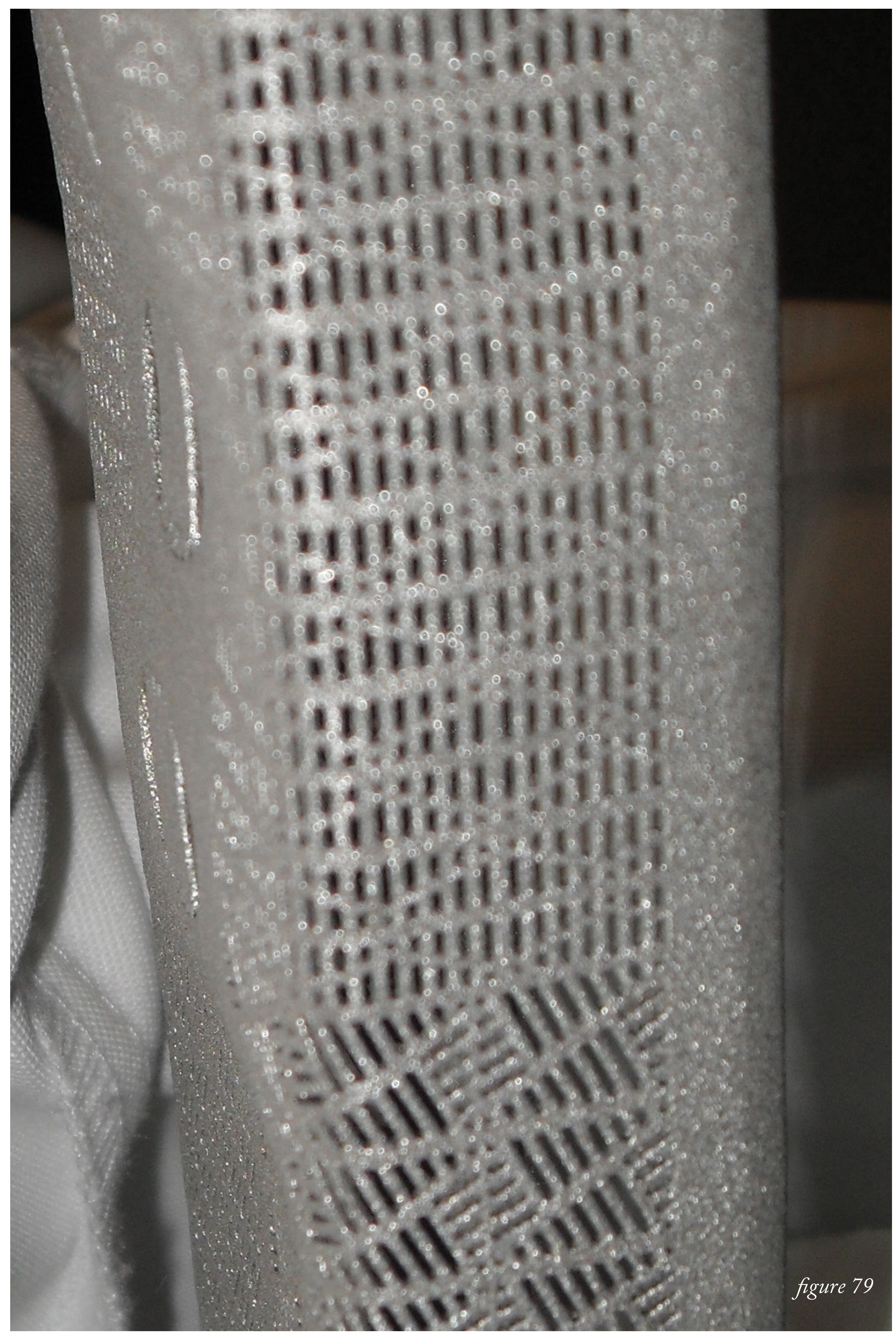

$-73-$ 


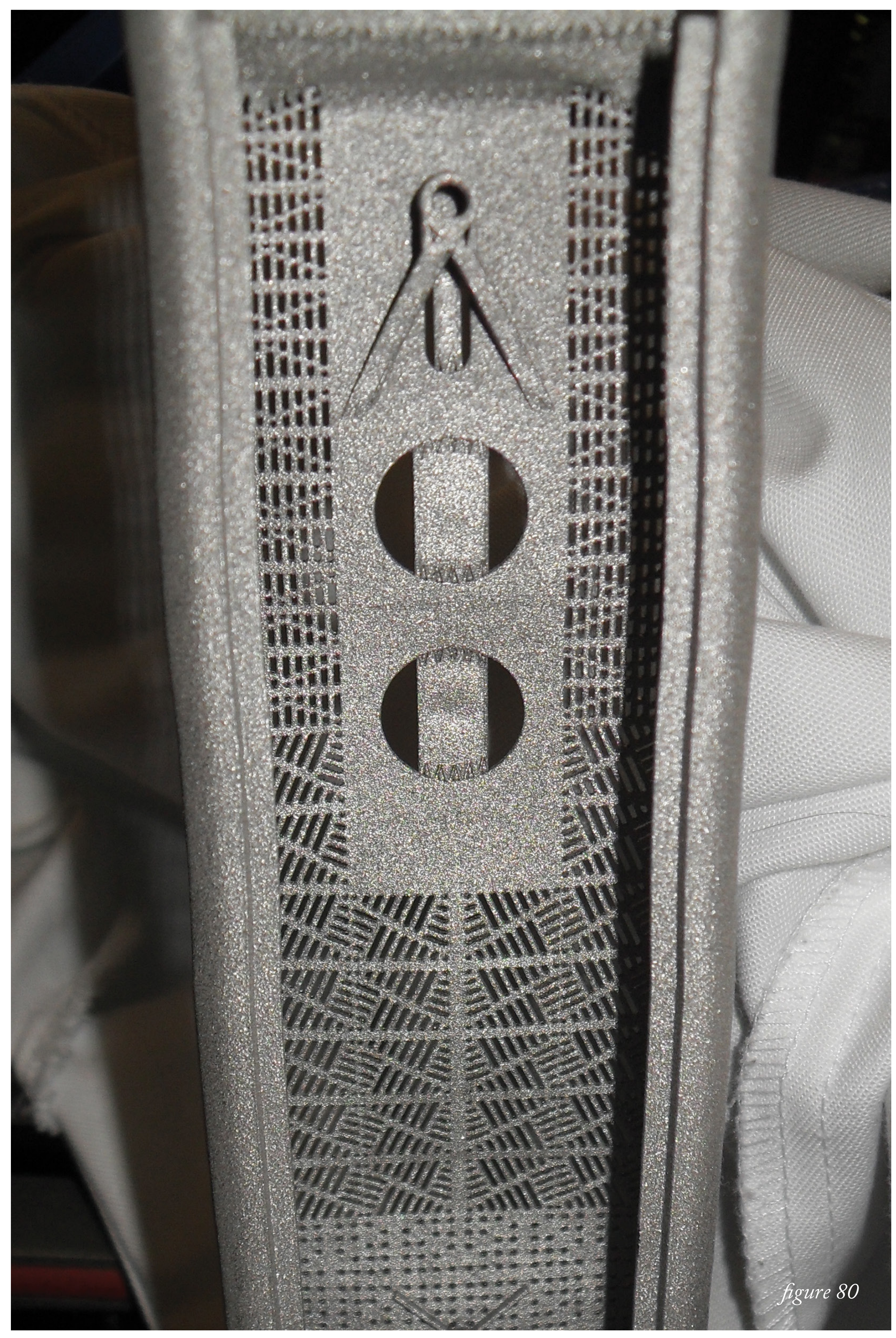




\section{1}

\section{Combination Lattice}

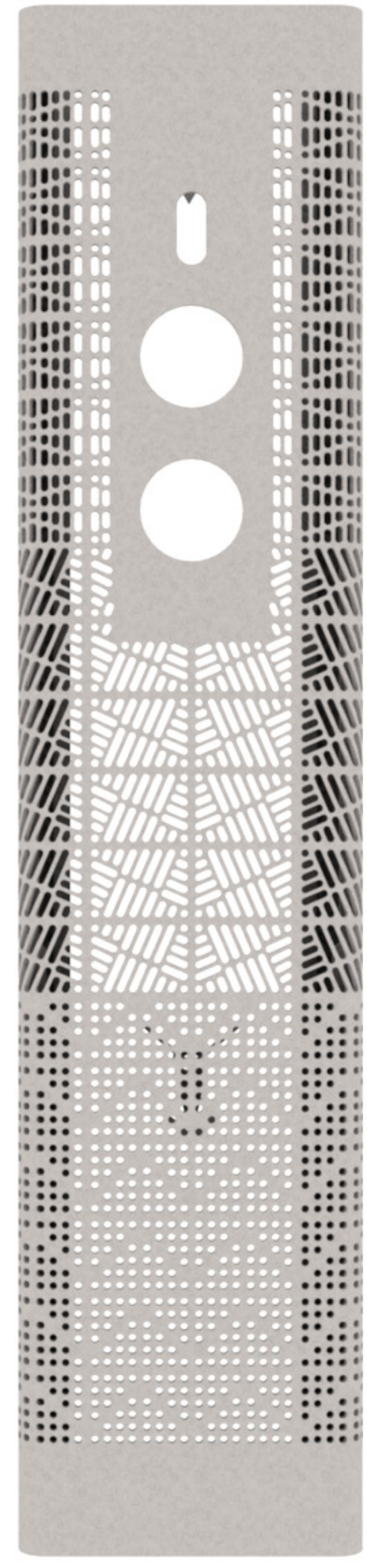

figure 81
Height: $212 \mathrm{~mm}$

Width: $47.5 \mathrm{~mm}$

Overall wall thickness: $0.8 \mathrm{~mm}$

Volume: $19.20 \mathrm{~cm}^{3}$

Cost:

Titanium - \$ 464

The second iteration of the combination lattice has a looser lattice configuration. In addition to this, bracing struts were run the length of the model to improve the structural strength and prevent the buckling effect that occurred on the previous iteration.

\section{Chosen lattice}

\author{
Circular \\ Slot at 50 degrees
}

Horizontal slot

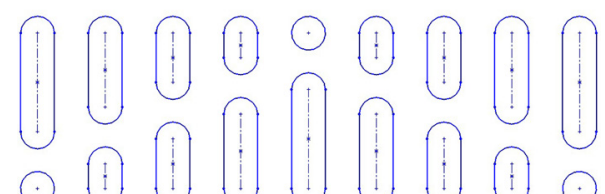




\section{Physical prints}

Iteration 3.1 shows a greater improvement in both structural integrity and design intention. The front, side and rear elevations are closely aligned with the digital file and the lack of buckling indicates that steps taken from the analysis of 3.0 have been validated.

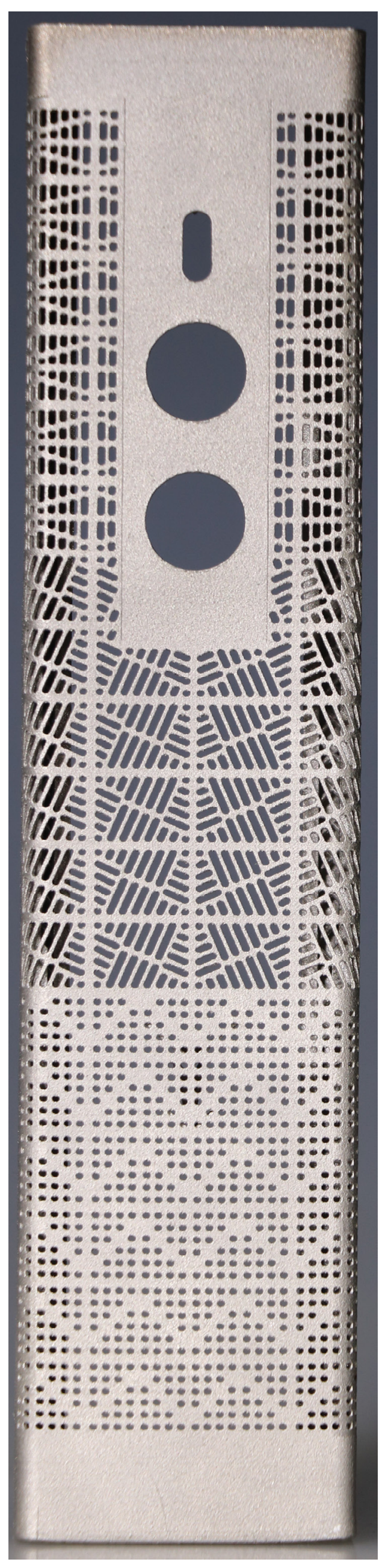

figure 82

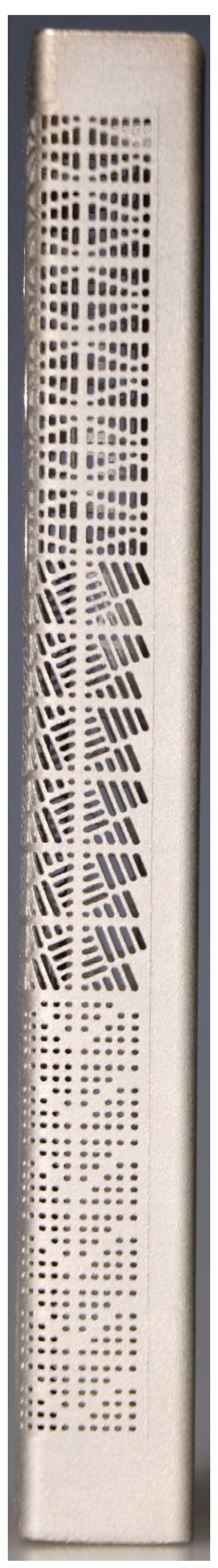

figure 83

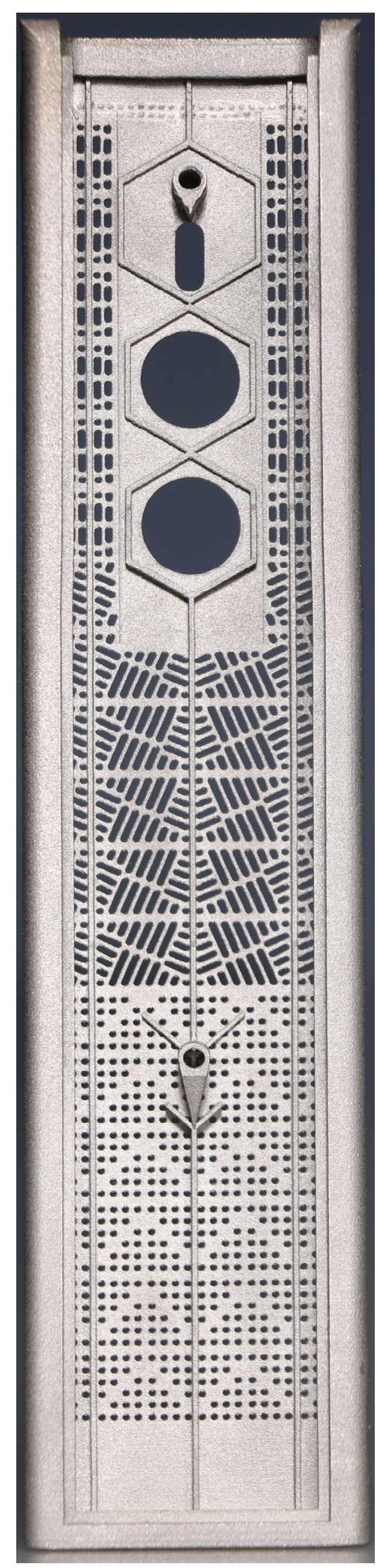

figure 84 
The bottom images shows the open section of iteration 3.1 with the top surface, top screw bracket and bottom screw bracket in detail. The top beams show a marked improvement from the previous iteration with the amount of buckling heavily reduced. However; there is still a small amount of buckling halfway down the beam suggesting that this area still has an issue with heat dissipation.

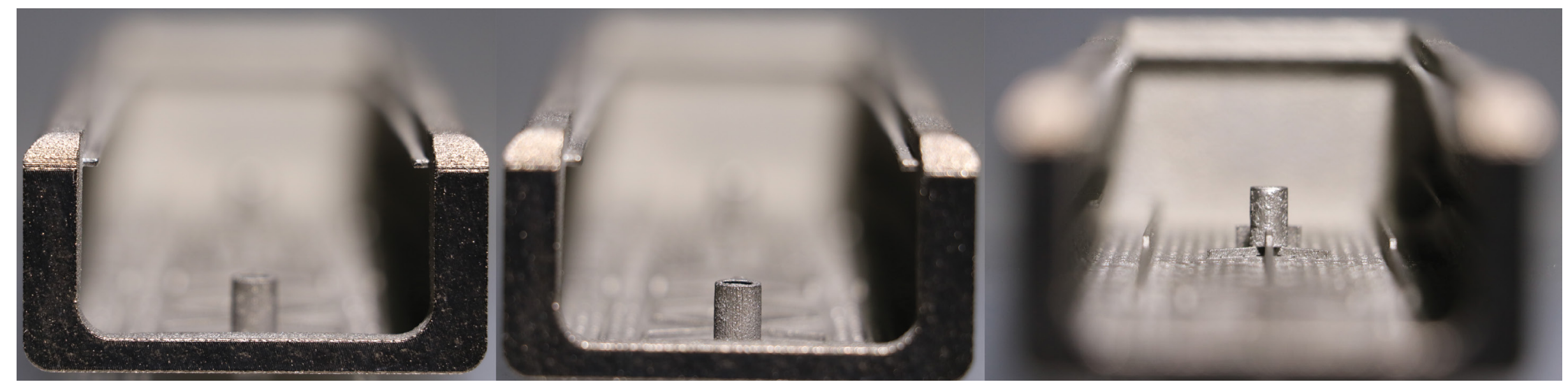

figure 85

The image on the right shows the top, front section of the model. Fine lines can be seen running parallel with the center section and the curved edge indicating an incorrect fit with the lattice section. The face and lattice were designed to be flush with each other. The printing process was ruled out as a cause after re-evaluating and correcting the CAD file.

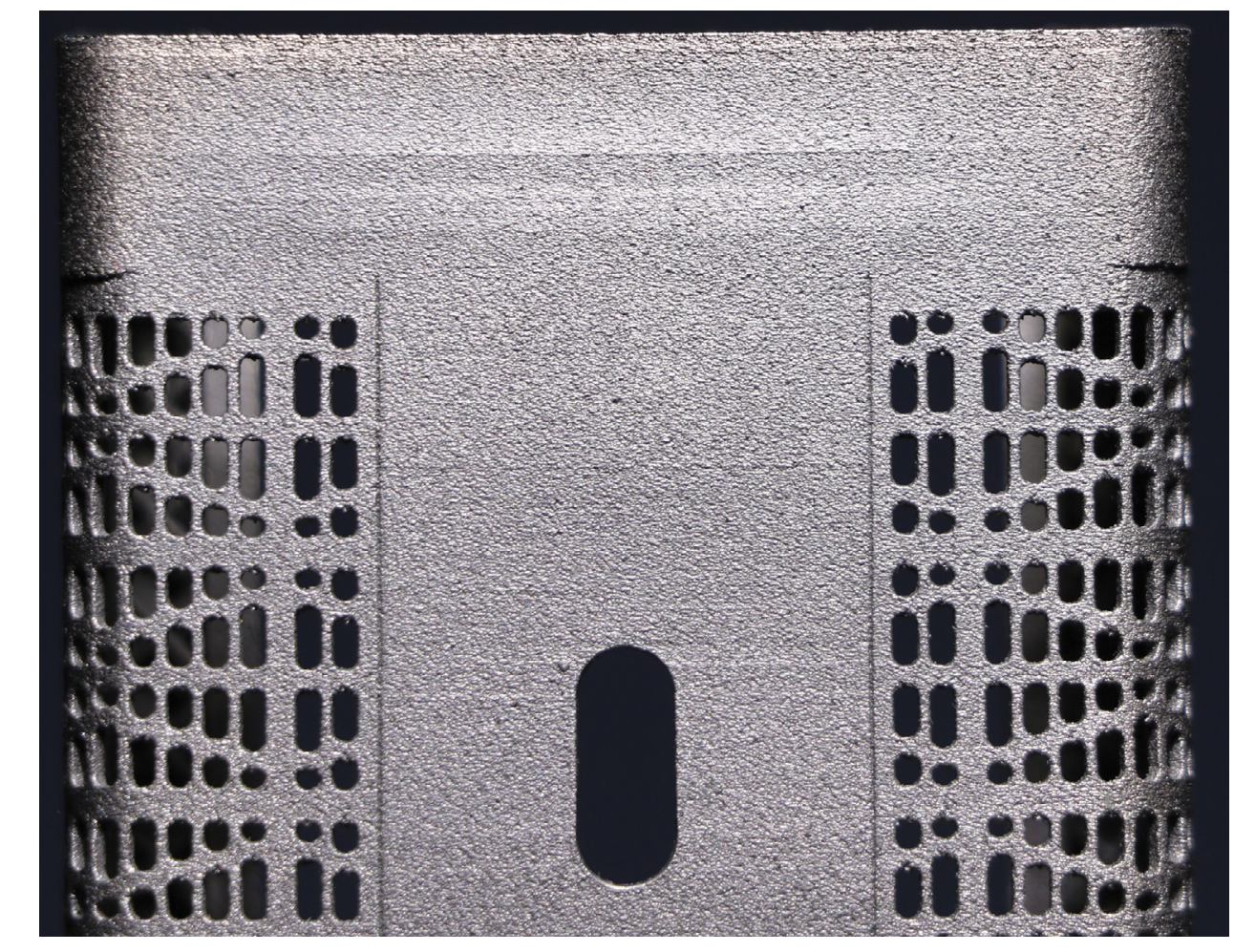

figure 86

In this image to the right, a lip or overhang can be seen which was not designed into the model. After close inspection, it was determined that the slight buckle in the middle of the part has caused the print to 'pinch' at the end of the printing run. Reinforcing the vertical struts will be trialled in the next iteration to correct this issue.

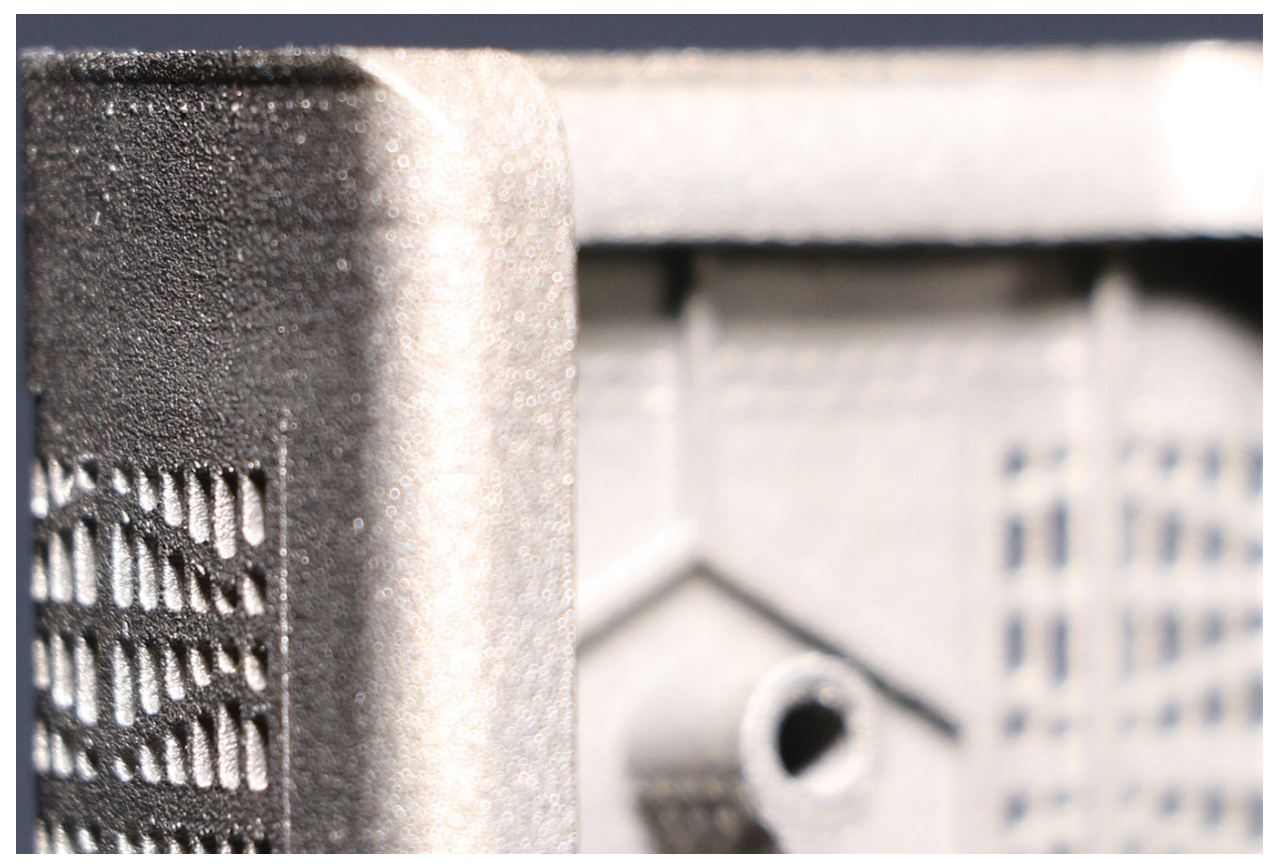

figure 87 


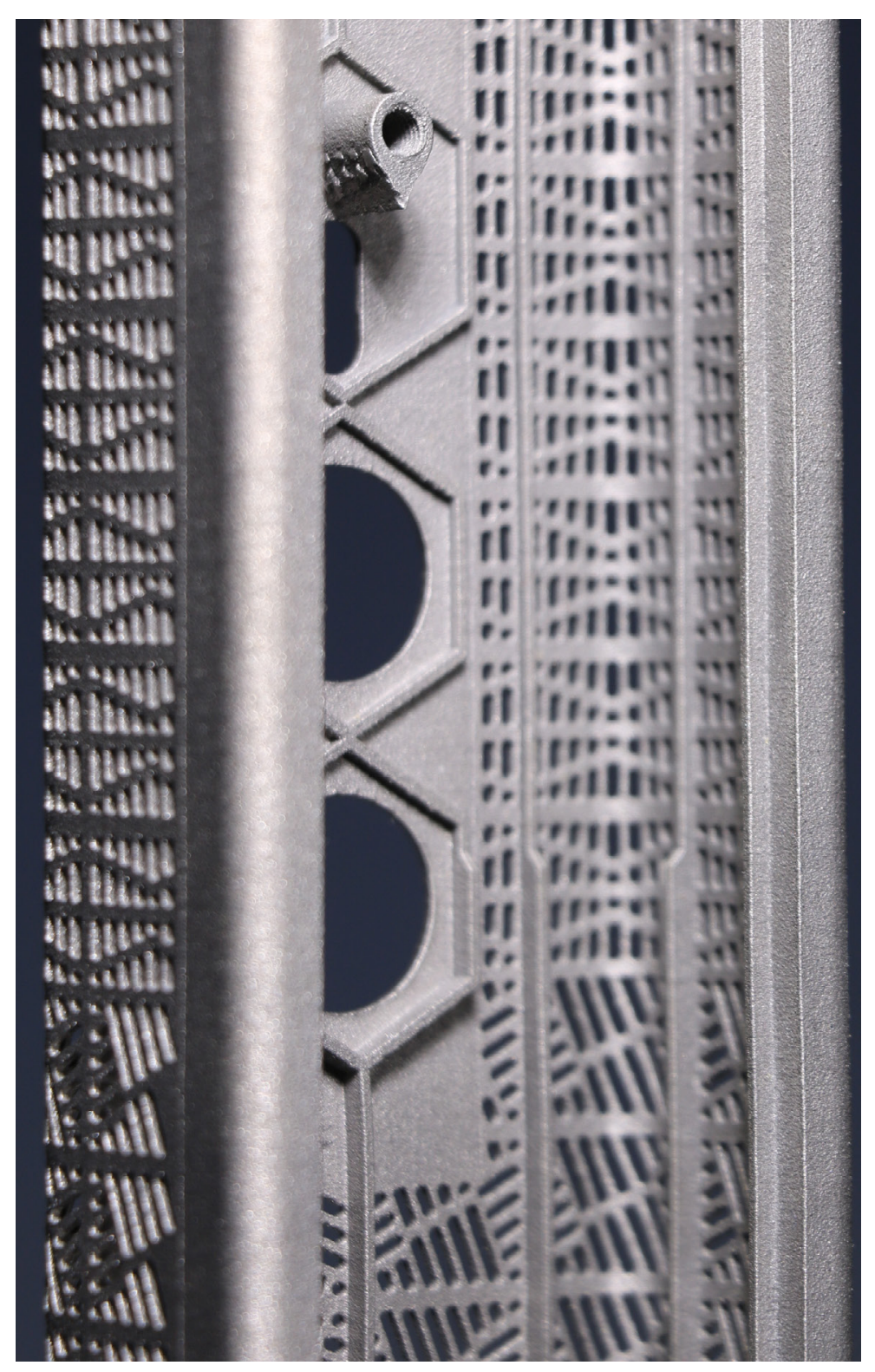

figure 88

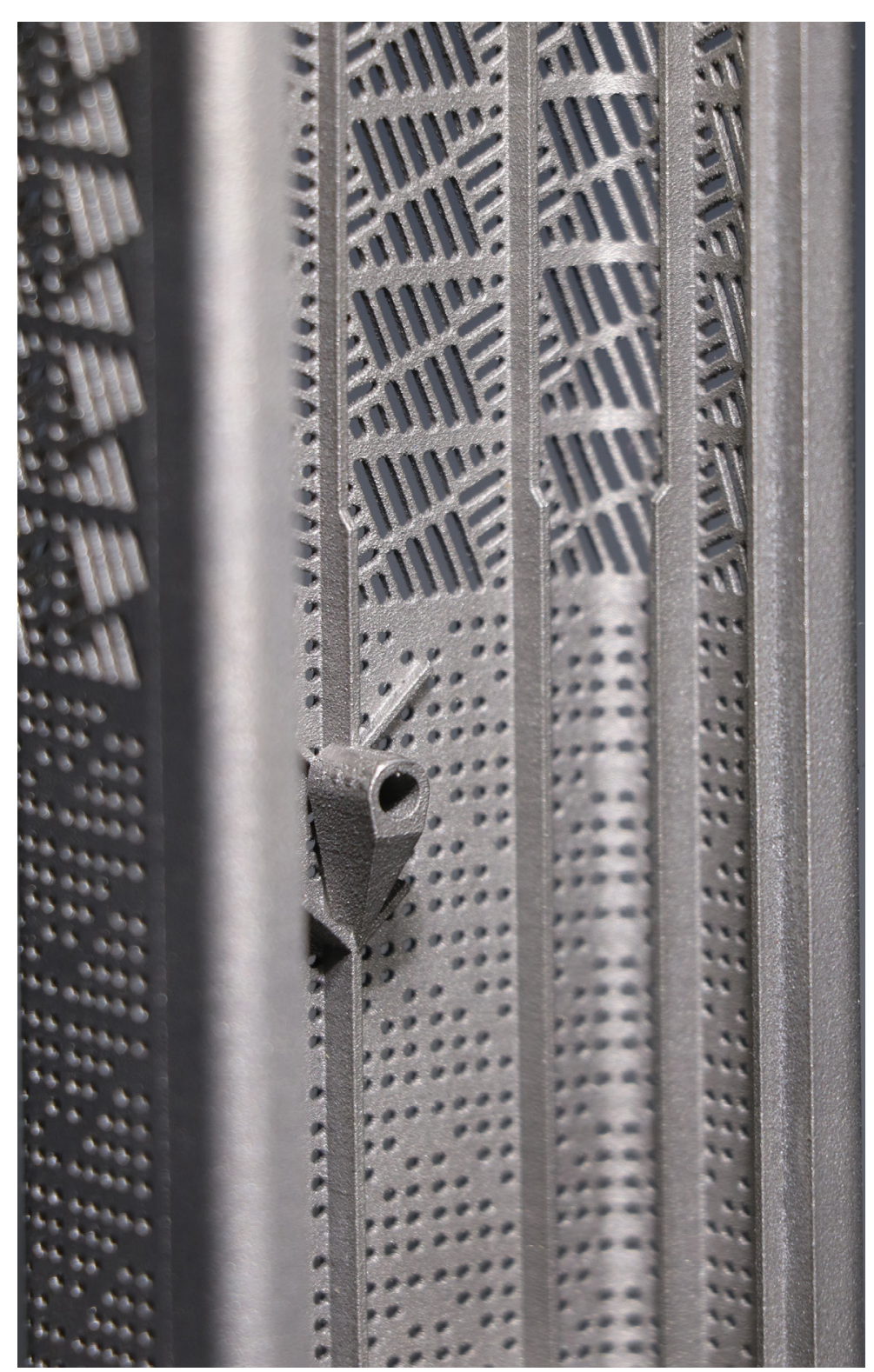

figure 89
As seen in iteration 3.0, serious structural buckling occurred causing the part to fail. To combat this, learning from 3.0 were incorporated into this design.

A hexagonal raised beam was placed around the cut out sections of the model to allow for greater vertical strength and to insure that the entire portion of the flat area was included.

Vertical structural beams were added, running the length of the part. The beams were designed to increase strength without adding excess weight.

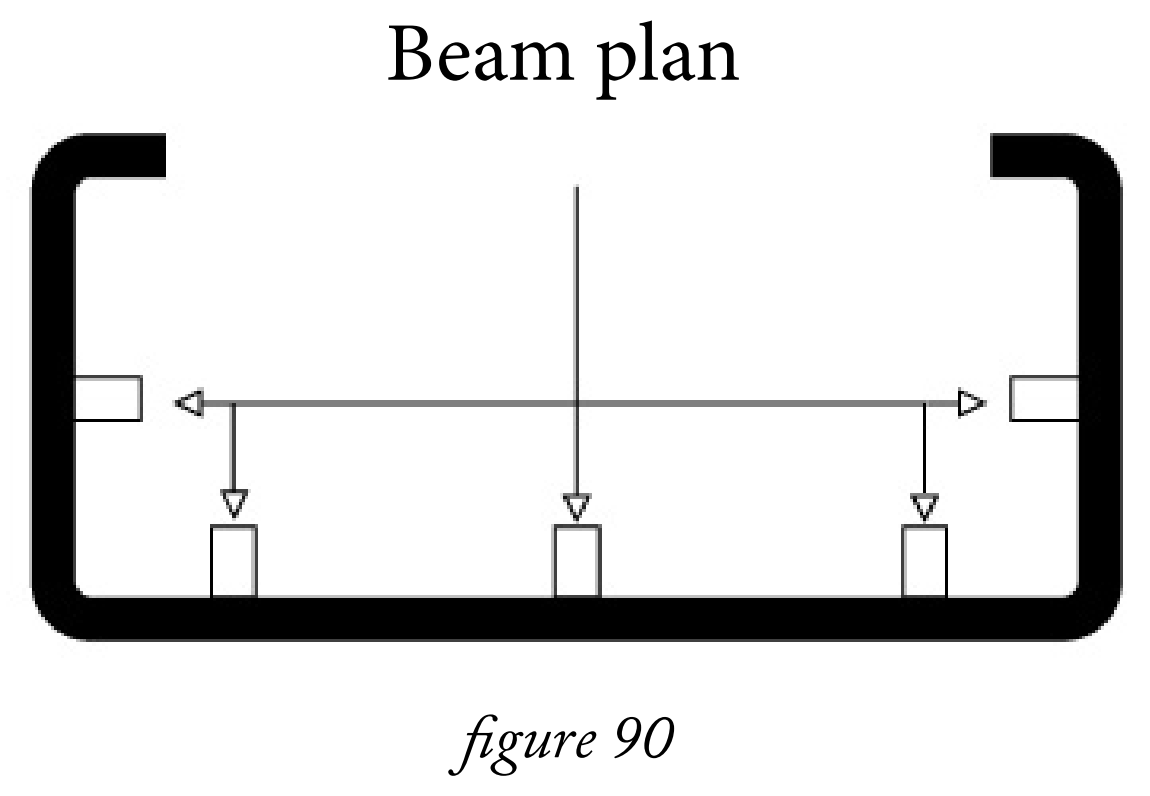

From the bottom of the part for one third of the part height, the beam height is $2 \mathrm{~mm}$. At every other third respectively the height decreases by $0.5 \mathrm{~mm}$. This is done to decrease material weight. Both the upper screw brackets have been redesigned with a 30 degree angle bladed edge to prevent the use of support material. 


\section{Evaluation}

This iteration, while more in line with its digital file than 3.0 still has a few surface and structural artifacts that need to be addressed.

1. A slight bend has been identified mid way along the part and a slight dibit has formed underneath the lower button hole. This is still caused by heat not being released quick enough by the part through the build and cooling phase. An increase in the beam height from a third of the length upwards will be used in the next iteration.
2. There are a series of lines on the front surface of the part which have been found to be a CAD artifact. These problems will be addressed in the next iteration by updating all digital files.

3. The top section of the part has overhangs that can be attributed to a 'pinching' event during the build process. To stiffen the main beams, a lattice of crosses will be inserted, running along the underside, to increase strength and lessen the problem. 

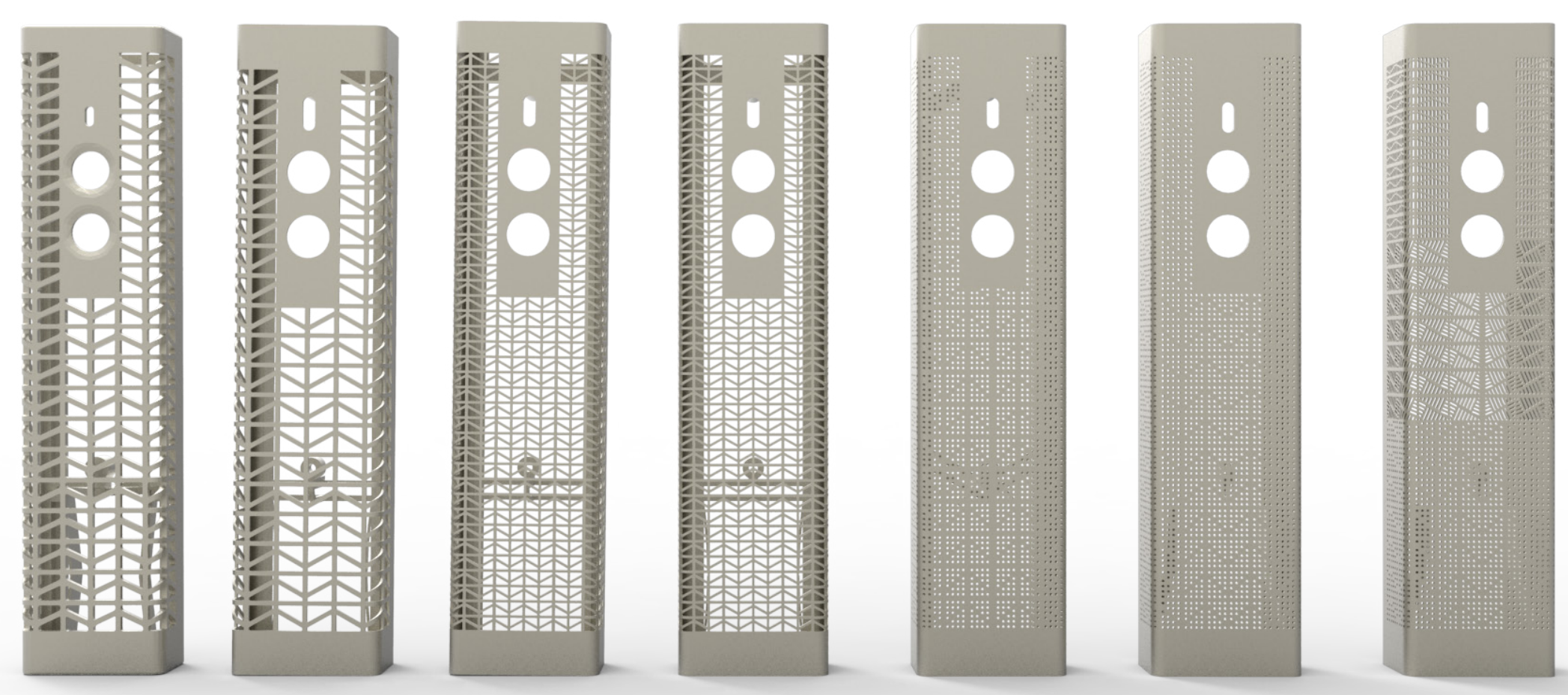

Progression of model iterations 1.0 - 3.1
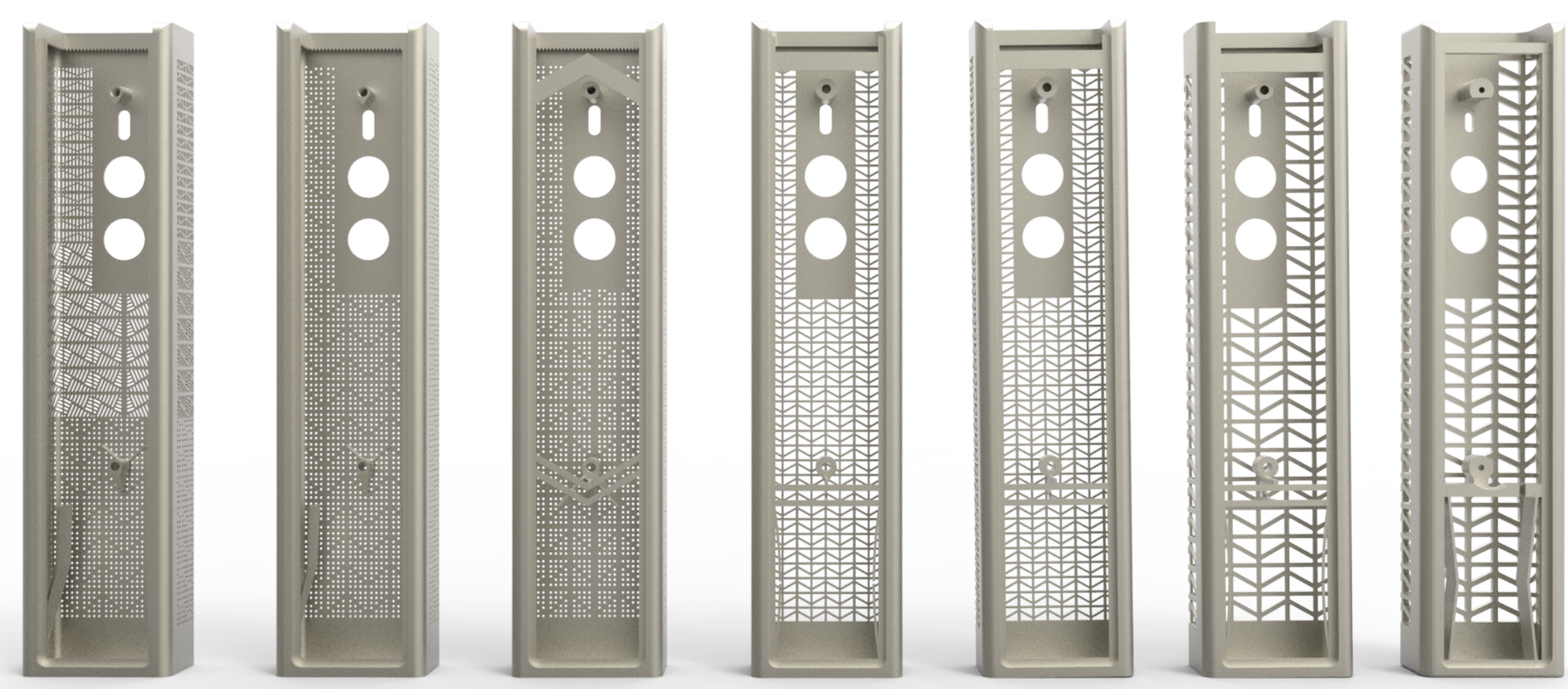

figure 91 


\section{2}

\section{Mono lattice}

Height: $212 \mathrm{~mm}$

Width: $47.5 \mathrm{~mm}$

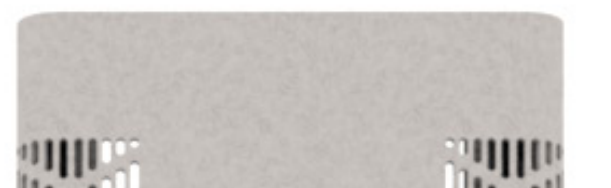

Overall wall thickness: $0.8 \mathrm{~mm}$

Volume: $20.30 \mathrm{~cm}^{3}$

Cost:

Titanium - \$ 467

The last iteration in this series was chosen to have one lattice pattern as this was the most aesthetically pleasing and followed the design intent with the original design. The lattice used is a pillar design with both the bottom and top caps set at 30 degrees.

\section{Chosen lattice}

Horizontal 30degree pillars

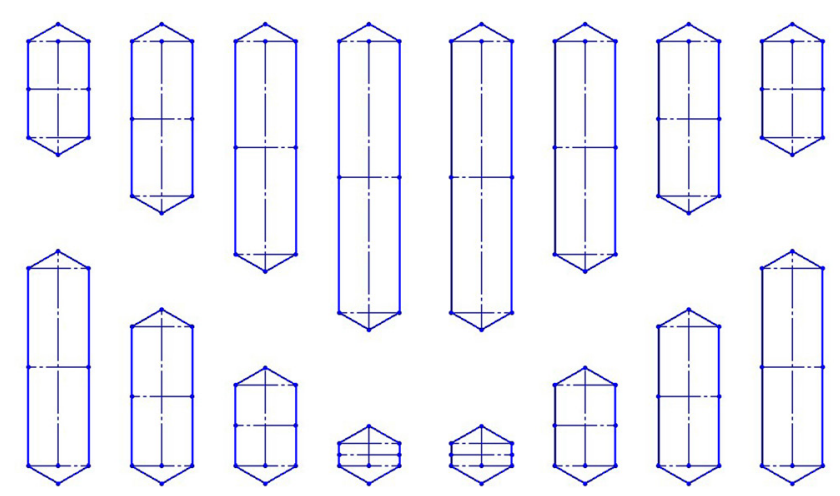

figure 92 


\section{Physical prints}

The final iteration in this series has taken all of the learning and observations from the previous models and incorporated them into one design. The undesirable buckling and scorched top has been eliminated and the model has good structural integrity.

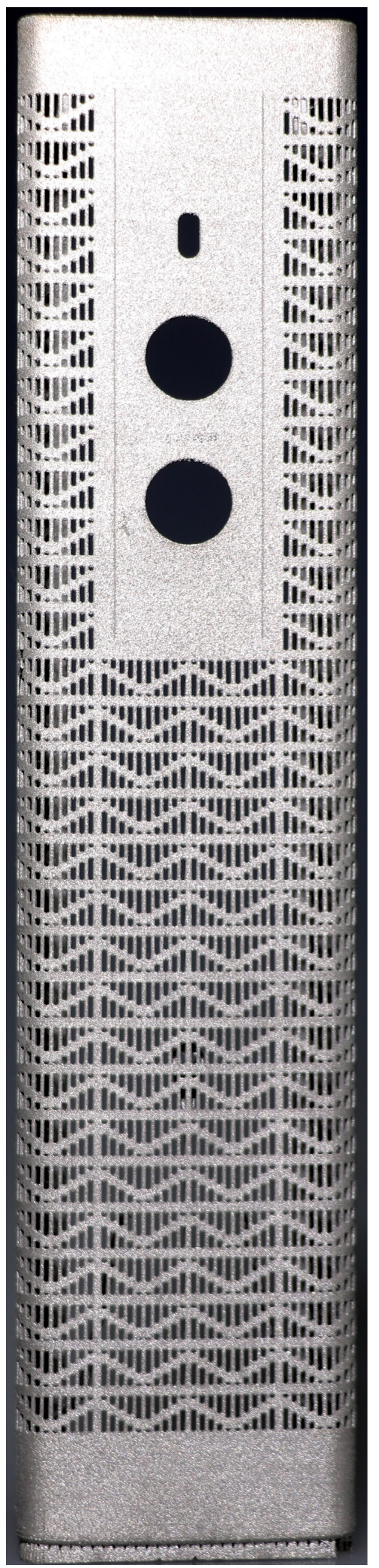

figure 93

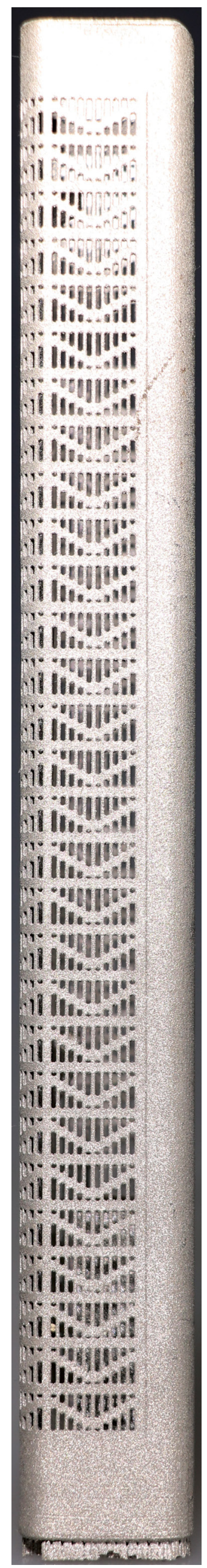

figure 94

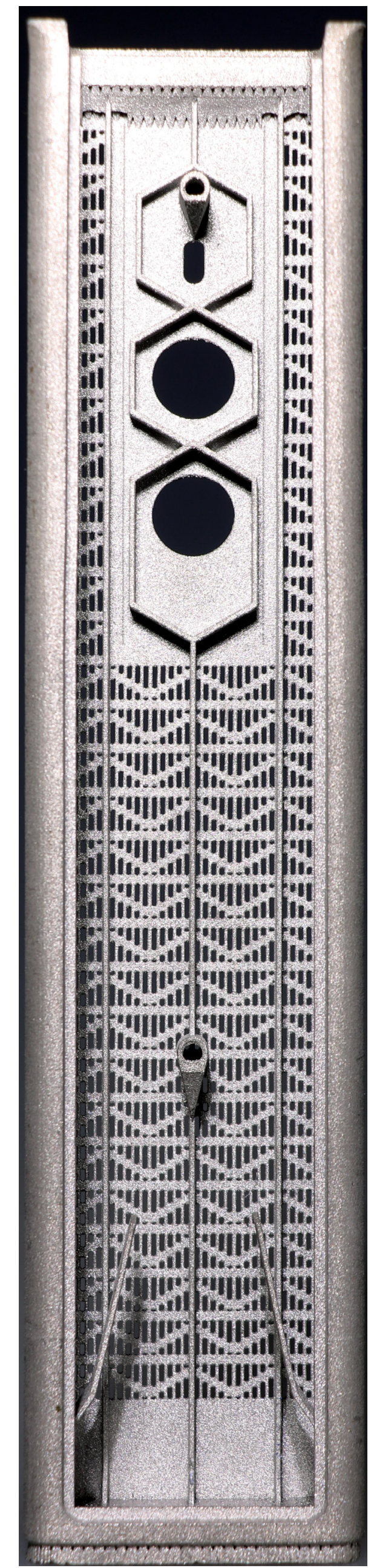

figure 95 
The view from the open section below shows a straight beam running the length of the part and good level of detail on the screw brackets. Also, leaf springs have been added to facilitate the power source for the remote ( 9 volt square battery pack).

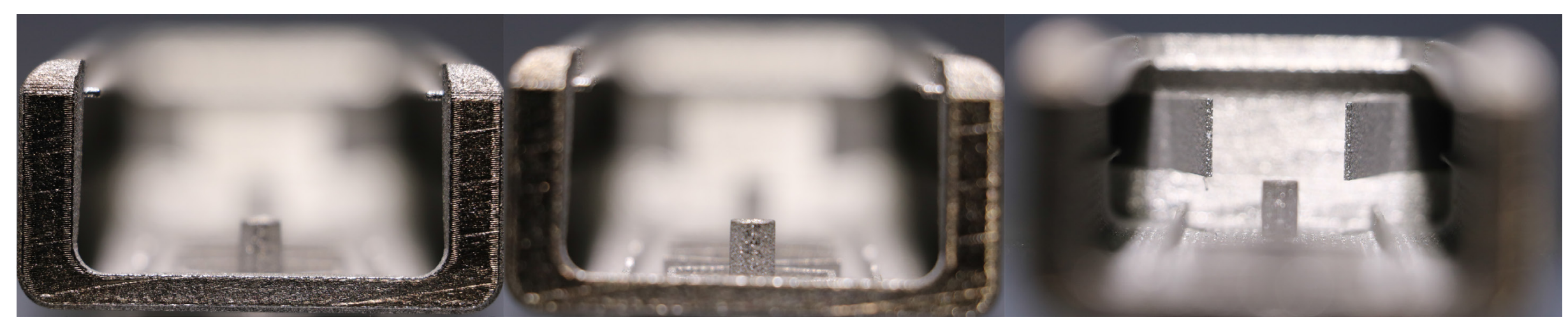

\section{figure 96}

The image below and to the right shows the top section of the part with attached support material. The decision to remove the saw tooth pattern was taken as the support was more difficult to remove than if the pattern was there. A bladed flat edge (with an angled face at 45 degrees towards the flat surface) was designed. This also ensured that the support material would not encroach onto the lattice, as shown in the top right image.

The base of the part can be seen with the material used to fix the part to the build plate still intact. The decision to increase the base thickness improved stability and allowed more area to 'fix' stopping the part to lift up.

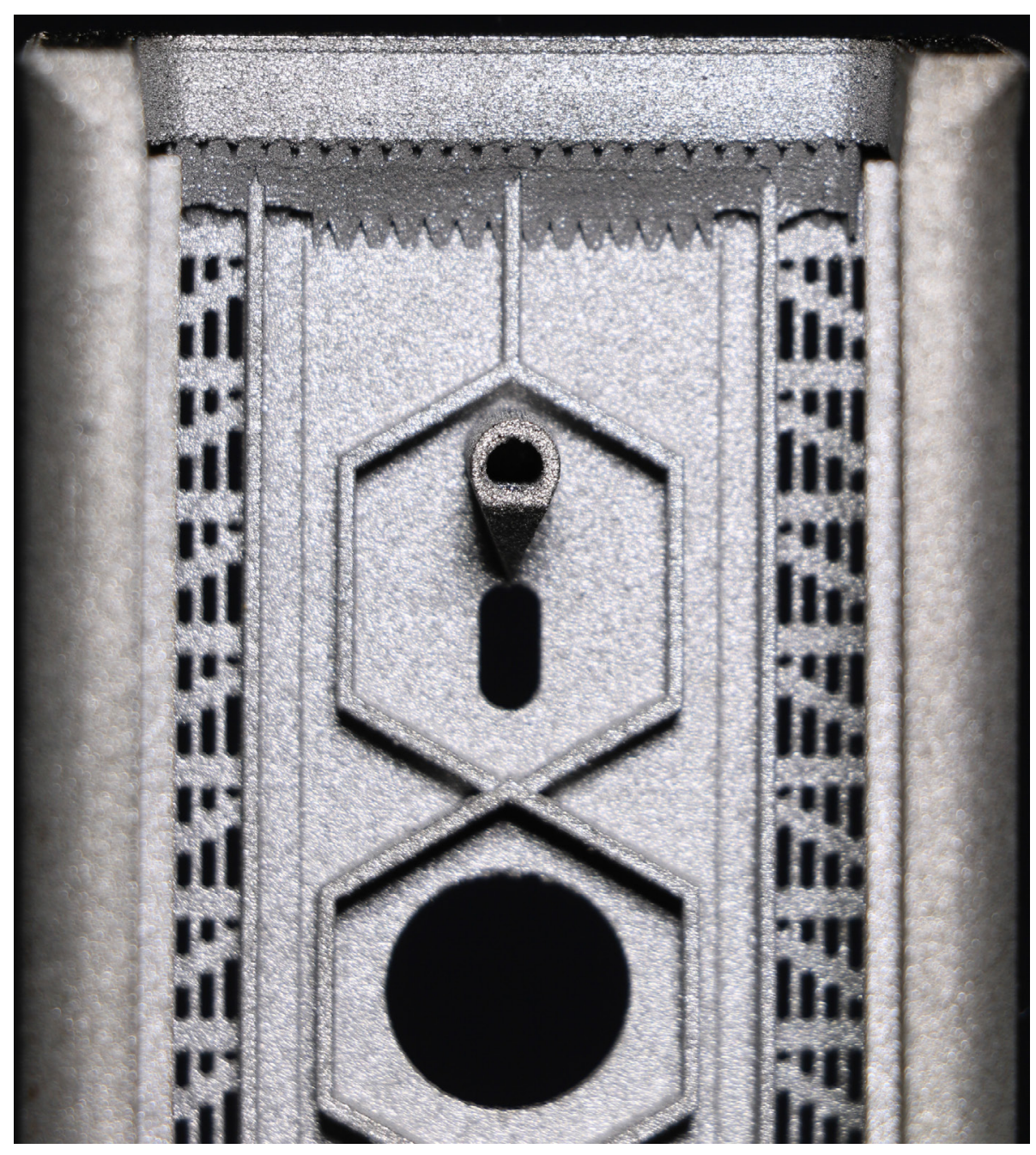

figure 97

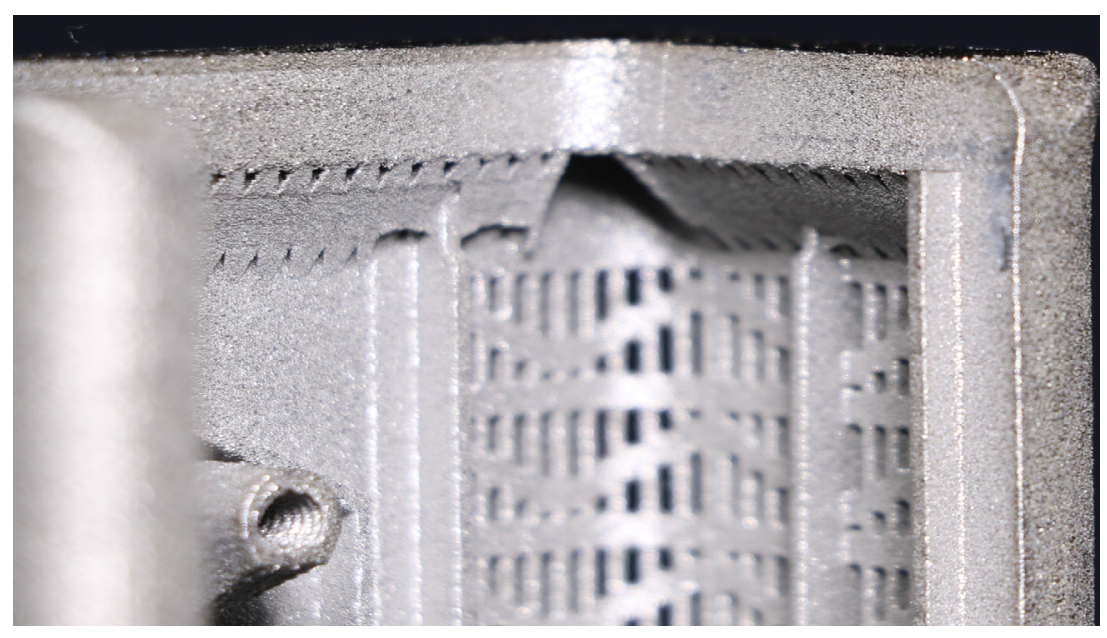

figure 98

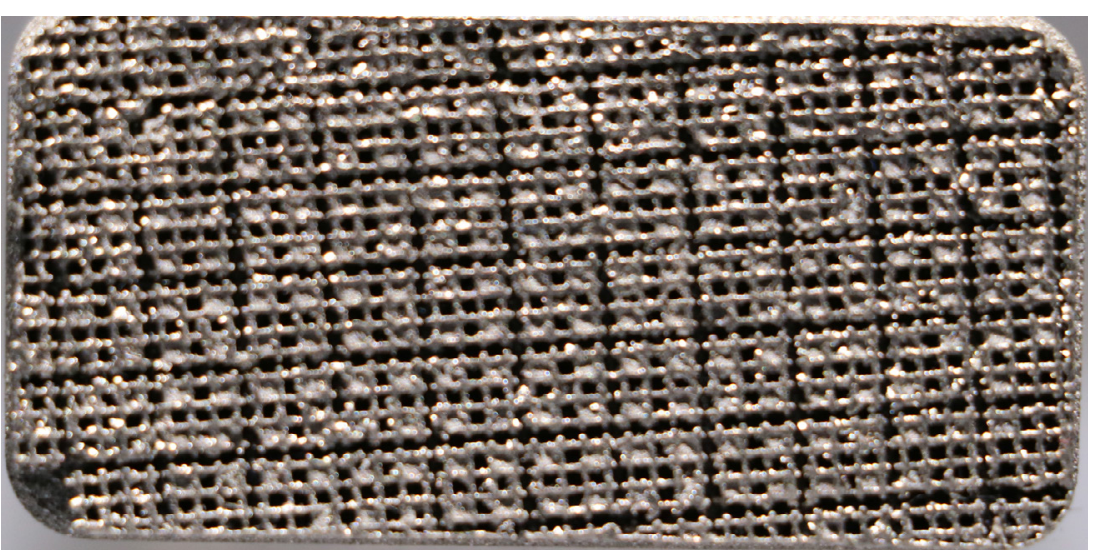

figure 99 


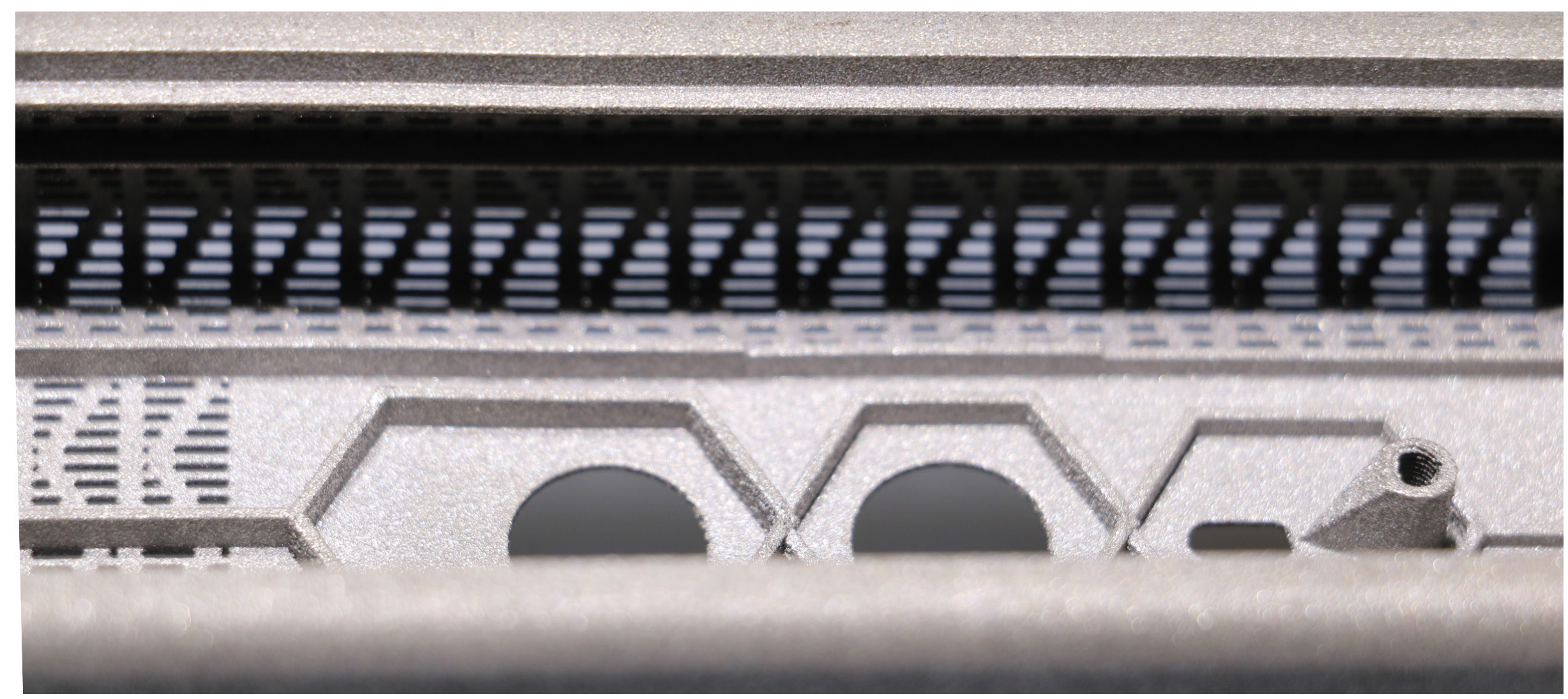

figure 100

The images above and below show the strengthening beam extending further along the part. This was done to correct for the slight bend in iteration 3.1 and the dibit that developed on the front surface. The hexagonal beam structure was also increased in height. The beam steps down by $0.5 \mathrm{~mm}$ after each hexagon is passed to continue to reduce mass.

Thread was also added to the screw brackets to allow for the attachment of the electronics board. The top screw bracket was also adjusted, giving the surface an angle of 30 degrees, which requires no support material.

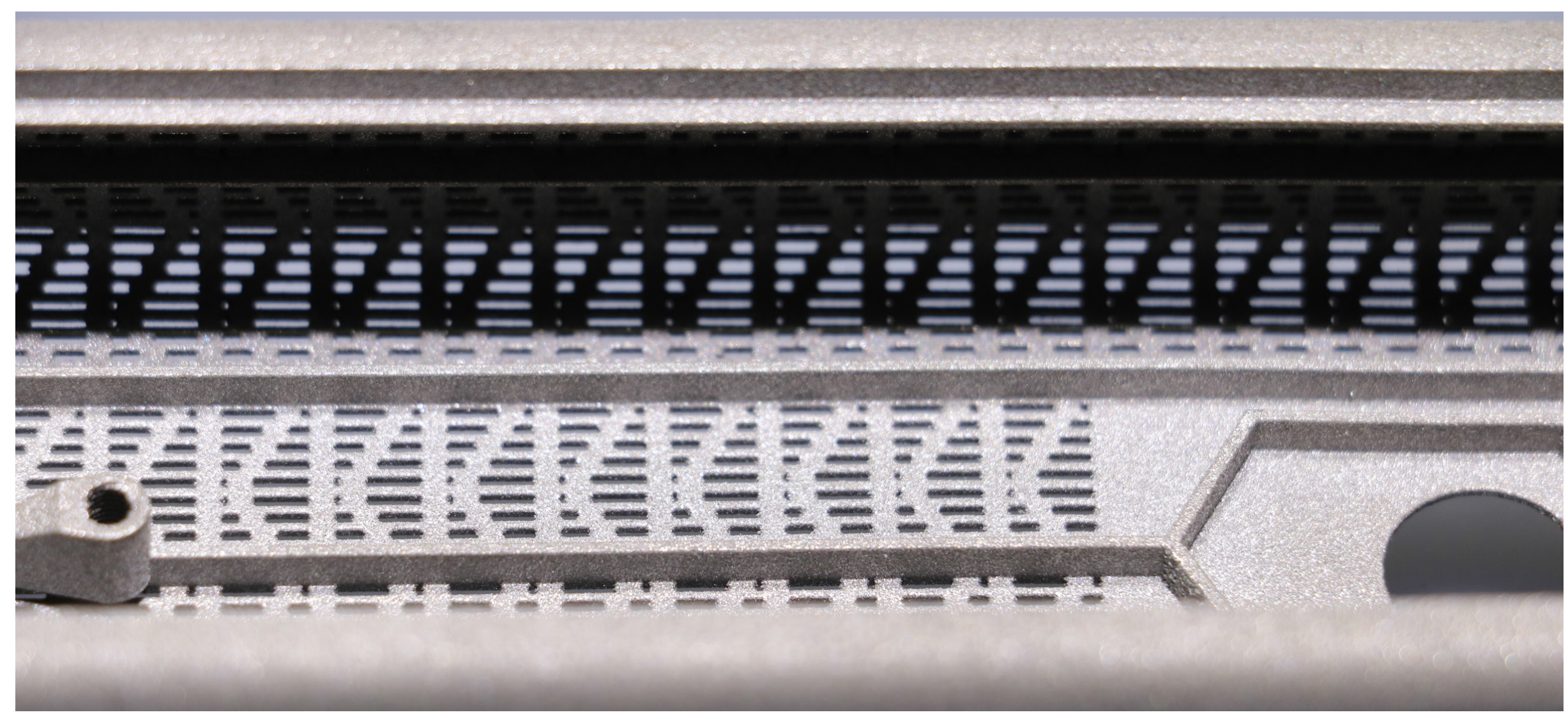

figure 101 


\section{Evaluation}

Iteration 3.2 conforms almost entirely with the criteria set out in this study. A few design features such as the size of the button holes and the complete reduction of support material were not achieved, but were deemed acceptable within the limitations of the design constraints.

Further CAD diagnostics will be run for the final developed design to eliminate the lines on the front of the model and angled leaf springs will be added to the rear to facilitate easier installation of the battery pack. 


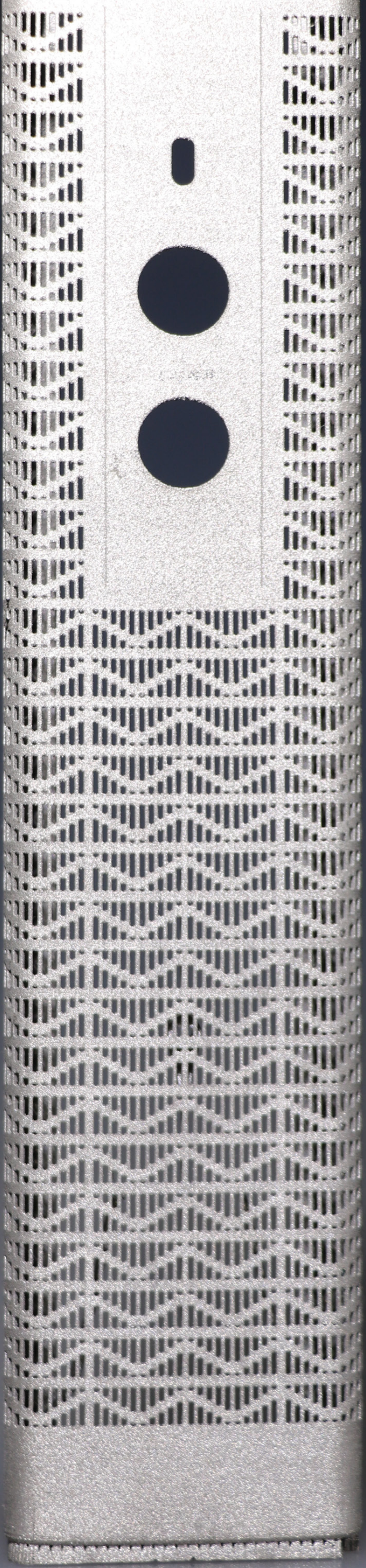

.11 ho . III III....?

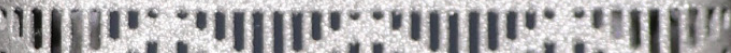

16...all III....

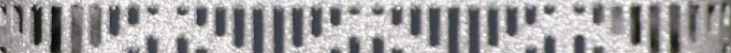
1....ull IIr....

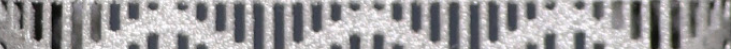

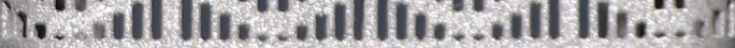
"1

1.

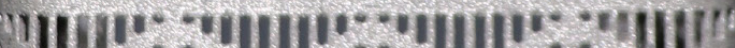

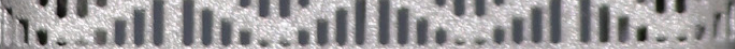

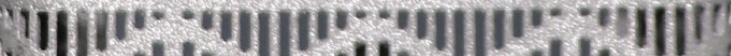

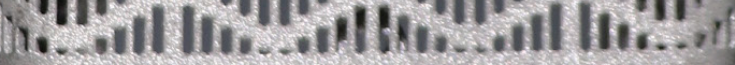
"ท

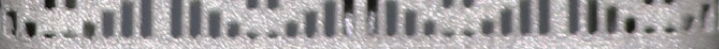

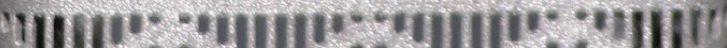

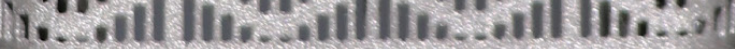
"1]|น"* -

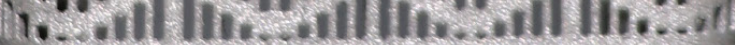

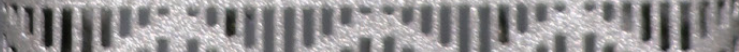

'11)

1.

"

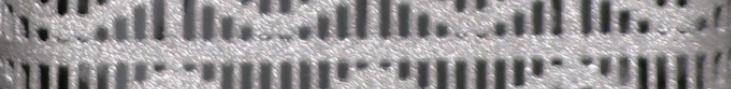

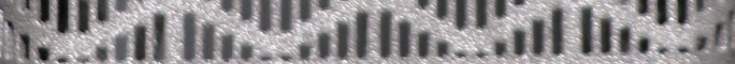

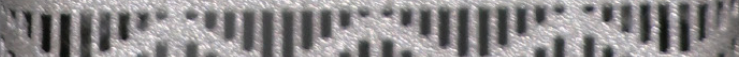

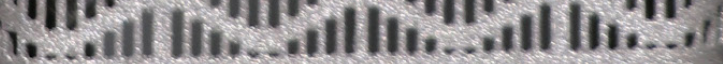




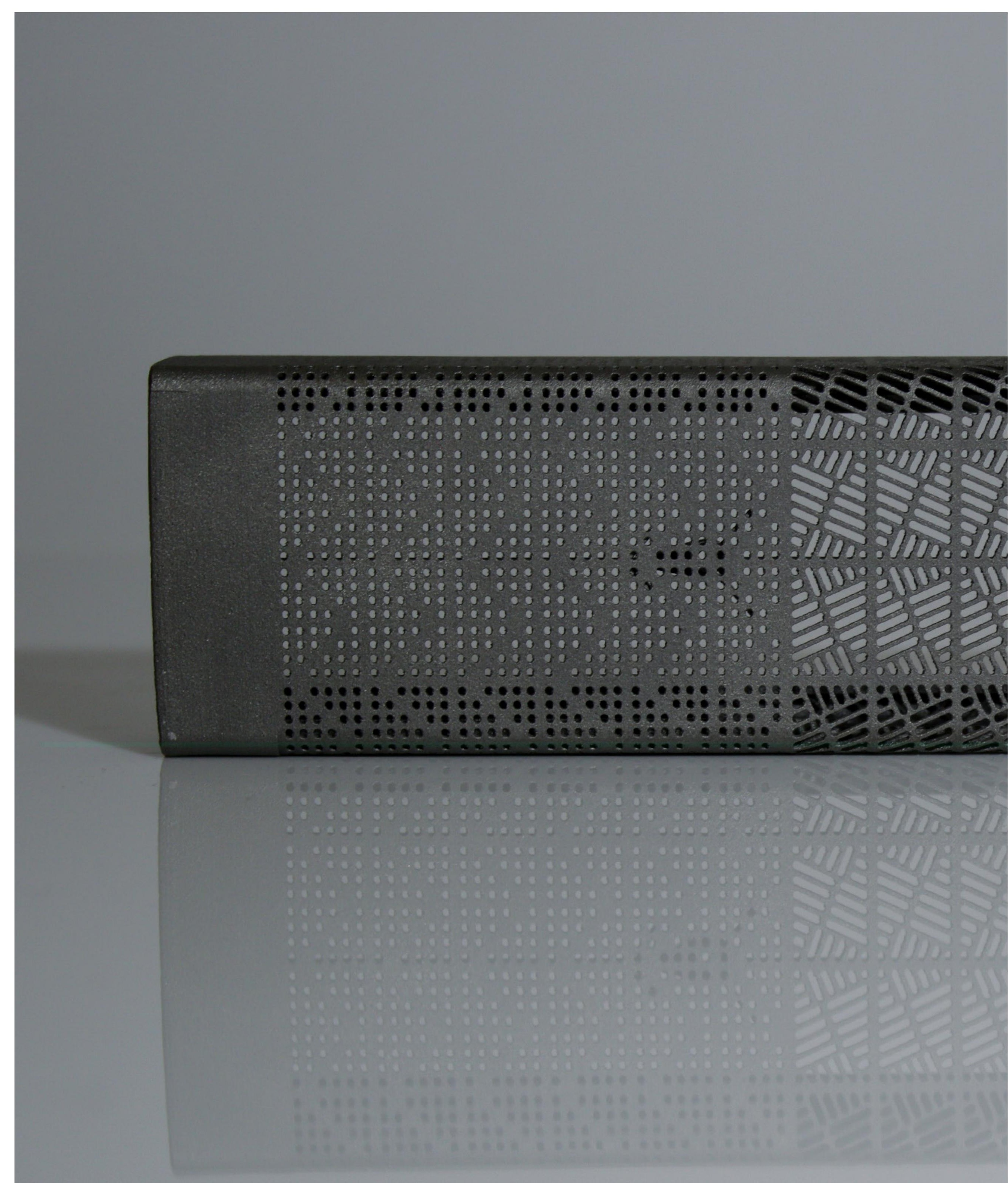


- 89 - 
$-90-$ 


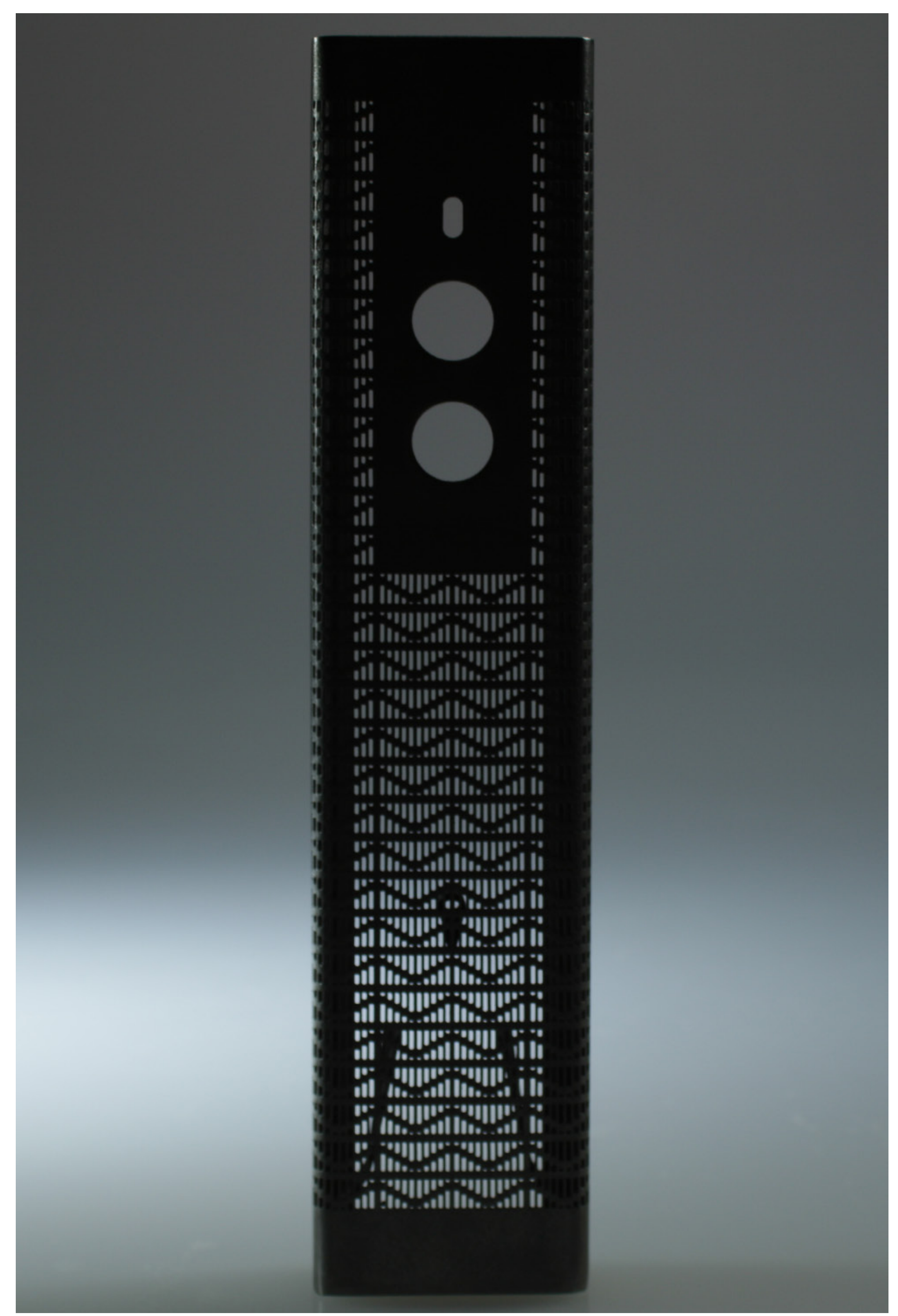

Figure 104: Back lit final design

\section{$-91-$}




\section{DEVELOPED DESIGN}

The development of this final concept is the last stage of this research. The developed design for this study is the culmination of the literature research into the SLM process, experimental exploration of the form, materials and analysis of design iterations.

This final iteration has achieved the design brief and criteria by producing a thin walled, structurally sound titanium electronics enclosure by optimising design features to be SLM 3D printed.

The lattice used in the final concept reflects on the lattice experimentation incorporating the findings from the previous iterations and print outcomes and reflects closley to the original aesthetic design intent. The CAD file creation followed the technical limitations throughout this thesis and can now be used to reproduce without any further design changes. 
Hight: $212 \mathrm{~mm}$

Width: $47.5 \mathrm{~mm}$

Overall wall thickness: $0.8 \mathrm{~mm}$

Volume: $20.15 \mathrm{~cm}^{3}$

Cost:

Titanium - \$ 467

\section{Chosen lattice}

\author{
Horizontal 30degree pillars
}

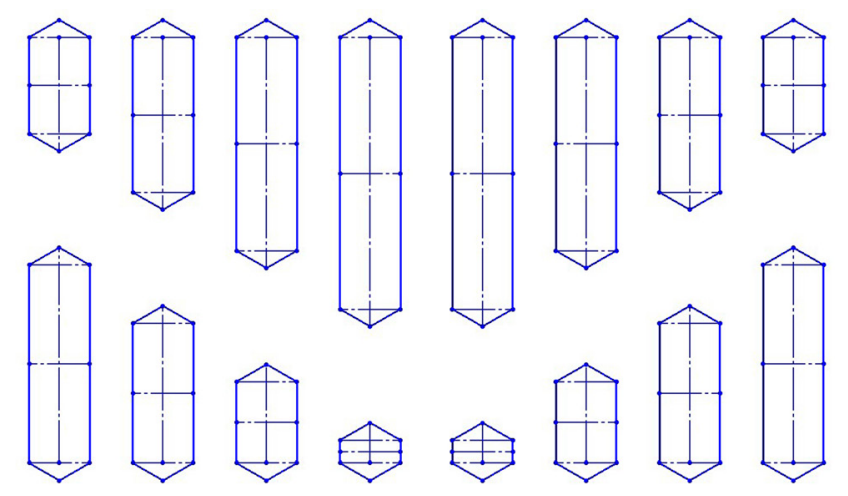

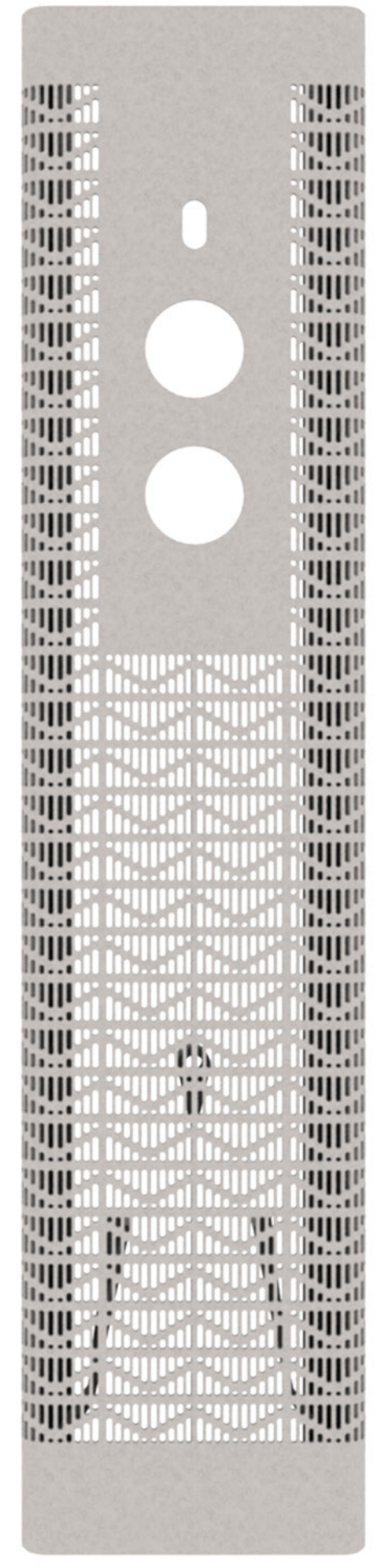

figure 105
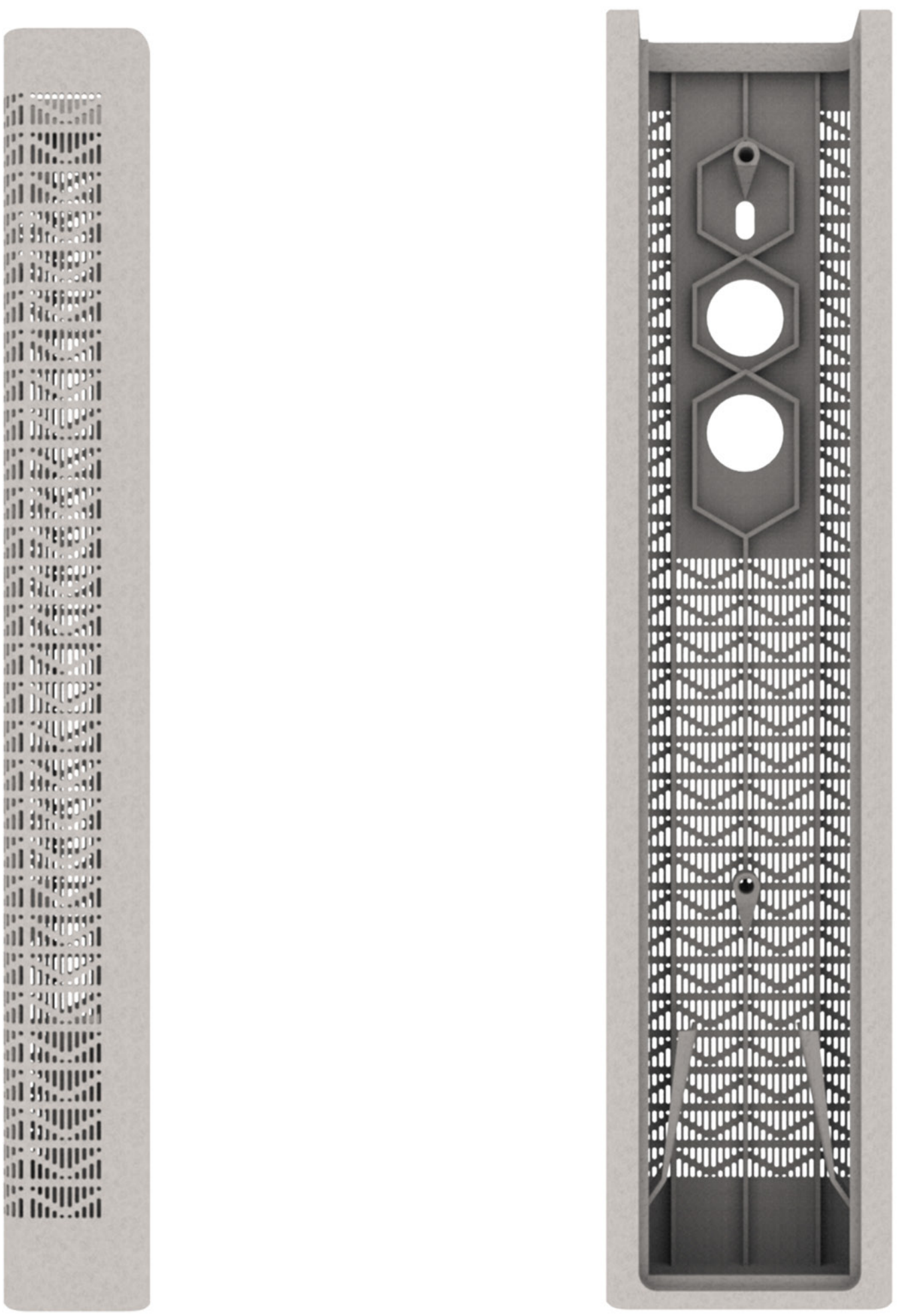

figure 106 figure 107 


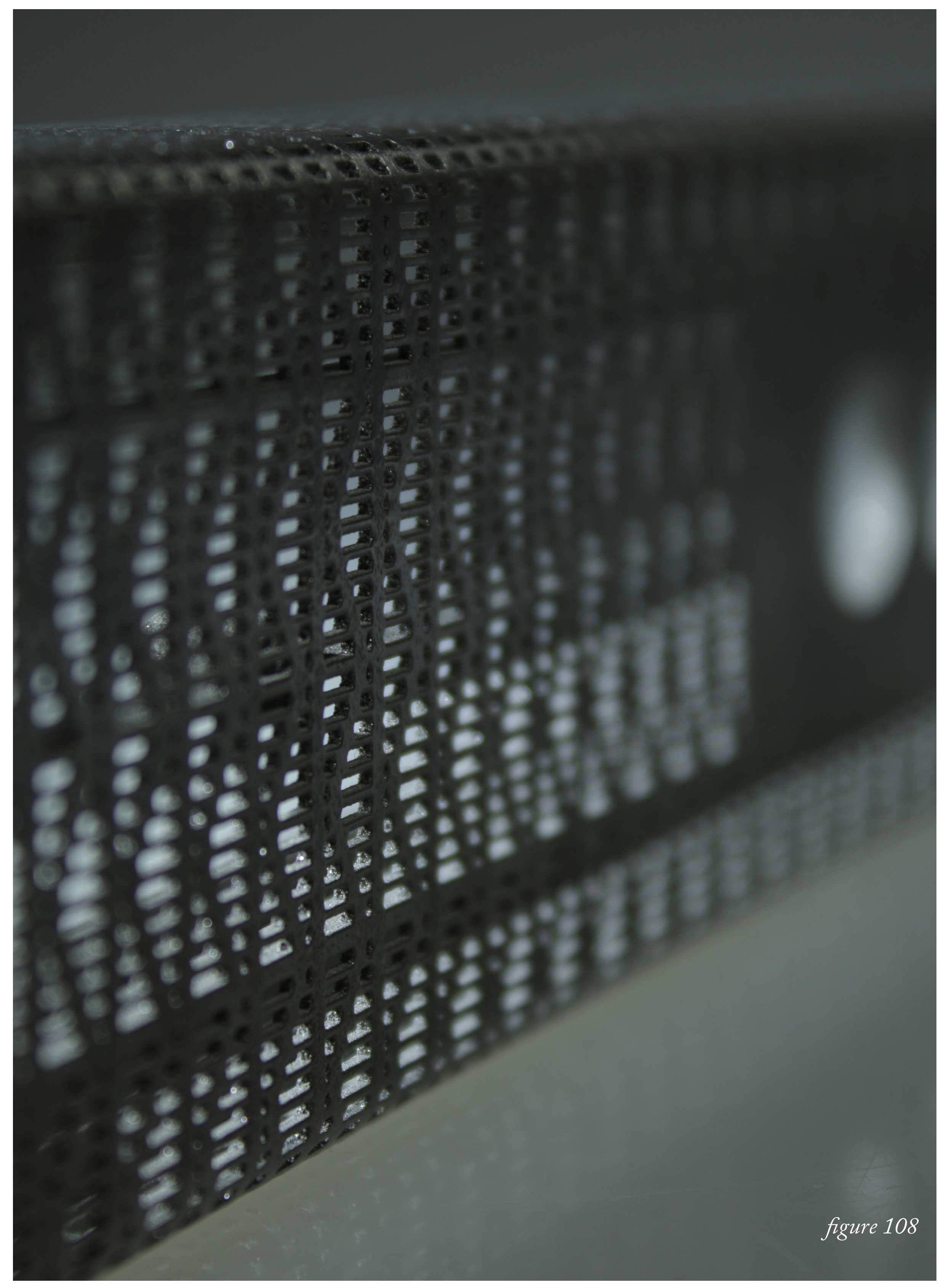




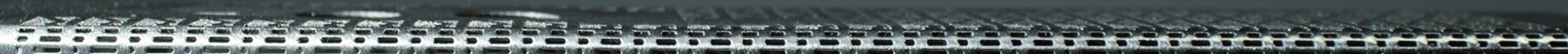

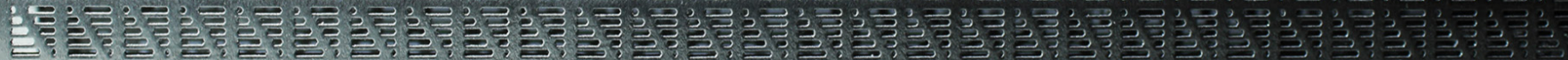

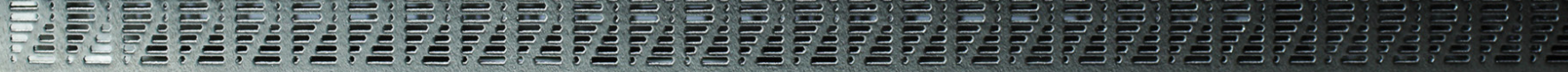

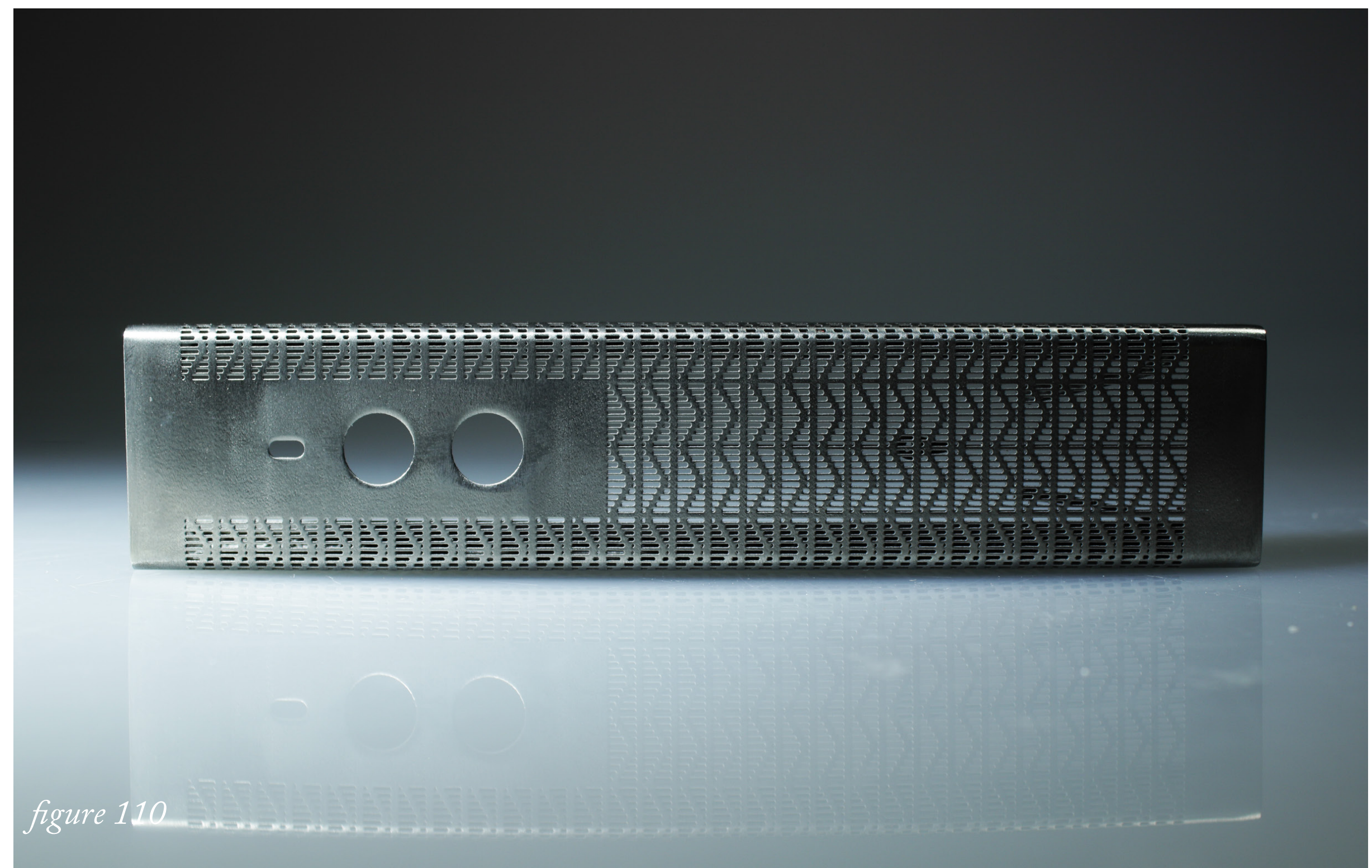




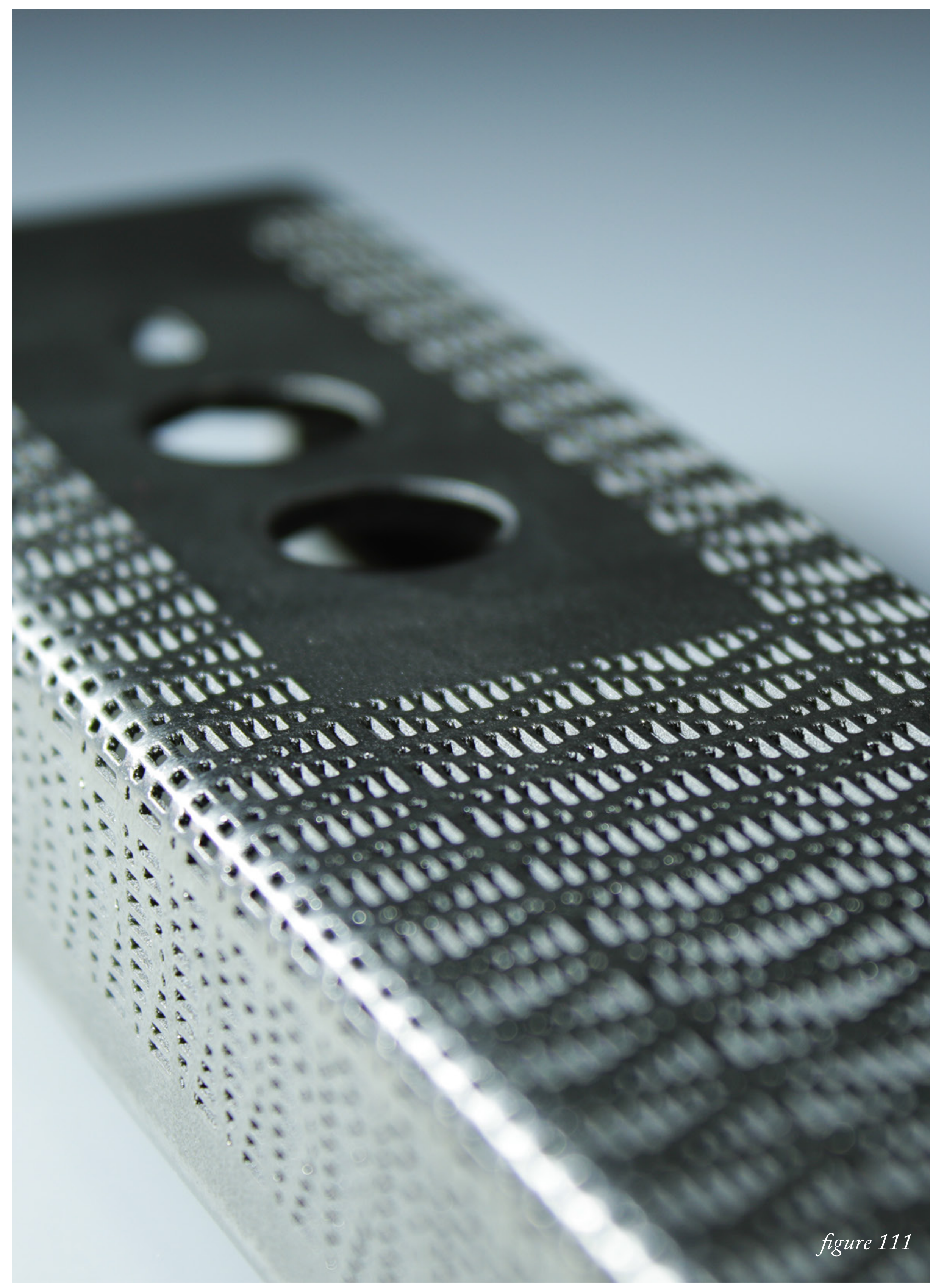




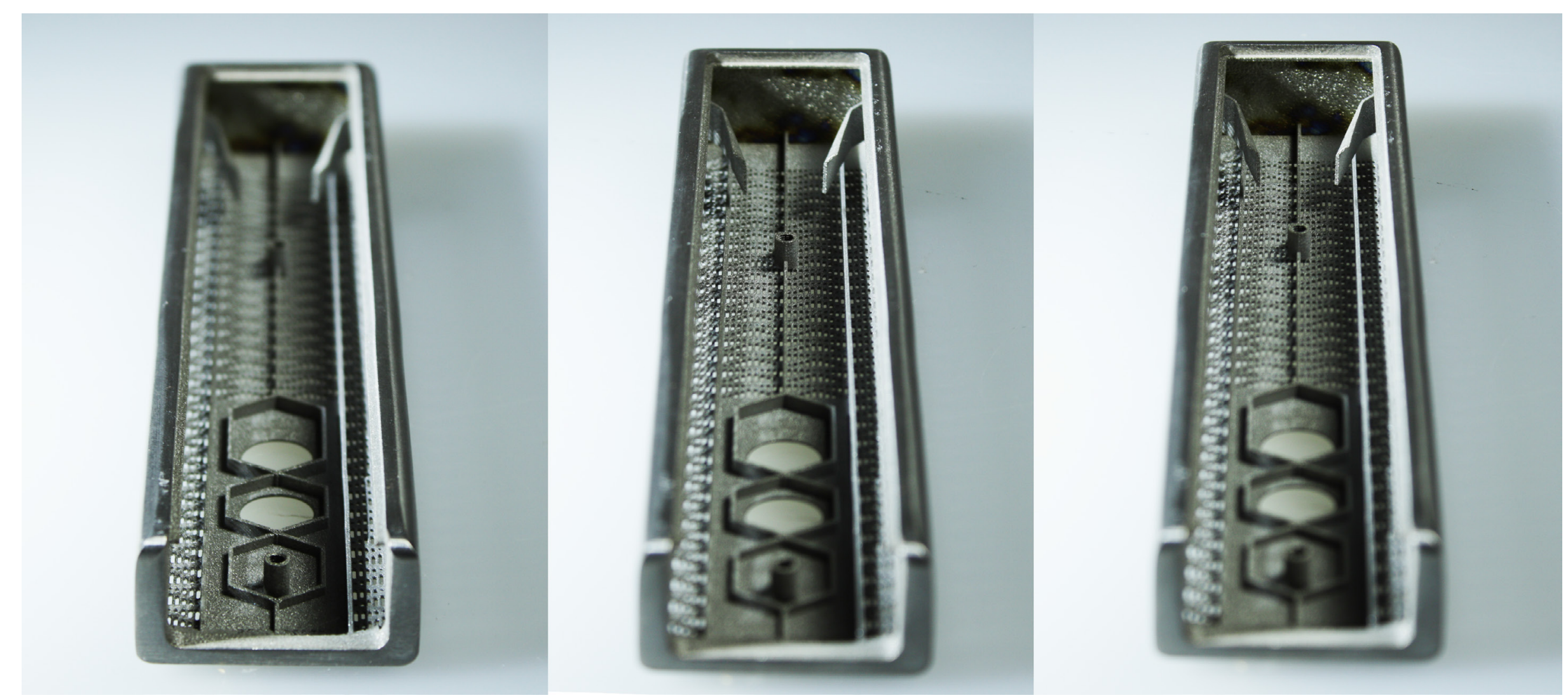

Figure 112: Level of detail left to right of interior final design

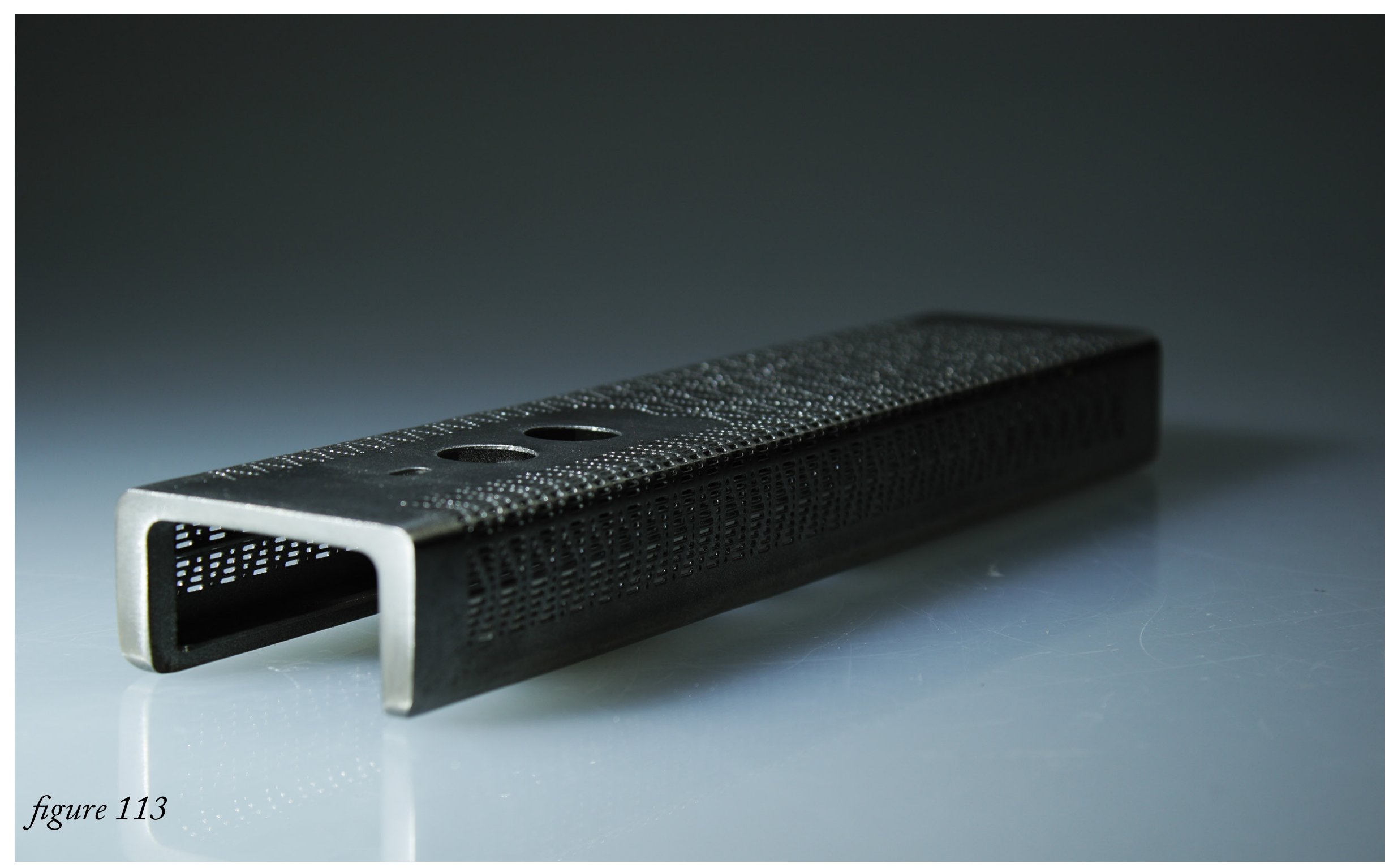




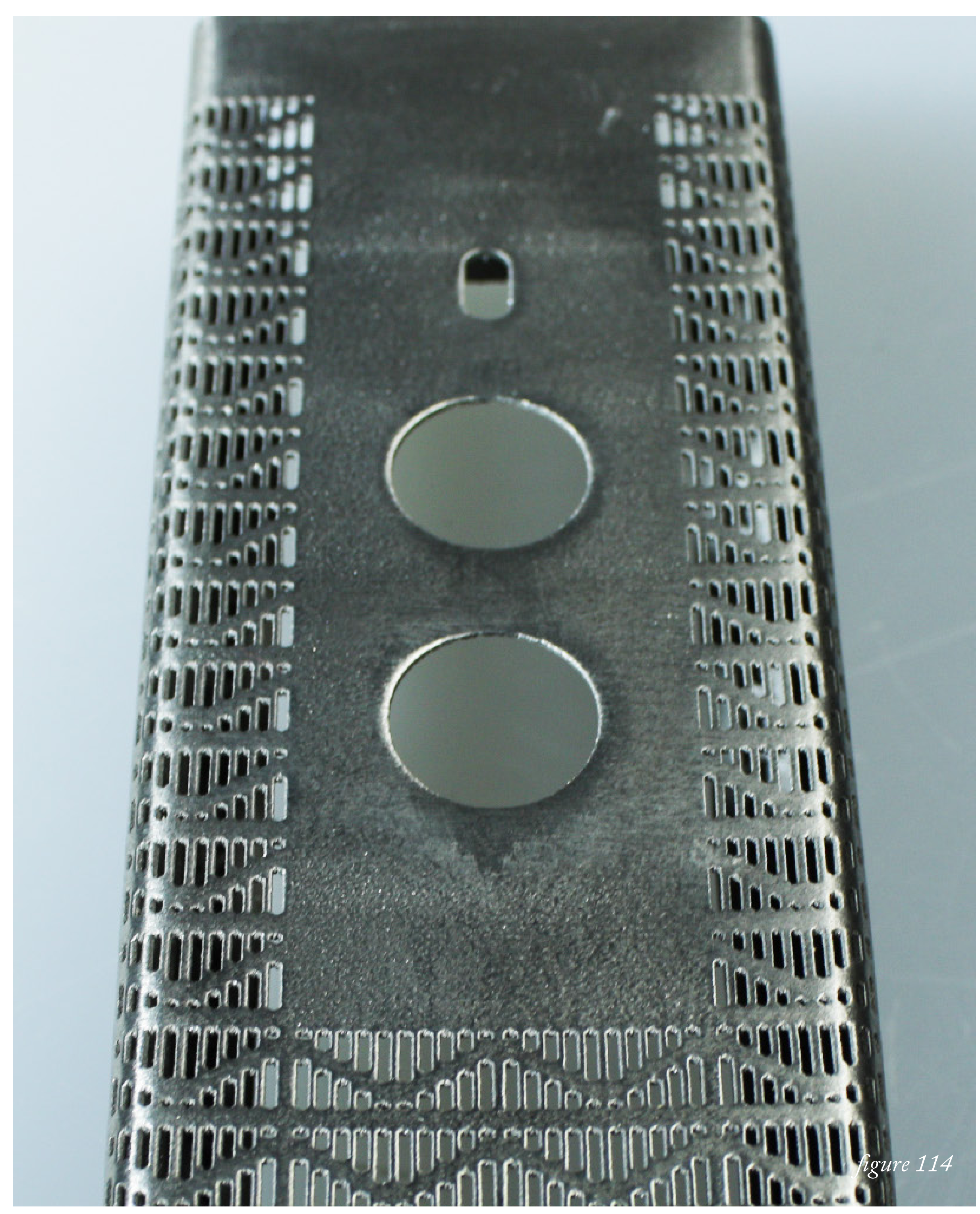




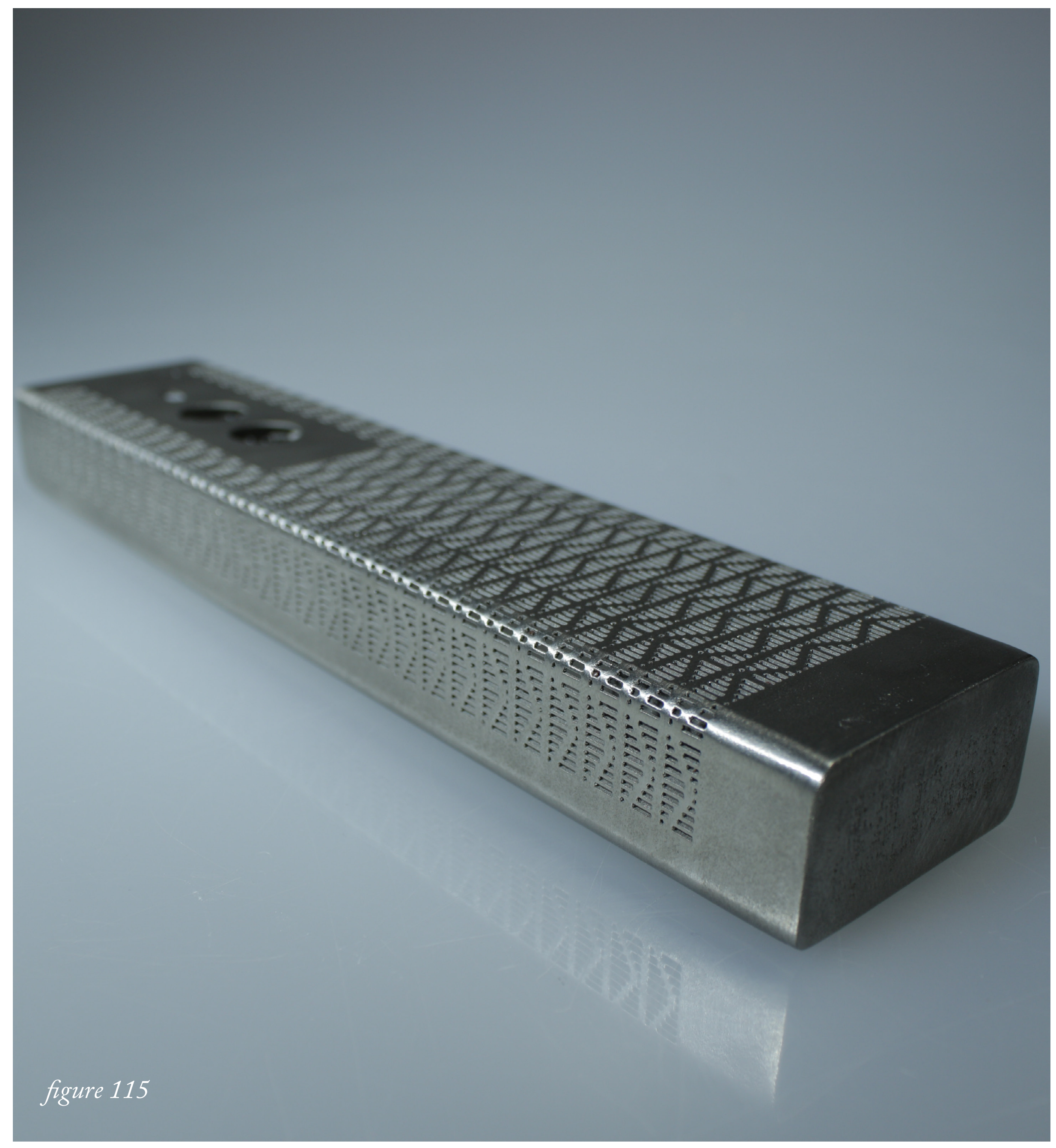

$-99-$ 


\section{Summary}

Seven physical 3D prints were produced as part of this research paper. These prints were based on multiple iterations of CAD files improving the criteria of waste and design intent. The criteria used during the development of the designs were a useful guideline to streamline the CAD process.

Four of the prints were in the desired material of titanium and were evaluated in more detail to gain further understanding of the optimisation process. The findings and design decisions made from the first print were in particular to address the structural integrity by reviewing the base and the lack of support beams. The second print that followed had a thicker base and support beams that reduced the warping effects from the heat dissipation. However; there were still slight distortions found in this print. Further modifications were made to address these and included an increase in the height of the support beams. The print also was pinching at the top, which required additional lattice to be incorporated in the CAD design. The third titanium print almost entirely met the criteria with regard to waste and design intent and only minor changes were made for the final print to enhance the model with regard to the installation of the battery pack.

The final developed print achieved all of the criteria from a waste reduction and design intent perspective. This design has achieved both removing the maximum amount of support material and retaining the look and feel of the original design. 


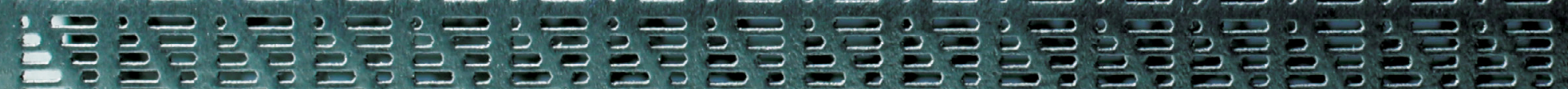

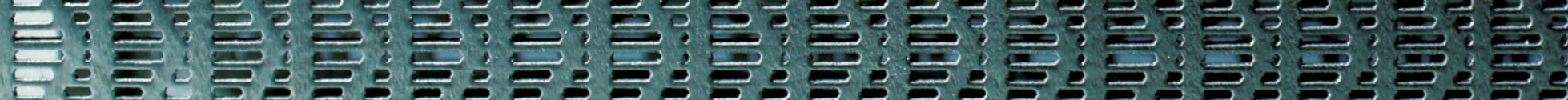

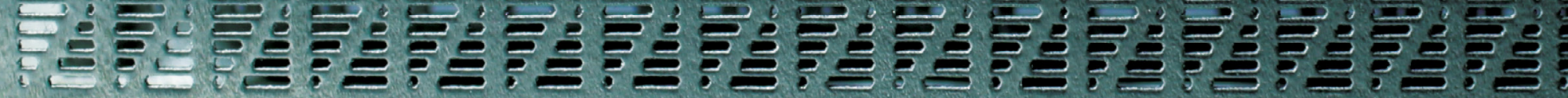




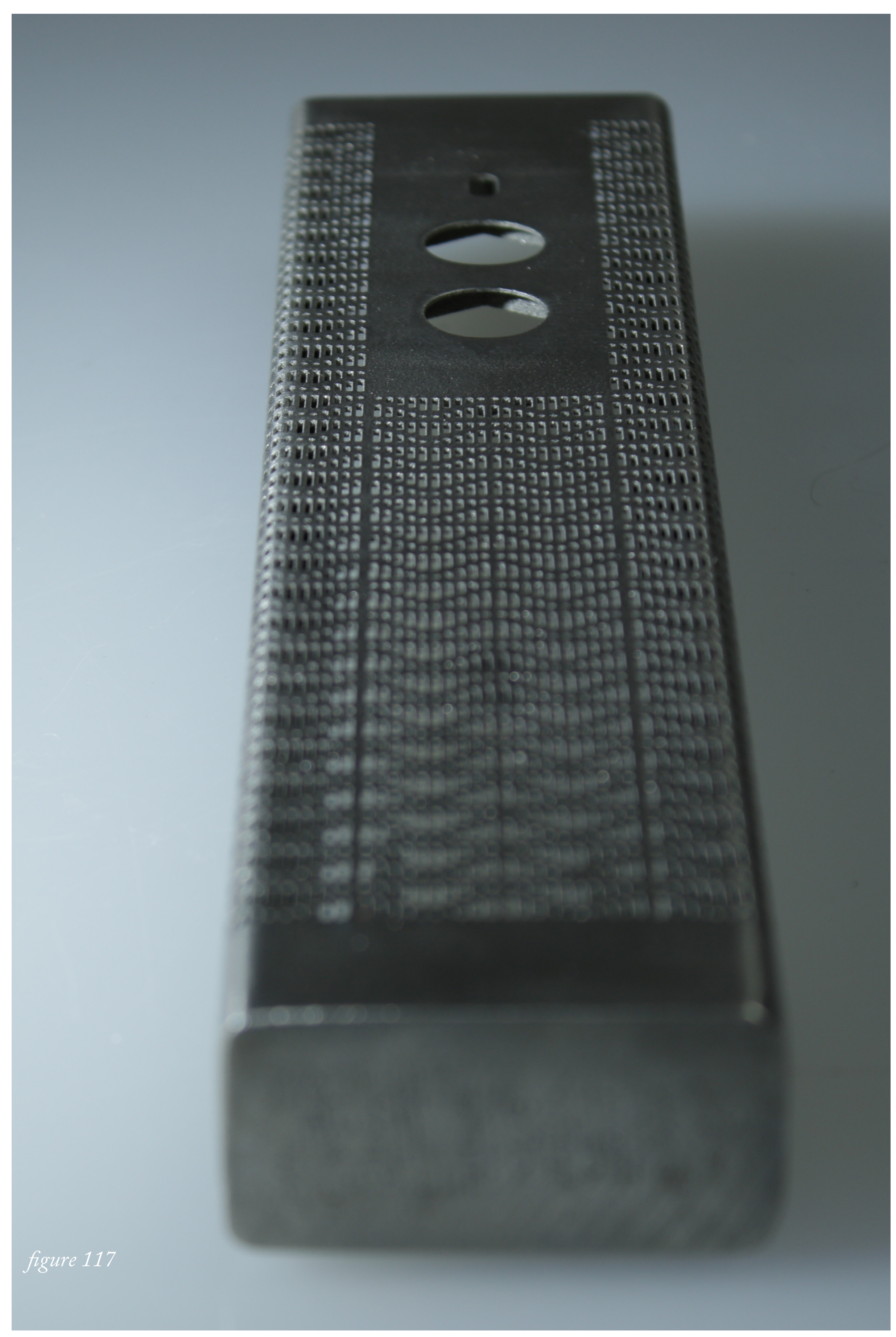




\section{O N CLUSION}

How can Computer Aided Design be optimised for Selective Laser Melting printing?

This research explored the limitations and creative workarounds of SLM 3D printing. Using primary and secondary sources, this study established machine limitations that were incorporated from first sketch to final print.

Through experimentation and physical titanium 3D prints further properties of SLM printing were revealed in comparison to the initial known machine limitations. The experiments provided essential imformation on the SLM process and highlighted the limited scope of information that is avaliable in the industrial design space. Creating an object with the SLM process is not an easy or cheap method of manufacturing. The imposed limitations were sometimes frustrating, but also extremely challenging to design against.

During the design iterations, the optimisation process was an important aspect to the overall design outcome. Waste issues, in the form of support material were mitigated against the need to produce a form that was both well designed and structurally sound. Using a slicing software is critical for a designer to reduce material and post processing effort. Through the optimisation process enhancements could be made through reducing the amount of interior material, but retaining the exterior form.

Machine limitations as well as the slicing software for the support material calculations were important inputs into design decisions. However; some design rules from secondary sources were not always reliable.

The study found that the margins of safety for structural integrity are not clearly identified and had to be discovered through experimentation. Scortch marks at the top of the print were caused by overheating of the part and was due to a transition from a thin section to a thicker section.

This study has highlighted for designers to inform themselves about the capabilities of the printers they intend to use to optimise their CAD files and improve the final outcome of the print.

The challenge of designing and working with a process like SLM and a material like titanium has forced me into re-evaluating what it means to create clean CAD files. The majority of $3 \mathrm{D}$ printing is quite forgiving if the file you use is not entirely correct. Small deviations are not immediately apparent and can easily be corrected post process, however the slightest discrepancy in SLM is not easily forgiven.

Nigel Cross's method of exploration, generation, evaluation and communication gave a solid structure to my design process and helped me achieve the developed design as a result. The process helped to correct bad CAD technique and ensure a progression of better iterations with every evolution.

SLM is a challenge, and with this research I hope this goes a small way into bringing this process faster into main stream design. The outcome of this thesis is not to stop at this point, but to generate interest for those who wish to research further. 
-105 - 


\section{LIST OF FIGURES}

Title page: Image by author

1 - 2 Image by author

3 Reference Class A Monoblock «pureaudio. (2011).

Retrieved from http://www.pureaudio.co.nz/?page_id=31

(with permission from owner)

4 - 6 Image by author

7 AM 400 additive manufacturing system. (2016).

Retrieved from http://www.renishaw.com/en/products--32460

(Permission given from Renishaw Media Hub under conditions).

8 Bike frame. (2016).

Retrieved from http://www.renishaw.com/en/products--32460

(Permission given from Renishaw Media Hub under conditions).

9 Topologically optimised seat post bracket. (2016).

Retrieved from http://www.renishaw.com/en/products--32460

(Permission given from Renishaw Media Hub under conditions).

10 Complete bike with 3D printed titanium alloy frame. (2016).

Retrieved from http://www.renishaw.com/en/products--32460

(Permission given from Renishaw Media Hub under conditions).

11 - 21 Image by author

22 Milling cutter work with splinters flying off on a light background. (2016).

Retrieved from http://www.shutterstock.com/pic-282416879/stock-photomilling-cutter-work-with-splinters-flying-off-on-a-light-background.html (Purchased from Shutterstock) 
23 Sketch drawing of a sports car. Non-branded concept car.

Retrieved from http://www.shutterstock.com/pic-129121721/stock-photosketch-drawing-of-a-sports-car-non-branded-concept-car.html (Purchased from Shutterstock)

24. Experimental iteration checklist. Image by author

25 Reference Class A Monoblock «pureaudio. (2011).

Retrieved from http://www.pureaudio.co.nz/?page_id=31

(with permission from owner)

26 Control Preamplifier « pureaudio

Retrieved from http://www.pureaudio.co.nz/?page_id=35

(with permission from owner)

27 - 117 Image by author 
$-108-$ 
- 109 - 


\section{B I B L I O G R A P H Y}

Air New Zealand. (2016, February 24). Air New Zealand is embracing the future of aircraft interiors by successfully producing $3 D$ printed components for its Business Premier cabins. Retrieved from Air New Zealand: http://www.airnewzealand.com/pressrelease-2016-airnz-to-3d-print-its-own-aircraft-interior-parts

Berman, B. (2012). 3-D printing: The new industrial revolution. Business Horizons Volume 55, Issue 2, 155-162.

Campanelli, S. L., Contuzzi, N., Angelastro, A., \& Ludovico, A. D. (2010). Capabilities and Performances of the Selective Laser Melting Process, New Trends in Technologies: Devices,. Retrieved from InTech: http://www.intechopen.com/books/new-trends-intechnologies--devices--computer--

Campbell, T. A., Williams, C. B., Ivanova, O. S., \& Garrett, B. (2011). Could 3D Printing Change the World? Technologies, Potential, and Implications of Additive Manufacturing. Washington: Atlantic Council.

Chantarapanich, N., Laohaprapanon, A., Wisutmethangoon, S., Jiamwatthanachai, P., Chalermkarnnon, P., Sucharitpwatskul, S., ... Sitthiseripratip, K. (2014). Fabrication of three-dimensional honeycomb structure for aeronautical applications using selective laser melting: a preliminary investigation. Rapid Prototyping Journal, Vol. 20 Iss: 6, 551-558.

Crouch, C., \& Pearce, J. (2012). Doing Research In Design. London: Bloomsbury Publishing.

Earls, A., \& Baya, V. (2014). Technology Forecast: The future of 3-D printing. Retrieved from PWC: http://www.pwc.com/us/ en/technology-forecast/2014/3d-printing/features/future-3dprinting.html 
Garner, S., \& Evans, C. (2012). Design and Designing. London: Burg Publishing.

Kruth, J. P., Mercelis, P., Van Vaerenbergh, J., Froyen, L., \& Rombouts, M. (2005). Binding mechanisms in selective laser sintering and selective laser melting. emeraldinsigh, 26-33.

Layerwise. (2016). Technology. Retrieved from 3D Systems: http://www.layerwise.com/technology

Lipson, H., \& Kurman, M. (2013). Fabricated: The New World of $3 D$ Printing. Indianapolis: John Wiley \& Sons, Inc.

Martin, B., \& Hanington, B. (2012). Universal Methods of Design. Beverly, MA: Rockport Publishers.

Mengoni, M., \& Germani, M. (2007). Aesthetic feature as a tool to preserve design intent. INTERNATIONAL CONFERENCE ON ENGINEERING DESIGN (pp. 1-15). Paris: Polytechnic University of Marche.

Morrow, W. R., Qi, H., Kim, I., Mazumder, J., \& Skerlos, S. J. (2007). Environmental aspects of laser-based and conventional. Journal of Cleaner Production 15, 932-943.

Neely, E. L. (2015, September 19). The Risks of Revolution: Ethical Dilemmas in 3D Printing from a US Perspective. Retrieved from Springer: http://link.springer.com/ article/10.1007/s11948-015-9707-4

Ponoko. (2016). 3D Design Rules. Retrieved from Ponoko: http://www.ponoko.com/starter-kits/design-rules-3d

Pure Audio. (2016). Reference Class A Monoblock. Retrieved from Pure Audio: http://www.pureaudio.co.nz/?page_id=31

Pye, D. (1968). The Nature and Art of Workmanship. London: Herbert Press.

Radis, L. (2015, May 5). GE Aviation gets FAA Certification for First 3D Printed Jet Engine Part. Retrieved from 3Dprinting. com: http://3dprinting.com/news/ge-aviation-gets-faacertification-for-first-3d-printed-jet-engine-part/

Rapid Advanced Manufacturing LTD. (2016). 3D Printing. Retrieved from Rapid Advanced Manufacturing LTD: http:// www.rapidman.co.nz/3d-printing 
Renishaw. (2016, July 3). Metal additive manufacturing (3D printing). Retrieved from Renishaw: http://www.renishaw.com/ en/metal-additive-manufacturing-3d-printing--15240

Sculpteo. (2016). 3D Printing Design Guidelines. Retrieved from Sculpteo: https://www.sculpteo.com/en/materials/materialsdesign-guidelines/\#brass-3d-printing-design-guidelines

Seabra, M., Azevedo, J., Araújo, A., Reis, L., Pinto, E., Alves, N., . . Mortágua, J. P. (2016, February 10-12). Selective laser melting (SLM) and topology optimization for lighter aerospace componentes. XV Portuguese Conference on Fracture (pp. 289296). Portugal: Elsevier. Retrieved from Science Direct.

Shapeways. (2016). Things to keep in mind when designing for $3 D$ Printing. Retrieved from Shapeways: http://www.shapeways. com/tutorials/things-to-keep-in-mind

Spears, T. G., \& Gold, S. A. (2016). In-process sensing in selective laser melting (SLM) additive manufacturing. Integrating Materials and Manufacturing Innovation, 1-25.

Stewart, E. (2013). Customized Complexity. Wellington, New Zealand: University of Victoria Wellington.

Sykes, C. (2015, June 29). NZ Heraid. Retrieved from Small Business: 3D Printing: http://www.nzherald.co.nz/business/ news/article.cfm?c_id=3\&objectid=11471694

Thomas, D. (2009). The Development of Design Rules for Selective Laser Melting. Cardiff, Wales, United Kingdom: University of Wales. Retrieved from https://repository. cardiffmet.ac.uk/dspace/handle/10369/913

Wohlers Associates. (2014). 3D Printing and Additive Manufacturing State of the Industry Annual Worldwide Progress Report. Fort Collins: Wohlers INC.

Wynn, D., \& Clarkson, J. (2005). Models of Designing. In D. Wynn, \& J. Clarkson, Design Process Improvement (pp. 34-59). London: Springer.

Zhou, C. (2015, July 30). 3D-printed house built in just three hours in China. Retrieved from Stuff: http://www.stuff.co.nz/ life-style/home-property/70675881/3D-printed-house-built-injust-three-hours-in-China 
$-113-$ 


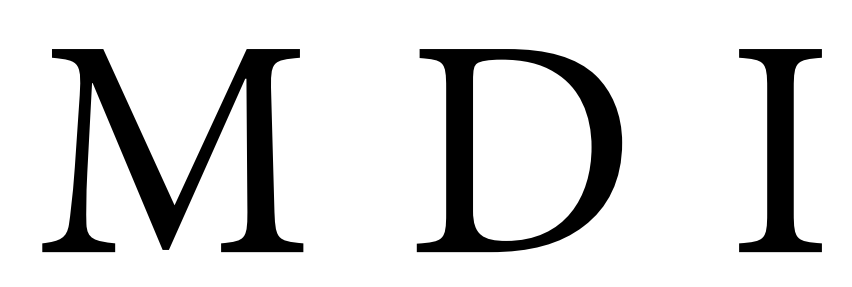

Design optimisation for 3D printed SLM objects

(2016) 